\title{
Influence of air-sea coupling on Indian Ocean tropical cyclones
}

\author{
Lengaigne Matthieu 1, 2, ${ }^{\star}$, Neetu S. ${ }^{3}$, Samson Guillaume ${ }^{4}$, Vialard Jérôme ${ }^{1}$, Krishnamohan K. S. ${ }^{1}$, \\ Masson Sébastien ${ }^{1}$, Jullien Swen ${ }^{5}$, Suresh I. ${ }^{3}$, Menkes Christophe E. 1,6
}

\author{
${ }^{1}$ Sorbonne Universités (UPMC, Univ Paris 06)-CNRS-IRDMNHN, LOCEAN Laboratory, IPSL, Paris, \\ France \\ 2 Indo.French Cell for Water Sciences, IISc.NIO.IITM.IRD Joint International Laboratory, National \\ Institute of Oceanography, Dona Paula, Goa, India \\ ${ }^{3}$ CSIR-National Institute of Oceanography, Dona Paula, Goa, India \\ ${ }^{4}$ Mercator Ocean, Ramonville.Saint.Agne, France \\ ${ }^{5}$ Laboratoire d'Océanographie Physique et Spatiale (LOPS), Univ. Brest, CNRS, IRD, Ifremer, IUEM, \\ Plouzané, France \\ ${ }^{6}$ Centre IRD, Nouméa, New Caledonia
}

${ }^{*}$ Corresponding author : Matthieu Lengaigne, email address : lengaign@locean-ipsl.upmc.fr

\begin{abstract}
:
This paper assesses the impact of air-sea coupling on Indian Ocean tropical cyclones (TCs) by comparing a 20 -year long simulation of a $14^{\circ}$ regional coupled ocean-atmosphere model with a twin experiment, where the atmospheric component is forced by sea surface temperature from the coupled simulation. The coupled simulation reproduces the observed spatio-temporal TCs distribution and TC-induced surface cooling reasonably well, but overestimates the number of TCs. Air-sea coupling does not affect the cyclogenesis spatial distribution but reduces the number of TCs by $\sim 20 \%$ and yields a better-resolved bimodal seasonal distribution in the northern hemisphere. Coupling also affects intensity distribution, inducing a four-fold decrease in the proportion of intense TCs (Cat-2 and stronger). Air-sea coupling damps TCs growth through a reduction of inner-core upward enthalpy fluxes due to the TC-induced cooling. This reduction is particularly large for the most intense TCs of the northern Indian Ocean (up to $250 \mathrm{~W} \mathrm{~m}-2$ ), due to higher ambient surface temperatures and larger TC-induced cooling there. The negative feedback of air-sea coupling on strongest TCs is mainly associated with slow-moving storms, which spend more time over the cold wake they induce. Sensitivity experiments using a different convective parameterization yield qualitatively similar results, with a larger $(\sim 65 \%)$ reduction in the number of TCs. Because of their relatively coarse resolution $\left(1 / 4^{\circ}\right)$, both set of experiments however fail to reproduce the most intense observed TCs. Further studies with finer resolution models in the Bay of Bengal will be needed to assess the expectedly large impact of air-sea coupling on those intense and deadly TCs.
\end{abstract}

Keywords : Tropical cyclones, Air-sea coupling, Indian Ocean, Cold wake, Regional coupled oceanatmosphere model 
Please note that this is an author-produced PDF of an article accepted for publication following peer review. The definitive publisher-authenticated version is available on the publisher Web site. 


\section{1. Introduction}

3 Tropical cyclones (TCs) track prediction has dramatically improved over the last decades, yet intensity 4 forecasts improvements are more limited (DeMaria et al. 2014). Internal dynamics, environmental forcing, 5 and interactions with the ocean are generally identified as important elements affecting TC intensity 6 evolution (Wang and $\mathrm{Wu}$ 2004). Various atmospheric large-scale conditions influence TC intensification, 7 such as strong vertical wind shear that increases inner-core static stability due to the vortex tilting (DeMaria 8 1996) or a dry mid-troposphere, which inhibits convective buoyancy (Emanuel et al. 2004). As TC 9 primarily draw their energy from evaporation at the surface of the ocean (e.g. Riehl 1950; Emmanuel 10 1986), the enthalpy fluxes at the air-sea interface also play an essential role on TCs intensification (e.g. 11 Emmanuel 1999). While the ocean provides the necessary thermal energy for TCs through moist surface enthalpy flux, TC intensity is also sensitive to the local evolution of Sea Surface Temperature (SST) under the storm eye (Schade 2000). The kinetic energy dissipated due to the strong wind stress at the air-sea interface (Emanuel 2003) results in a significant SST cooling under the TC, largely through vertical mixing (e.g. Price 1981; Jullien et al. 2012; Vincent et al. 2012a). This TC-induced cooling acts to limit the TC intensification (Cione and Uhlhorn 2003). The fundamental role of air-sea heat exchanges in the TC intensification paradigms hence emphasizes the need for quantifying and understanding the feedback of this TC-induced cooling on TC characteristics.

Through a statistical analysis of 23 TCs in the Atlantic, Cione and Ulhorn (2003) provided observational evidences to support the key role played by air-sea coupled feedbacks on TCs intensification: in this limited dataset, TCs inducing large SST cooling indeed generally experience a weaker upward surface enthalpy flux (up to $40 \%$ reduction for a $\sim 1^{\circ} \mathrm{C}$ change) and a weaker TC intensification rate. The levelling-off of TC-induced cooling with increasing TC intensity (from Cat-2) was further interpreted as an indirect evidence of the negative ocean feedback onto TC intensification (Lloyd and Vecchi 2011). The faster TC translation speed for increasing TC intensity was also interpreted as indirect evidence of air-sea coupling 
1 a weaker SST cooling, hence favoring a stronger TC intensification. Including an upper ocean parameter in 2 statistical intensity forecasting reduces TC intensity forecast errors by $\sim 5 \%$ on average (DeMaria et al. 3 2005; Mainelli et al. 2008). Similarly, accounting for ocean stratification allows increasing the explained 4 variance of TC intensification accounted by the maximum potential intensity theory (Balaguru et al. 2015; 5 Miyamoto et al. 2017). This indicates that the oceanic subsurface stratification also influences the cooling 6 under the TC, with more pronounced cooling in regions of shallow thermocline, such as cyclonic eddies, 7 that may feedback more on the TC. This is supported by the numerous observational case studies that 8 reported a rapid change of the intensification rate of TCs passing over oceanic eddies (e.g., Shay et al. 9 2000; Lin et al. 2005). Similarly, at the large-scale, the ocean negative feedback on the TCs varies due to 10 contrasted oceanic stratifications in different basins (e.g. Vincent et al. 2014).

12 A large body of literature using coupled atmosphere-ocean models further demonstrated that North 13 Atlantic and Pacific TCs intensity forecasts were significantly improved when the TC-induced ocean 14 feedback was accounted for (some cyclones were otherwise over-intensifying; e.g., Bender and Ginis 2000; 15 Hong et al. 2000; Lin et al. 2005; Ito et al. 2015). Other coupled modelling idealized case studies confirmed 16 that the TC-induced cooling limits TC intensification (e.g. Bender et al. 1993; Schade and Emmanuel 1999; 17 Zhu et al. 2004; Chen et al. 2010; Liu et al. 2011; Ma et al. 2013; Halliwell et al. 2015) but could also 18 impact the TC size (Chen et al. 2010; Ma et al. 2013) and asymmetrical structures (Zhu et al. 2004; Chen et 19 al. 2010). TC tracks are on the other hand rather insensitive to air-sea coupling (Zhu et al. 2004; Chen et al. 2010; Liu et al. 2011). Finally, it has become increasingly evident that the oceanic component of these models needs to include three-dimensional processes to correctly simulate the TC-induced upper ocean response, especially for slow-moving TCs (Yablonsky and Ginis 2009; Halliwell et al. 2011).

24 The studies discussed above assessed the impact of air-sea coupling on TCs from case studies of specific TCs, using short-term coupled model integrations. This is enlightening for the processes involved, but does not allow estimating the climatological effect of air-sea coupling on TCs statistics (count, distribution, 
1 intensity, etc...). Only a handful of studies using high-resolution climate models, able to explicitly simulate 2 realistic TCs, did investigate this climatological effect by comparing long-term ( 20 years) coupled and 3 uncoupled model integrations at global scale (Ogata et al. 2016) and regionally for the Pacific (Jullien et al. 4 2014) and Atlantic TCs-prone regions (Ogata et al. 2015; Zarzycki 2016). These studies indicate that air5 sea coupling reduce the number of TCs numbers by 5 to $9 \%$ in the North Atlantic and Pacific (Zarzycki 6 2016) and by $10 \%$ in the South Pacific (Jullien et al. 2014). Air-sea coupling in particular reduces 7 cyclogenesis in the Coral Sea, where a shallow thermocline promotes large TC-induced cooling, leading to 8 a more realistic cyclogenesis pattern in the South Pacific (Jullien et al. 2014). In contrast, cyclogenesis 9 patterns were not considerably affected by air-sea coupling in the north Pacific and Atlantic (Zarzycki

number most intense TCs simulated in those models. This reduction is not spatially uniform in the northern hemisphere (Ogata et al. 2015, 2016) resulting in an equatorward shift of the maximum of intense TC distribution in the North Atlantic and North Pacific that improves the representation of their climatological distribution and north-south asymmetry. The shallow northwest Pacific and Atlantic thermocline indeed promotes intense TC-induced cooling, hence limiting TC intensification and reducing the number of most intense TCs there. The impact of air-sea coupling operates through a reduction of the enthalpy flux fuelling the TC in response to the TC induced cooling. The enthalpy flux reduction is $\sim 20 \%$ when averaged over all TCs (Jullien et al. 2014; Zarzycki 2016) but reaches up to $26 \%$ for hurricanes $\left(>33 \mathrm{~m} . \mathrm{s}^{-1}\right.$ ) in north Pacific and Atlantic (Zarzycki 2016).

Except for the global study of Ogata et al. (2016), all short and long-term coupled modelling studies mentioned above have been performed either in the Atlantic or Pacific basins. The Indian Ocean (IO) is however home to about $20 \%$ of the global TC activity. TCs in the northern IO mainly occur in the western and central part of the Bay of Bengal (BoB; Fig. 1a). The strong vertical shear during the southwest monsoon inhibits cyclones, leading to a bimodal seasonal distribution, with preferential occurrences during the pre- and post-monsoon (Menkes et al. 2011, Li et al. 2013). Although northern IO just accounts for 7\% 
1 of TCs worldwide, those TCs have catastrophic impacts, with 14 of the 20 deadliest world TCs in recent 2 history having occurred in the BoB (Longshore 2008). TCs in the southern IO occur over an elongated 3 band centred on $15^{\circ} \mathrm{S}$ from November to April (Fig. 1a), with enhanced TC occurrence over the 4 southwestern IO around the Mauritius, La Reunion and Madagascar islands (Mavume et al. 2009). Only a 5 few studies reported a TC-induced upper ocean cooling in the northern (e.g., Sengupta et al. 2008; 6 McPhaden et al. 2009; Neetu et al. 2012; Girishkumar et al. 2014) and southern IO (Vialard et al. 2009). 7 Even fewer observation-based studies discussed the potential feedback of this oceanic response on IO TC 8 intensification, and only for the case of the BoB (Ali et al. 2007; Lin et al. 2009; Yu and McPhaden 2011). 9 Analyses of moored buoys data for instance indicated that a combined warm subsurface layer and strong 10 salinity stratification played an essential role in the rapid intensification of the Nargis TC in the BoB (e.g. 11 Lin et al. 2009; Yu and McPhaden 2011).

13 Very different upper ocean thermohaline structures in the two IO TC-prone regions may result in a different sensitivity of TCs to ocean-atmosphere coupling. The BoB is indeed characterized by a strong haline stratification that may limit the amplitude of TC-induced cooling and promote TC intensification (Sengupta et al. 2008; Neetu et al. 2012). In stark contrast, the cyclogenesis region in the southwestern IO is one of 17 the rare oceanic regions where warm SSTs coexist with a shallow thermocline ridge (Vialard et al. 2009), 18 hence potentially favouring an enhanced cooling below the storm and a strengthened negative oceanic 19 feedback at the early stages of the storm intensification (Xie et al. 2002). Ogata et al. (2016) results suggest that these differences may be responsible for a stronger reduction of intense TCs in the southwestern IO than in the BoB but their global perspective and their focus on intense TCs did not allow a detailed quantification of the influence of air-sea coupling on TC characteristics in the IO. To our knowledge, this study is the first one to address this question using a regional coupled model simulation over a long period.

We use a regional IO, $\sim 25-\mathrm{km}$ resolution coupled ocean-atmosphere model (Samson et al. 2014) to assess the negative feedback of air-sea coupling on the TC amplitude in this basin. This model simulates realistic spatial and seasonal distributions of IO tropical cyclones, as well as their variations in association with the 
1 leading modes of IO interannual climate variability (Samson et al. 2014). We will compare TC statistics 2 from two twenty year-long experiments (a reference coupled experiment and forced atmospheric 3 experiment, i.e. with no air-sea coupling) to provide a reliable statistical assessment of the impact of air-sea 4 coupling on IO TCs. This approach has already been successfully used to study the effect of air-sea 5 coupling on the south Pacific TC climatology (Jullien et al. 2014). The rest of the paper is organised as 6 follows. Section 2 describes the observed datasets and the modelling framework. In section 3, we first 7 validate the climatological TC spatio-temporal distribution and assess the impact of air-sea coupling on IO 8 TC characteristics. Section 4 will validate the TC-induced cooling in the coupled simulation and discuss the 9 mechanisms of the negative air-sea coupling feedback on TCs. Section 5 discusses the robustness of results presented in the previous sections when choosing a different convective parameterization in the 11 atmospheric model. The final section provides a summary and a discussion of our results.

\section{Datasets and methods}

18 In this study, we use an IO configuration of the NOW (NEMO-OASIS3-WRF) regional coupled model. 19 NOW couples the NEMO (Nucleus for European Modelling of the Ocean) ocean general circulation model 20 (Madec et al. 2008) to the WRF (Weather Research and Forecasting Model) regional atmospheric model (Skamarock and Klemp 2008) through the OASIS3 coupler (Valcke 2013). This configuration has been extensively described and validated in Samson et al. (2014). We therefore only provide a brief summary of 23 this configuration in the following.

The ocean model parameterizations include a turbulent kinetic energy scheme for vertical mixing (Blanke and Delecluse 1993), bi-laplacian viscosity and an iso-neutral laplacian diffusivity for subgrid-scale mixing (Lengaigne et al. 2003). Atmospheric model physics include the WRF single-moment six-class 
1 microphysics scheme (Hong and Lim 2006), the Goddard shortwave radiation scheme (Chou and Suarez 2 1999), the Rapid Radiation Transfer Model for longwave radiation (Mlawer et al. 1997), the Yonsei 3 University planetary boundary layer (Noh et al. 2003) and the four-layer Noah land surface model (Chen et 4 al. 1996). It also includes the updated Kain-Fritsch (KF) atmospheric convective scheme (Kain 2004), a 5 mass-flux convergence scheme that allows shallow convection, includes a minimum entrainment rate to 6 suppress widespread convection in marginally unstable relatively dry environments, and an updated 7 downdraft formulation. This scheme provides the best simulations of TC intensity and track prediction in 8 the northern IO (Srinivas et al. 2013), with higher convective warming and stronger vertical motions 9 relative to the other tested cumulus schemes. As discussed in Samson et al. (2014), the KF scheme allows 10 simulating stronger TCs (up to $56 \mathrm{~m} \cdot \mathrm{s}^{-1}$ ) than the Betts-Miller-Janjic (BMJ) moist convective adjustment 11 scheme (up to $45 \mathrm{~m} \cdot \mathrm{s}^{-1}$, Janjic 1994) but leads to a large overestimation of the number of IO TCs. Deep 12 convection is an essential mechanism for TCs, and the results presented here may be sensitive to the 13 convective scheme. The sensitivity of our results to the choice of convective scheme will thus be addressed 14 in section 5 by comparing results obtained using KF with those obtained using the BMJ convective scheme. The wind stress drag coefficient parameterization over the ocean is based on the work of Donelan et al. 16 (2004).

18 This configuration covers the IO region $\left[25.5^{\circ} \mathrm{E}-142.5^{\circ} \mathrm{E}, 34.5^{\circ} \mathrm{S}-26^{\circ} \mathrm{N}\right]$, with the oceanic and atmospheric 19 component sharing the same $1 / 4^{\circ}$ horizontal grid. The ocean component has 46 vertical levels, with an enhanced $5 \mathrm{~m}$ resolution in the upper ocean. The atmospheric component has 28 sigma vertical levels, with a higher resolution of $30 \mathrm{~m}$ near the surface. NEMO lateral boundary conditions are prescribed from a $1 / 4^{\circ}$ resolution global ocean model forced by Drakkar forcing dataset (Brodeau et al. 2010). Those of WRF are taken from 6 hourly ERA-Interim reanalysis (Dee et al. 2011). The 1st of January 1989 initial condition is provided from ERA-Interim for the atmosphere and from the $1 / 4^{\circ}$ DRAKKAR simulation mentioned above for the ocean. A 21 year coupled simulation is performed with this setup using 1989-2009 lateral boundary conditions, and will be referred to as KF-CPL (for Kain-Fritsch coupled). The first year of this experiment 
1 is discarded, and this simulation is hence analysed over a 20 -years period.

3 Samson et al. (2014) demonstrated that this configuration is able to capture the main features of the Indian

4 Ocean climate. At seasonal timescales, it reproduces the seasonal rainfall distribution and the northward 5 seasonal migration of monsoon rainfall over the Indian subcontinent. It also captures the observed 6 interannual variability associated with the Indian Ocean Dipole (Saji et al. 1999; Webster et al. 1999) and 7 El Niño Southern Oscillation (e.g. Xie et al. 2009). More importantly for our study, its relatively high 8 horizontal resolution allows to explicitly simulate TCs, with realistic cyclogenesis, track density patterns 9 and a realistic seasonal cycle, including the observed bimodal distribution in the northern IO (Samson et al. 2014). The seasonal evolution of the large-scale atmospheric parameters involved in TC genesis is also 11 properly captured.

\subsection{Sensitivity experiments}

We follow a similar strategy to Jullien et al. (2014) to isolate the influence of air-sea coupling on TCs. We perform a twin uncoupled atmospheric simulation (referred to as KF-FOR) using the same WRF atmospheric configuration, lateral boundary conditions and SST fields from the KF-CPL simulation, from which TC-induced cold wakes have been suppressed. Cold wake signals are removed by masking the coupled model SST within $3^{\circ}$ of each TC positions and from 1 day before to 30 days after the TC passage. Masked regions are then filled using bilinear interpolation from neighbouring regions. As a result, these forced simulations do not account for any ocean feedback. Comparing TCs in the coupled and forced simulations will therefore allow us to infer the impact of air-sea coupling on TC characteristics in the IO. An illustration of the strategy employed to remove the SST signature of TCs in the forced experiment is provided on Figure 2: as can be seen on that particular example, the cold wake is efficiently supressed from the KF-FOR surface boundary condition.

The small perturbations induced by the cold wake removal are sufficient to change the courses of TCs 
1 between the forced and coupled simulations, due to the chaotic nature of the atmosphere. Trajectories of 2 simulated TCs in the forced and coupled experiments will therefore be different and TCs in these two 3 simulations cannot be compared individually. Comparing the statistics of the simulated TCs in the forced 4 and coupled experiments will however allow us to infer the influence of air-sea coupling on IO TC 5 characteristics. A similar strategy was successfully used by Jullien et al. (2014) to assess the impact of air6 sea feedback under South Pacific TCs.

7

\subsection{Tracking methodology and cyclogenesis indices}

TCs from both simulations are tracked using the same methodology as in Samson et al. (2014). The following criteria are used to distinguish tropical cyclones from intense mid-latitude systems at each time step:

- $10 \mathrm{~m}$ wind $>17.5 \mathrm{~m} \cdot \mathrm{s}^{-1}$ associated with a local sea level pressure minimum

- $\quad 850 \mathrm{hPa}$ vorticity $>3 * 10^{-4} \mathrm{~s}^{-1}$

- $\quad 700-300 \mathrm{hPa}$ mean temperature anomaly $>1^{\circ} \mathrm{K}$

TC temperature anomalies are calculated with respect to their large-scale environment: the TC region is defined as 3 radii of maximum wind around the TC centre while the environmental temperature is averaged between 6 and 9 radii. Trajectories are then constructed by recursively detecting the closest neighbouring grid points that meet all above criteria. If no matching point is identified, all criteria are relaxed except vorticity. This relaxation technique allows following TCs over land and avoids counting the same TC twice. Tracks shorter than 1 day are eliminated. The vorticity and temperature thresholds are similar to those considered in previous studies (Jourdain et al. 2011; Jullien et al. 2014; Samson et al. 2014).

In the rest of the paper, we define TCs as storms verifying the above criteria. TC definition from official centres can differ from one TC-prone basin to another, rendering comparison of TCs characteristics between basins difficult: for instance, a TC is defined as a tropical system with sustained 10-m winds of at least $17 \mathrm{~m} . \mathrm{s}^{-1}$ in the west Australian and the northern IO basins, while this threshold is $33 \mathrm{~m} \cdot \mathrm{s}^{-1}$ for the 
1 southwestern IO. Following the TCs official definition from the World Meteorological Organization, we 2 define TCs using a $17.5 \mathrm{~m}-\mathrm{s}^{-1}$ on the sustained $10-\mathrm{m}$ winds and use the Saffir-Simpson scale to define TC 3 categories as: tropical storm (Cat-0 TC for $17.5 \mathrm{~m} \cdot \mathrm{s}^{-1}<\mathrm{V}_{\max }<33 \mathrm{~m} . \mathrm{s}^{-1}$ ), Category $1 \mathrm{TC}$ (Cat-1 TC for $33 \mathrm{~m} . \mathrm{s}^{-}$ $4{ }^{1}<\mathrm{V}_{\max }<43 \mathrm{~m} \cdot \mathrm{s}^{-1}$ ), Category $2 \mathrm{TC}\left(\mathrm{Cat}-2 \mathrm{TC}\right.$ for $43 \mathrm{~m} \cdot \mathrm{s}^{-1}<\mathrm{V}_{\max }<50 \mathrm{~m} \cdot \mathrm{s}^{-1}$ ), Category $3 \mathrm{TC}$ (Cat-3 TC for 50 $\left.5 \mathrm{~m} . \mathrm{s}^{-1}<\mathrm{V}_{\max }<59 \mathrm{~m} . \mathrm{s}^{-1}\right)$, Category $4 \mathrm{TC}\left(\mathrm{Cat}-4 \mathrm{TCs}\right.$ for $\left.59 \mathrm{~m} . \mathrm{s}^{-1}<\mathrm{V}_{\max }<70 \mathrm{~m} . \mathrm{s}^{-1}\right)$ and Category $5 \mathrm{TC}(\mathrm{Cat}-5$ 6 TC for $\left.\mathrm{V}_{\max }>70 \mathrm{~m} \cdot \mathrm{s}^{-1}\right)$.

8 Following Emmanuel and Nolan (2004), we use the Genesis Potential Index (GPI) to better understand the 9 influence of large-large environmental parameters on the cyclogenesis. The GPI monthly index is 10 constructed as in Emanuel and Nolan (2004) as

$$
\mathrm{GPI}=\underbrace{\left|10^{5} \eta\right|^{3 / 2}\left(1+0.1 V_{\text {shear }}\right)^{-2}}_{\text {dynamic }} \underbrace{\left(\frac{H}{50}\right)^{3}\left(\frac{V_{\text {pot }}}{70}\right)^{3}}_{\text {thermal }}
$$

12 where $\square$ is the absolute vorticity at $850 \mathrm{hPa}$ in $\mathrm{s}^{-1}, \mathrm{H}$ is the relative humidity at $600 \mathrm{hPa}, \mathrm{V}_{\text {pot }}$ is the 13 maximum potential intensity calculated using a routine provided by K. Emanuel (http://emanuel.mit.edu 14 /products) and $\mathrm{V}_{\text {shear }}$ is the magnitude of vertical wind shear between 850 and $200 \mathrm{hPa}$ in $\mathrm{m} . \mathrm{s}^{-1}$.

\subsection{Validation datasets}

Observed TC positions and magnitudes are derived from the International Best Track Archive for Climate Stewardship (IBTrACS) (Knapp et al. 2010), that merges TC tracks and intensities data from various operational meteorological forecast centres. The maximum wind speed value characterizing the TC strength is taken as the 10-minute averaged wind at 10 meters. Observed SST response under TCs is characterized using a blend of Tropical Rainfall Measuring Mission (TRMM) Microwave Image (TMI) and advanced Microwave Scanning Radiometer (AMSR-E) SST data (http://www.remss.com/measurements/sea-surfacetemperature/oisst-description), which offer the advantage of being insensitive to atmospheric water vapour and provide accurate observations of SST beneath clouds and is available from 1998 onwards. The atmospheric parameters that control TC intensification (vertical wind shear, mid-tropospheric humidity, 
1 and maximum potential intensity) are extracted from the ERA-Interim atmospheric reanalysis (Dee et al. 2 2011).

4 3. Influence of air-sea coupling in IO TCs climatology

6 Figure 1 compares the spatial distribution of IO TCs genesis and density for observations, KF-CPL and KF7 FOR simulations. In the northern Indian Ocean, cyclogenesis is maximum in the southern part of the BoB 8 and Arabian Sea (around $5^{\circ} \mathrm{N}$ ), although cyclogenesis also occurs further north in the BoB (Figure 1a). In 9 this basin, most observed TCs travel northward and/or westward (not shown). Maximum TC density is consequently found northwestward of the maximum cyclogenesis between $5^{\circ} \mathrm{N}$ and $20^{\circ} \mathrm{N}$ in the western 11 half of the BoB. While weakening over the Indian peninsula, some storms cross the Indian peninsula and 12 re-intensify when reaching the Arabian Sea to pursue their trajectory further westward (not shown). TCs 13 form less frequently over the Arabian Sea, with four times less TCs as compared to the BoB. In the southern IO, cyclogenesis occurs mostly between $5^{\circ} \mathrm{S}$ and $20^{\circ} \mathrm{S}$ with a maximum located in the central part of the basin (around $80^{\circ} \mathrm{E}$ ), and a weaker, secondary maximum northwest of Australia. Maximum TC density is shifted poleward relative to cyclogenesis. In this region, TCs usually travel southwestward between $10^{\circ} \mathrm{S}$ to $15^{\circ} \mathrm{S}$ to then deviate and travel in a southeastward direction between $20^{\circ} \mathrm{S}$ and $30^{\circ} \mathrm{S}$, being advected by climatological tropospheric winds (not shown). The KF-CPL simulation successfully captures these spatial patterns for both the northern and southern IO (Figure 1b). The modelled cyclogenesis exhibits a poleward bias in the $\mathrm{BoB}$ and a slight equatorward bias in the southern hemisphere. The maximum simulated TC density is shifted eastward in the southern IO and the model does not reproduce the gap in TC density around $100^{\circ} \mathrm{E}$, offshore the west Australian coast. The major bias in the KF-CPL simulation is to produce three times more TCs than in observations (Figure 1d).

Air-sea coupling does not significantly impact the spatial patterns of cyclogenesis and TC tracks in the IO (Figure $1 b_{2} c$ ). The only apparent change is a $20^{\circ}$ eastward shift of the maximum TC density region in the southern IO from $85^{\circ} \mathrm{E}$ to $65^{\circ} \mathrm{E}$, which is not statistically significant (not shown). The most robust impact 
1 of the oceanic feedback is a $20 \%$ decrease in the numbers of TCs (Figure 1d), which is slightly larger in 2 the northern IO $(\sim 25 \%)$ than in the southern IO $(\sim 17 \%)$.

4 In the southern IO, TCs preferentially occur in austral summer, i.e. from November to April, with very few 5 cyclones forming during boreal winter (Figure 3a). This seasonal cycle is reasonably well captured by the 6 re-analysis GPI (Figure 4a): in this region, high mid-tropospheric relative humidity, low vertical shear and 7 high maximum potential intensity combine to favour cyclogenesis during austral summer in the southern 8 IO (Figure 4b-e), when the Intertropical Convergence Zone is well established (e.g. Menkes et al. 2011). 9 The seasonal evolution of southern IO TC statistics is generally well captured by KF-CPL, with a maximum TC activity (Figure 3b) and related large-scale favourable environmental conditions during 11 austral summer (Figure 4a-e). The vorticity is however strongly overestimated in the model (Figure 4d).

13 In the northern IO, the observed seasonal TC distribution exhibits a very peculiar bimodal distribution 14 (Figure 3e). TCs preferentially occur during pre-monsoon (April-June) and post-monsoon (September15 December), with much fewer TCs in July-August and January-April. Our results are consistent with 16 Menkes et al. (2001) who attributed this bimodal distribution to the dominant effect of increased vertical 17 wind shear that overcome the opposite effect of increased relative humidity during the summer monsoon 18 (Figures $4 \mathrm{f}-\mathrm{j}$ ), preventing the formation of tropical storms during that season. The KF-CPL simulation 19 captures this specific bimodal cyclogenesis distribution reasonably well (Figure 3f), although it overestimates the proportion of TCs occurring during the core of the summer monsoon (July-August). Only Cat-0 TCs (with Vmax $<33 \mathrm{~m} . \mathrm{s}^{-1}$ ) however develop in KF-CPL (and observations) during this period (not shown). The seasonal evolution of the large-scale atmospheric drivers of the modelled TCs is also generally well captured (Figures $4 \mathrm{~g}-\mathrm{j}$ ). As in the ERA-I re-analysis, the large increase of vertical shear during the monsoon results in a GPI minimum. This minimum is less marked than in ERA-I, probably because of a more favourable vorticity, which is consistent with too many TCs during the monsoon (Figure 3f). Another noticeable mismatch is the tendency for the post-monsoon TC-prone season to occur one month earlier 
1 (September-October) than in observations (October-November). This bias can be tracked back to a similar

2 bias in seasonal GPI (Figure 4f), most likely related to an earlier post-monsoon humidity decrease in the 3 model (Figure 4h).

5 The oceanic feedback reduces the number of TCs throughout the year (Figure $3 b_{2}$ f). TCs are indeed $\sim 15-$ $625 \%$ less numerous in coupled simulations during the TC-prone seasons of both hemisphere, and this 7 decrease reaches $\sim 30 \%$ during boreal winter in the southern hemisphere (Figure 3d), and $40 \%$ during the 8 summer monsoon in the northern IO (Figure 3h). This impact is thus larger during non-cyclonic seasons, 9 i.e. when the large-scale environmental conditions are less favourable to TC development (Figure $3 b_{2} c$ and 10 $3 \mathrm{f}_{2} \mathrm{~g}$ ). Overall, this brings the coupled model seasonal cycle closer to observations than the forced model (Figure $3 \mathrm{e}_{2} \mathrm{f} g$ ), i.e. air-sea coupling seems to contribute to the observed bimodal seasonal distribution of TCs in the northern IO.

14 Figure 5 summarizes the simulated and observed IO TC intensity distribution. In observations, $12 \%$ of the TCs are Cat-2 or more in the northern IO and $22 \%$ in the southern IO (see inset in Figure 5), with maximum TC winds that can exceed $70 \mathrm{~m} \cdot \mathrm{s}^{-1}$. For both hemispheres, the KF-CPL experiment is able to 17 simulate TCs with winds of up to $56 \mathrm{~m} \cdot \mathrm{s}^{-1}$ but very rarely exceeds Cat-2. This results in a general tendency 18 for KF-CPL to considerably underestimate the percentage of intense TCs (Cat-2 and more), with only 2-3\% 19 of the TCs exceeding Cat-1 (see inset in Figure 5). Symmetrically, KF-CPL overestimates the percentage of Cat-0 TCs by $\sim 10 \%$ (Figure 5). As in Ogata et al. (2015, 2016) and Jullien et al. (2014), our rather coarse 25-km resolution indeed does not simulate the sharp eyewall structure of tangential winds for strongest TCs correctly. The radius of maximum wind speed is indeed overestimated in KF-CPL $(75 \mathrm{~km})$ relative to observations (50 km; not shown), as expected from a 1/4 ${ }^{\circ}$ resolution (Gentry and Lackmann 2010).

The oceanic feedback has a considerable impact on the TCs intensity distribution: there is a four-fold decrease of strong (Cat-2 and above) TCs in the KF-CPL simulation (2\%) relative to KF-FOR (8\%). For 
1 instance, the most intense TC simulated in KF-FOR reaches $64.5 \mathrm{~m} . \mathrm{s}^{-1}$, while it is limited to $56 \mathrm{~m} . \mathrm{s}^{-1}$ in $\mathrm{KF}$ 2 CPL. As a consequence, the proportion of tropical storms (Cat-0) is $10 \%$ larger in the coupled than in the 3 forced experiment. In agreement with Ogata et al. (2016), we do not find any significant change in the 4 location of the region of strongest TCs when air-sea coupling is accounted for, neither in the northern nor in 5 the southern IO (not shown). However, while Ogata et al. (2016) found a considerably larger decrease of 6 the number of strong TCs in the southern than in the northern IO, our results indicate a more symmetrical 7 decrease on both sides of the equator.

9 We also checked that the decrease in tropical cyclogenesis and the weaker TC intensity in KF-CPL compared to KF-FOR cannot be attributed to changes in large-scale environmental parameters that remain 11 very similar in the two simulations (Figure 4). These changes in TC characteristics can hence confidently 12 be attributed to the oceanic feedback on the TC, rather than to a change in the large-scale background 13 atmospheric conditions. The mechanisms of this TC intensity reduction as a result of air-sea coupling are 14 further investigated in the next section. ocean surface along their track, mainly through vertical mixing and upwelling (e.g. Price et al. 1981; Jullien et al. 2012; Vincent et al. 2012ab). We estimate cooling under TCs as in Vincent et al. (2012ab). To characterize the ocean response to TCs, we first subtract the mean SST seasonal cycle to obtain SST anomalies. The ocean response to TCs is then retrieved along their tracks. Average SST anomalies within a fixed $200 \mathrm{~km}$ radius around each TC track position are computed, from 10 days before to 30 days after TC passage. This $200 \mathrm{~km}$ radius corresponds to the area where SST influences TC intensity (Cione and Uhlhorn 2003; Schade 2000).

The observed and modelled composite evolution of the cooling along all IO TCs tracks is shown in Figure

6a. On average, the model simulates the temporal evolution and amplitude of TC-induced cooling 
1 accurately. SST starts decreasing a few days before the TC reaches a given location and maximum cooling 2 occurs 1 day after the TC passage (Figure 6a). The decay timescale is far slower: it takes about 30 days for 3 SST to stabilize and remain on average $0.2^{\circ} \mathrm{C}$ colder than pre-storm SST, as previously discussed by Lloyd 4 and Vecchi (2011) and Vincent et al (2012a). The temporal evolutions of the composite SST cooling under 5 TCs are very similar for the southern and northern IO for both model and observations (not shown). The 6 amplitude variations of the cooling as a function of TC maximum wind however differs between the two 8 intensity in both hemispheres, this increase is $\sim 50 \%$ larger for the northern IO $\left(-0.43^{\circ} \mathrm{C}\right.$ per $\left.10 \mathrm{~m} . \mathrm{s}^{-1}\right)$ than 9 for the southern IO $\left(-0.30^{\circ} \mathrm{C}\right.$ per $10 \mathrm{~m} \cdot \mathrm{s}^{-1}$; Figure $\left.6 \mathrm{~b}\right)$. There is hence a tendency for TCs to induce a larger oceanic cooling for a given TC wind intensity in the northern than in the southern IO. This behaviour is reasonably well captured by the model, despite an overestimated slope in both hemispheres $(0.72$ 12 and $0.51^{\circ} \mathrm{C}$ per $10 . \mathrm{m} \cdot \mathrm{s}^{-1}$ for the northern and Southern hemisphere, respectively; Figure $6 \mathrm{c}$ ).

14 Two different reasons may explain this larger cooling in the northern hemisphere. First, differences in TC translation speeds can affect the amplitude of the TC-induced cooling (Zedler 2009; Mei et al. 2012): slower-moving TCs indeed result in a larger TC-induced cooling for a given TC wind intensity, as they 17 spend a longer time at a given location and hence input more momentum into the ocean, which eventually 18 leads to enhanced vertical mixing and upwelling. Figure 7 a however reveals that the modelled TCs 19 translation speed distribution does not differ much between the two hemispheres, with a $4.60 \mathrm{~m} . \mathrm{s}^{-1}$ average over the northern IO compared to $4.77 \mathrm{~m} . \mathrm{s}^{-1}$ average in the southern IO. Although generally slower than in the model, translation speed distributions do not significantly differ in observations between the two 22 hemispheres (not shown), with a $3.73 \mathrm{~m} \cdot \mathrm{s}^{-1}$ average over the northern IO compared to $3.77 \mathrm{~m} . \mathrm{s}^{-1}$ average in 23 the southern IO. These results suggest that differences in TC translation speed cannot explain the 24 differences in TC-induced cooling amplitude between the two hemispheres.

26 The other plausible hypothesis relates to the differences in oceanic stratification between the two 
1 hemispheres. Those can indeed influence the amplitude of TC-induced SST signature (e.g. Lloyd and 2 Vecchi 2011; Vincent et al. 2012b; Neetu et al. 2012, Jullien et al. 2014). Vincent et al. (2012b) indeed 3 demonstrated that the upper-ocean pre-cyclone stratification modulates the TC-induced cooling amplitude 4 by up to an order of magnitude for a given level of TC kinetic energy input to the upper ocean. Following 5 Vincent et al. (2012b), we characterize TC-induced surface cooling inhibition by the ocean background 6 state by the Cooling Inhibition Index (CI). The CI is defined as the cube root of the potential energy 7 necessary to produce a $2{ }^{\circ} \mathrm{C}$ surface cooling via vertical mixing. $\mathrm{CI}$ is a physically relevant measure of this 8 inhibition since it integrates two important parameters for the cooling amplitude: the mixed layer depth 9 before the cyclone passage, and the strength of stratification underneath. As illustrated on Figure $7 \mathrm{~b}$, the CI distribution underneath TCs is different between the two hemispheres, with generally weaker upper ocean 11 stratification in the northern IO (average CI of 23) compared to the southern hemisphere (average CI of 29). 12 Figure 7c displays the IO CI spatial distribution during the cyclonic season of each hemisphere. Most of the 13 Northern IO TCs occur over the western BoB (contours on Figure 7c), which is characterized by relatively 14 low CI, ranging from 20 to 30 . In the southern IO, the core of the TC-prone region (between $10^{\circ} \mathrm{S}$ and $25^{\circ} \mathrm{S}$ ) is characterized by larger $\mathrm{CI}$, exceeding 30.

17 Figure $7 \mathrm{~d}$ shows the depth of the SST- $2^{\circ} \mathrm{C}$ isotherm, a proxy for the thermocline depth that is currently 18 used as an alternative to CI for estimating the influence of oceanic stratification on the TC-induced cooling (e.g. Lloyd and Vecchi 2011). The SST- $2^{\circ} \mathrm{C}$ isotherm map is very similar to that of CI (Figure $7 c_{2}$ d), which includes the effect of salinity. This indicates that, although salinity can influence CI close to the coasts in the Bay of Bengal (Neetu et al. 2012), the large-scale CI structure is largely controlled by the thermocline depth in both hemispheres. In the southern hemisphere main TC development region, there is a strong effect of westward-propagating waves forced by the seasonally-varying Ekman pumping signal (Perigaud and Delecluse 1992; Masumoto and Meyers 1998), so that the deep thermocline there is a result of the wind-stress curl induced downwelling a couple of months before (i.e. during austral winter). During that season, the positive wind stress curl associated to the southern flank of the easterlies (south of $25^{\circ} \mathrm{S}$ on 
1 Figure 7d) is located much more north, and results in the deep thermocline under cyclones, that favour a 2 higher CI (Figure 7b) and weaker cooling for a given TC intensity (Figure $6 b_{2} c$ ). Most NIO TCs occur in 3 the western BoB, where thermocline is shallow (Figure 7d), leading to a low CI (Figure 7c). The shallow 4 thermocline in the western $\mathrm{BoB}$ is due to upwelling-conducive positive wind stress curl there during the 5 extended cyclonic season (Figure 7d). The wind structure hence promotes a shallow thermocline under the 6 main TCs area in the NIO, favouring a lower CI (Figure 7b) and a stronger cooling for a given TC intensity $7 \quad$ (Figure $\left.6 b_{2} c\right)$.

9 Overall, the larger TC-induced cooling for a given TC-category in the northern hemisphere is not due to 10 differences in propagation speed between the two hemispheres. Rather, it is due to the climatologically 11 deeper thermocline under the main TCs region in the southern than in the northern hemisphere, that can 12 itself be linked to the wind stress and Ekman pumping in each hemisphere. Because of those different 13 oceanic responses to TCs, we will detail the processes associated with the TC coupling separately for each 14 hemisphere below.

16 Figure 8 provides a southern IO composite of wind speed, SST and upward enthalpy flux at the air-sea 17 interface (latent plus sensible heat flux) under TCs, for KF-CPL and KF-FOR. In this composite, we aim at 18 comparing the SST and flux response for a given TC strength. As the TCs intensity distribution is skewed 19 towards stronger TCs in KF-FOR than in KF-CPL, averaging all TCs in each simulation would result in stronger composited TCs winds in KF-FOR (not shown). We hence first build composite for each 21 experiment for a given wind intensity, by averaging all TCs within $5 \mathrm{~m} \cdot \mathrm{s}^{-1}$ wide bins. The composite of 22 Figure 8 is the average of those given wind intensity composites, so that differences between KF-FOR and 23 KF-CPL only reflect the impact of air-sea coupling and not that of the different TC wind distributions. As a 24 result, the TC wind composites exhibit very similar wind speeds in both simulations (Figure 8 $\mathrm{a}_{2} \mathrm{~b}_{2} \mathrm{c}$ ), 25 indicating that our compositing strategy efficiently filters out TC intensity differences between the two 26 simulations. The 10-m wind speed composite features a clear cyclone eye with weaker winds and 
asymmetric eye wall for both simulations (Figure $8 \mathrm{a}_{2} \mathrm{~b}$ ). Tangential winds are stronger on the storm's lefthand side because TC translation speed adds up on the left-hand side and subtracts on the right-hand side. The SST beneath TCs is warmer on the lower quadrant and cooler on the upper quadrant in KF-FOR (Figure 8e), due to the tendency of southern IO TCs to move poleward from warm tropical SSTs to cold subtropical SSTs. The SST beneath TCs is very different in KF-CPL, with an additional strong cooling towards the rear-left of the TC track (Figure 8d). The TC cold wake exhibits a clear asymmetrical structure (Figure 8d,f), with a one Radius of Maximum Wind shift to the left-hand side of the TC in agreement with observations (e.g., Vincent et al. 2012a). This asymmetry is the result of enhanced vertical mixing on the left hand side of the TC due to translation speed and to wind-current resonance at near-inertial periods (Jullien et al. 2012; Vincent et al. 2012a). Most intense inertial oscillations (and associated vertical shear) are indeed generated to the left of the track in the southern hemisphere, where TC winds rotate in the same direction as inertial currents, thus increasing the energy transfer to these currents (e.g., Price 1981). The radial structure of the enthalpy flux from the ocean to the atmosphere, that are largely dominated by latent heat fluxes (from $85-90 \%$ within the TC core to $90-95 \%$ outside one radius of maximum wind), resembles that of the wind structure, with stronger latent heat release in regions of larger winds for both KF-FOR and KF-CPL experiments. These fluxes are rather weak in the eye region, reaching a maximum within the eye wall and then slowly reduce outside the eye wall (Figure $8 g_{2} h$ ). Regarding the asymmetrical features, the enthalpy flux is larger in the lower right quadrant (Figure 8h) in KF-FOR, most likely because SST is higher there (see Figure 8e). This is expected from the Clausius-Clapeyron relation, which yields an exponential growth of upward latent heat fluxes with SST when relative humidity and air-sea temperature differences are assumed to be constant:

$$
L=A * u_{10} * \exp (\beta * S S T)
$$

where $\mathrm{A}$ and $\beta$ are positive constants characteristic of the Clausius-Clapeyron relation and $\mathrm{u}_{10}$ is the $10-\mathrm{m}$ wind speed. Despite the slightly larger wind speeds in the left quadrant (see Figure 8b), the radial structure of the enthalpy flux is dominated by its exponential dependence on SST, resulting in larger latent heat release in the lower right quadrant where SST is warmer. This feature is not as clear in KF-CPL, because of 
1 the strong TC-induced cooling in this quadrant. In addition to these differences in spatial structure, TC2 induced oceanic cooling also reduces the amplitude of this upward enthalpy flux (Figure 8i). As expected, 3 this reduction is maximum under the maximum TC-induced cooling, in the lower left quadrant of the TC $4 \quad\left(120 \mathrm{~W} \cdot \mathrm{m}^{-2}\right.$ reduction, i.e $\sim 20 \%$ of the maximum enthalpy flux). The average enthalpy reduction within $5200 \mathrm{~km}$ of the TC centre is $\sim 40 \mathrm{~W} . \mathrm{m}^{-2}$, representing a $6 \%$ reduction of the total enthalpy flux fuelling the 6 TC in the southern IO.

8 Figure 9 provides a similar picture for northern hemisphere TCs. As for southern hemisphere TCs, northern 9 IO TCs wind composites are very similar for the KF-CPL and KF-FOR experiments (Figure 9a $\mathrm{a}_{2} \mathrm{~b}_{2} \mathrm{c}$ ), 10 implying that our compositing methods has removed the effect of different wind speed distributions and 11 focuses on air-sea coupling. The KF-FOR SST beneath the TC is generally warmer in the northern than in 12 the southern IO (Figure $9 \mathrm{e}$ vs. $8 \mathrm{e} ; 29^{\circ} \mathrm{C}$ vs. $28^{\circ} \mathrm{C}$ ) and is rather homogeneous spatially (the BoB is 13 uniformly warm during the cyclonic seasons). The slightly warmer SSTs at the rear of the TC are due to the 14 poleward decrease of SST (TCs form close to the equator and move poleward). KF-CPL exhibits a strong cooling at the rear of the TC on its right hand side, as a result of translation speed and resonance between inertial oscillations and wind vector rotation that occurs to the right of the track in the northern hemisphere (e.g., Price, 1981). As expected from Figure $6 b_{2} c$, the cooling is larger in the northern (Figure 9f) than in 18 the southern IO (Figure 8f), reaching up to $1.1^{\circ} \mathrm{C}$. As for the southern IO, KF-FOR enthalpy fluxes are 19 generally larger on the lower left quadrant where SST is slightly warmer (Figure 9e,h). The maximum enthalpy flux reduction due to coupling with the ocean is approximately twice as large in the northern than in the southern IO $\left(\sim 230 \mathrm{~W} . \mathrm{m}^{-2}\right.$ vs. $\left.120 \mathrm{~W} \cdot \mathrm{m}^{-2}\right)$ : this probably results from the combined effect of larger TC-induced cooling and warmer SST in the northern hemisphere. While this reduction is mainly localized at the rear of the TC in southern IO (Figure 8i), this reduction is also prominent right under the TC in the northern IO. This results in a considerably larger upward latent heat flux reduction within 200km of the TC centre $\left(\sim 63 \mathrm{~W} . \mathrm{m}^{-2}\right.$, representing a $10 \%$ reduction of the total enthalpy flux fuelling the TC against $6 \%$ in the southern IO). 
2 We first investigate the intensity dependency of the upward enthalpy flux, SST and intensification rate of 3 intensifying TCs in KF-FOR (Figure 10). The intensification rate is calculated here as the difference 4 between the TC intensity $12 \mathrm{~h}$ after and $12 \mathrm{~h}$ before for each TC point. As expected from eqn. (2), the 5 amplitude of the enthalpy flux fuelling the TC increases with TC intensity for both hemispheres (Figure 6 10a). For a given TC wind intensity, the enthalpy flux is however systematically larger in the northern 7 compared to the southern IO in KF-FOR experiment. It is for instance $\sim 850 \mathrm{~W} . \mathrm{m}^{-2}$ for $45-50 \mathrm{~m} . \mathrm{s}^{-1} \mathrm{TCs}$ in 8 the southern IO, against $\sim 1050 \mathrm{~W} \cdot \mathrm{m}^{-2}$ in the northern $\mathrm{IO}$. This difference can be attributed to the 9 systematically $\sim 1^{\circ} \mathrm{C}$ warmer SSTs in the northern IO (Figure 10c), which lead to higher enthalpy fluxes as 10 indicated by eqn. (2). Consistently with those larger enthalpy fluxes, the TC intensification rates are 11 generally larger in the northern than in the southern IO for the KF-FOR experiment, especially for 12 maximum wind speeds above $35 \mathrm{~m} \cdot \mathrm{s}^{-1}$ (Figure 10b). It must however be noted that these differences in 13 intensification rate may also partly be driven by the different large-scale environmental parameters that are 14 also different in the two basins (Figure 4).

16 Figure 11 further compares the impact of air-sea coupling on TC intensification in the southern and 17 northern IO by showing the intensifying TCs KF-CPL minus KF-FOR enthalpy fluxes, intensification rates 18 and SST differences, as a function of wind intensity. In the southern IO, air-sea coupling reduces the 19 enthalpy flux by $\sim 10 \%$ for a given storm strength, i.e. from $\sim 20 \mathrm{~W} \cdot \mathrm{m}^{-2}$ for weak storms to $\sim 50 \mathrm{~W} . \mathrm{m}^{-2}$ for the 20 strongest TCs. This translates into a reduction of TC intensification rate of up to $\sim 0.8 \mathrm{~m} . \mathrm{s}^{-1}$ per day for 21 storms of intermediate strength (25 to $40 \mathrm{~m} \cdot \mathrm{s}^{-1}$ ), i.e. a $10 \%$ reduction of the intensification rate compared to 22 the uncoupled simulation. This picture is quantitatively very different for the northern IO. In this region, 23 air-sea coupling reduces the enthalpy flux from $30 \mathrm{~W} \cdot \mathrm{m}^{-2}$ for weak TCs to up to $260 \mathrm{~W} . \mathrm{m}^{-2}$ for the 24 strongest TCs. This reduction for strongest TCs in the northern IO is hence five times larger than that in the southern IO and corresponds to a $25 \%$ enthalpy flux decrease relative to the forced simulation. This 26 translates into a considerably larger reduction, of up to $3.2 \mathrm{~m} . \mathrm{s}^{-1}$ per day, of the intensification rate of 
1 strongest TCs, i.e. a $40 \%$ reduction. This reduction is $\sim 20-30 \%$ for TCs of intermediate intensity (i.e. 35 to $\left.245 \mathrm{~m} . \mathrm{s}^{-1}\right)$. The different background SST allows understanding the larger sensitivity of northern IO TCs to 3 air-sea coupling. Based on eqn. (2), the air-sea coupling influence on the latent heat flux under TCs can be 4 approximated as:

$$
\Delta L_{C P L-F O R}=A * u_{10} * \exp \left(\beta * S S T_{F O R}\right) *\left(\exp \left(\beta * \Delta S S T_{C P L-F O R}\right)-1\right)
$$

6 where $\triangle \mathrm{L}_{\mathrm{CPL}-\mathrm{FOR}}$ is the KF-CPL minus KF-FOR upward latent heat flux for a given wind storm intensity $7 \quad \mathrm{u}_{10}, \mathrm{SST}_{\mathrm{FOR}}$ is the ambient SST under the TC (i.e. the KF-FOR SST, which does not account for air-sea 8 coupling) and $\triangle \mathrm{SST}_{\mathrm{CPL}-\mathrm{FOR}}$ is the TC-induced cooling under the storm track. From equation (3), two factors 9 can contribute to the larger impact of air-sea coupling on the heat flux. First, as displayed on Figure $6 b_{2} c$, $10 \Delta \mathrm{SST}_{\mathrm{CPL}-\mathrm{FOR}}$ is larger in the northern IO than in the southern IO for a given TC intensity, arguably because 11 of the difference in the ocean stratification in these two basins. Second, the ambient SST $_{\text {FOR }}$ is also larger in 12 the northern than in the southern IO (Figure 10b). These two factors contribute to a larger upward latent 13 heat flux reduction due to coupling in the northern hemisphere, and hence a larger impact on the cyclone growth rate. This illustrates the important contribution of background SST and air-sea interactions on the TC number and intensity distributions for the northern compared to southern IO.

17 Previous studies (e.g. Mei et al. 2012) indicate that air-sea coupling has a larger influence on slowlymoving cyclones. We have hence repeated Figure $11 \mathrm{a}_{2} \mathrm{c}$ analysis separately for NIO slowly and fast moving 19 TCs (separating the dataset into two equal parts using a $4 \mathrm{~m} \cdot \mathrm{s}^{-1}$ threshold). This analysis demonstrates that the strong impact of air-sea coupling on northern IO intense cyclones mainly arises from slowly-moving TCs. The coupling-induced intensification rate reduction indeed hardly reaches $\sim 0.15 \mathrm{~m} . \mathrm{s}^{-1}$ for fast-moving TCs stronger than $35 \mathrm{~m} . \mathrm{s}^{-1}$ (i.e. a $8 \%$ reduction), while it is as high as $0.9 \mathrm{~m} . \mathrm{s}^{-1}$ (i.e. a $50 \%$ reduction) for slow moving TCs (Figure 11e). The larger impact of coupling for slow TCs is generally attributed to their tendency to induce larger oceanic cooling (e.g. Zedler 2009; Mei et al. 2012). The oceanic cooling under northern IO slow cyclones is however hardly larger than that under slow cyclones in our simulations

(Figure 11f), yielding almost no change in the upward latent heat flux. This suggests that, in our 
1 simulations at least, the main cause for a larger impact of coupling on slow cyclones is that they spend 2 more time over the cold wake they have induced, and hence experience the decreased upward enthalpy 3 fluxes for a longer time.

\section{5. Sensitivity of the results to the atmospheric convective scheme}

7 Deep atmospheric convection is central to processes by which TCs grow. It is hence possible that our 8 results would be radically changed with a different convective parameterization. As discussed in section 2 , 9 we hence performed an additional set of experiments with the Bett-Miller-Janjic cumulus parameterization convective parameterization than on the BMJ convective parameterization.

As KF-CPL, BMJ-CPL successfully captures the observed cyclogenesis and TC density spatial patterns both for the northern and southern IO (Figure 12a,b). This simulation however yields a far more realistic number of IO TCs (Figure 12d), in contrast to KF-CPL that produces three times more TCs as in observations (see Figure 1d). As in KF, air-sea coupling does not significantly impact the IO cyclogenesis and TC track spatial patterns (Figure $12 b_{2} c$ ). As in KF, the ocean feedback considerably decreases the number of TCs developing in both hemispheres in the IO (Figure 12d), with an even larger decrease in BMJ $(\sim 65 \%)$ than in KF experiments $(\sim 20 \%)$. In BMJ-CPL, the TC counts are consequently in very good agreement with observations.

The mean seasonal cycle of the number of IO TCs is generally well captured by BMJ-CPL, with a maximum TC activity during austral summer in the southern IO (Figure 13b), and a bimodal TC 
1 distribution in the northern IO (Figure 13f), with TCs preferentially occurring during the pre and post2 monsoon seasons. The observed absence of TCs during the core of the summer monsoon (July-August) is 3 even better captured by BMJ-CPL (Figure 13f) than by KF-CPL (Figure 3f). Another noticeable 4 improvement of BMJ-CPL is the better seasonal phasing of TC occurrence during the post-monsoon season 5 (October-November; Figure 13e, $\mathrm{f}$ ). The seasonal evolution of the large-scale atmospheric parameters 6 driving the TC seasonal evolution is also well captured by BMJ-CPL for both hemispheres (not shown, see 7 also Samson et al. 2014). Although of different magnitude, the relative impact of air-sea coupling on 8 seasonal changes in TC number in BMJ (Figure $13 \mathrm{~d}_{2} \mathrm{~h}$ ) is very similar to that of KF (Figure $3 \mathrm{~d}_{2} \mathrm{~h}$ ), with a 9 larger decrease during non-cyclonic seasons as compared to cyclonic seasons.

BMJ-CPL underestimates the proportion of strongest cyclones even more than KF-CPL (Figure 14). While 12 KF-CPL is able to simulate relatively intense tropical cyclones (up to Cat-3, the most intense simulated TC 13 reaching a surface maximum wind speed of $56 \mathrm{~m} \cdot \mathrm{s}^{-1}$ ), BMJ-CPL never experiences TCs above Cat-1 (the 14 most intense simulated TC reaching a surface maximum wind speed of $46 \mathrm{~m} . \mathrm{s}^{-1}$ ). In addition, KF-CPL experiment generally simulates a smaller, more realistic radius of maximum wind speed $(\sim 75 \mathrm{~km})$ compared to the BMJ-CPL experiment ( $100 \mathrm{~km}$; see Samson et al. 2014). Despite these biases, the oceanic feedback onto TC intensity distribution acts in a similar way: coupling shifts the TC intensity distribution towards weaker cyclones (Figure 14). As for KF, there is no significant change in the spatial distribution of strongest TCs neither in the northern or southern IO (not shown).

Compared to KF (Figure 6a), BMJ-CPL largely overestimates the amplitude of maximum TC-induced cooling (Figure $15 \mathrm{a} ;-0.6^{\circ} \mathrm{C}$ in observations vs $-1{ }^{\circ} \mathrm{C}$ in $\mathrm{BMJ}-\mathrm{CPL}$ ). This is probably related to the overestimated TC size in BMJ, which results in a longer influence of strong TC-winds at a given oceanic point and an enhanced upwelling (Vincent et al. 2012a). As for KF-CPL, the TC-induced cooling is larger in the northern than in the southern IO for a given TC amplitude (Figure $15 b_{2} c$ ). This can also be attributed (not shown) to an ocean stratification that favours more intense SST cooling in the northern IO. 
2 BMJ TC composites for both hemispheres give qualitatively similar results to those of Figure 8 and 9 for $3 \mathrm{KF}$ (not shown). BMJ-FOR also yields larger intensification rates for northern IO intensifying TCs than for 4 the southern IO (Figure 16a), consistent with a warmer SST leading to larger upward enthalpy fluxes (not 5 shown). TC-induced cooling also acts to reduce the intensification rate in both hemispheres, by up to 1.6 $6 \mathrm{~m} . \mathrm{s}^{-1}$.day ${ }^{-1}$ in the 30 to $35 \mathrm{~m} \cdot \mathrm{s}^{-1} \mathrm{TC}$ wind intensity range (Figure $16 \mathrm{~b}$ ) against only 0 to $0.8 \mathrm{~m} \cdot \mathrm{s}^{-1}$. day ${ }^{-1}$ for 7 KF. The larger effect of coupling on northern IO versus southern IO strong TC intensification rates 8 however cannot be confirmed in BMJ simulations, due to the absence of strong TCs (Cat2 and more) in 9 those simulations. Overall, the two parameterizations yield qualitatively similar (but quantitatively 10 different) effects of air-sea coupling on IO TCs.

12 6. Summary and discussion

24 Our results reveal that the spatial distribution of cyclogenesis in the IO is not affected by air-sea coupling. 25 This result may partly be related to the fact that large-scale environmental parameters controlling cyclogenesis such as vertical wind shear or relative humidity are not sensitive to ocean-atmosphere coupling in our modelling framework. However, our results demonstrate that air-sea coupling reduces the 
1 TCs number counts by $\sim 20 \%$ in both hemispheres. It also impacts the TC seasonal distribution: the bimodal 2 character of TC seasonal distribution in the northern IO is better represented in the coupled run, as a 3 consequence of a larger air-sea coupling induced TC reduction during the summer monsoon than during the 4 pre and post-monsoon. Air-sea coupling also shifts the TC distribution toward weaker TCs (7\% of Cat 2 5 and stronger TCs in the forced simulation vs. $2 \%$ in the coupled one). Large-scale TC-favourable 6 atmospheric background parameters do not change between the forced and coupled simulations, and those 7 changes can hence be confidently attributed to air-sea interactions below TCs.

9 The inner-core upward enthalpy flux that fuels the TCs is reduced in the coupled simulation in response to 10 the TC-induced ocean cooling. This reduction is larger in the northern IO (up to $\sim 200 \mathrm{~W} \cdot \mathrm{m}^{-2}$ for the most 11 intense simulated TCs, corresponding to a 20-30\% reduction) than in the southern IO (up to $\sim 60 \mathrm{~W} . \mathrm{m}^{-2}$ for 12 the most intense simulated TCs, corresponding to a $10 \%$ reduction). This larger upward enthalpy flux 13 reduction also yields a larger coupling-induced TC intensification rate reduction in the northern IO. The 14 growth rate of the strongest intensifying TCs is indeed $~ 50 \%$ weaker in the coupled than in the forced simulation in the northern IO, against a $\sim 15 \%$ reduction - and only for moderate TCs - in the southern IO. This contrast in the air-sea coupling impact on TCs can be attributed to the higher ambient SST and larger TC-induced cooling for a given storm intensity in the northern IO. This larger TC-induced cooling in the northern IO is a consequence of a relatively shallow thermocline in the TC prone region of the Bay of Bengal during the cyclonic season. Finally, we find that the strong impact of air-sea coupling on strongest NIO cyclones is largely attributable to slowly-moving cyclones, probably because they spend more time over the cooling they induce.

The robustness of these results is assessed from another set of 20-year long twin experiments with a different parameterization of deep atmospheric convection. This set of experiments also simulates the spatial and seasonal distributions of TCs realistically. It yields a more realistic number of TCs, but only TCs up to Cat-1 (up to $40 \mathrm{~m} \cdot \mathrm{s}^{-1}$ ) and an overestimated TC-induced cooling (probably because of the overestimated radius of maximum winds). The impact of air-sea coupling is qualitatively similar in the two 
1 sets of experiments. Air-sea coupling does not affect the TC spatio-temporal distribution, but considerably

2 reduces the number of TCs, especially during the non-cyclonic season leading to a more realistic bimodal 3 seasonal TC distribution in the northern IO. This reduction is considerably larger in the later configuration $4(\sim 65 \%)$ than in the initial one $(\sim 20 \%)$. Finally, the percentage of strongest simulated TCs also decreases 5 when air-sea coupling is included, with similar mechanisms. The lack of intense TCs (Cat-2 and more) in 6 the BMJ configuration however prevents assessing the inter-hemispheric differences in air-coupling impact 7 on TCs.

11 Our results also indicate that air-sea coupling does not only decrease the percentage of strongest simulated 12 TCs but also considerably reduces the overall number of TCs. This has also been reported by Jullien et al. 13 (2014) for South Pacific TCs and by Zarzycki (2016) for north Pacific and Atlantic TCs. This suggests that 14 even the small cooling under tropical storms $\left(\sim 0.5^{\circ} \mathrm{C}\right)$ may be sufficient to decrease surface enthalpy fluxes enough to prevent TC genesis and intensification. In addition, our results suggest that this reduction is larger during the non-cyclonic season, resulting in a much better resolved bimodal character of northern IO seasonal distribution in the coupled simulation. This stronger sensitivity of TCs counts during non-cyclonic seasons may be related to less favorable atmospheric conditions during that season. In the forced simulation, while the unfavorable atmospheric conditions prevent these TCs to exceed $33 \mathrm{~m} \cdot \mathrm{s}^{-1}$, the absence of TC-induced cooling still allows TCs to form in non-cyclonic season. In the coupled run, the storminduced oceanic cooling combined with unfavorable atmospheric conditions may considerably limit TCs formation. In other words, TC formation may be more sensitive to the negative oceanic feedback when atmospheric environmental parameters are already unfavorable. The influence of air-sea coupling on the cyclogenesis spatial distribution may however depend on the basin. Jullien et al. (2014) indeed suggested that air-sea coupling reduces cyclogenesis specifically in the Coral Sea, leading to a more realistic cyclogenesis pattern in the south Pacific. In contrast, cyclogenesis patterns were not considerably affected by air-sea coupling in the north Pacific and Atlantic (Zarzycki 2016) as in our Indian Ocean study. 
2 Our results reveal the sensitivity of TCs intensification to air-sea coupling is very different between the 3 northern and southern IO. This sensitivity is rather modest in the southern IO: there is a 10\% enthalpy flux 4 reduction, similar for all TCs strength, but the response in terms of intensification rate changes mainly 5 affect modest TCs, with weak intensification rate changes for the strongest simulated TCs. In contrast, this 6 impact is stronger and larger ( $25 \%$ enthalpy flux reduction) for the most intense simulated TCs (45 to 50 $\left.7 \mathrm{~m} . \mathrm{s}^{-1}\right)$ than for modest for weak TCs $(\sim 10 \%$ enthalpy flux reduction) in the northern IO. This results in a 8 modest impact of air-sea coupling on TCs intensification rate for weak TCs but in a considerable impact for 9 the strongest simulated TCs $\left(\mathrm{V}_{\max }>35 \mathrm{~m} . \mathrm{s}^{-1}\right)$, with a $\sim 30 \%$ reduction when air-sea coupling is accounted 10 for. Our results further reveal that this impact is even larger when considering only slow moving TCs 11 ( $50 \%$ reduction). The amplitude of the coupled feedback derived from this analysis is in line with the observational estimates from Cione and Uhlhorn (2003), who reported a total enthalpy fluxes reduction within the core (radius of $60 \mathrm{~km}$ ) of $\sim 40 \%$ for strong TCs. They are also in line with model estimate of 14 Zarzycki (2016) who reported a 20\% enthalpy flux reduction for all TCs and a $\sim 30 \%$ reduction for Cat-1 and more TCs. This larger impact of air-sea coupling on strongest TCs has already been reported in several studies (Jullien et al. 2014; Zarzycki 2016; Vincent et al. 2014).

The fact that two convective parameterizations that yield quite different TC numbers, radius and intensity in general provide qualitatively similar results about the influence of air-sea coupling is re-assuring. However, the inability of BMJ to yield strong cyclones limits our ability to evaluate the robustness of our results with respect to TC intensity. Our results additionally suggest that the TC-intensity dependence of our results is sensitive to the convective parameterization. Using the Bett-Miller-Janjic cumulus parameterization instead of that of Kain-Fritsch indeed yields a stronger sensitivity (1 to $2 \mathrm{~m} . \mathrm{s}^{-1}$.day ${ }^{-1}$ ) for modest TCs $\left(30-35 \mathrm{~m} . \mathrm{s}^{-1}\right)$ as compared to our reference configuration $\left(0\right.$ to $0.6 \mathrm{~m} . \mathrm{s}^{-1}$.day $\left.{ }^{-1}\right)$. This suggests that the modelled reduction rate may depend on the convective parameterization, calling for further studies employing varying atmospheric configurations as well as a higher spatial resolution allowing to resolve 
2 As discussed above, most studies discussing the impact of air-sea coupling on TCs suggest a considerably 3 larger impact of air-sea coupling on the strongest simulated TCs. As for other regional modelling studies 4 (Jullien et al., 2014; Ogata et al., 2015), the rather coarse resolution of our model $\left(1 / 4^{\circ}\right)$ does not allow to 5 simulate strongest TCs (Category 3 and above), as this resolution smoothens the sharp tangential winds 6 eyewall structure and underestimates the strongest eyewall updrafts and compensating inner-eye subsidence 7 (Gentry and Lackmann 2010). A more realistic distribution of extreme TCs would require an atmospheric 8 model with finer resolution of $\sim 10 \mathrm{~km}$ (Jung et al., 2012; Manganello et al. 2012; Satoh et al., 2012; 9 Murakami et al., 2015). A promising follow-up to the present work would hence be to develop a $\sim 10 \mathrm{~km}$ 10 resolution regional air-sea coupled model using the same oceanic and atmospheric components for the $11 \mathrm{BoB}$, where air-sea coupling seems to have a particularly strong negative feedback on slowly-moving 12 intense TCs (which are also the most destructive ones),due to warm SST and a relatively shallow 13 thermocline. This would allow assessing the impact of air-sea coupling in this region, where 14 of the 20 14 deadliest cyclones in history have developed (Longshore 2008).

17 Acknowledgments: ML, NS and JV thank IFCPAR (Indo French Centre for Promotion of 18 Advanced Research), New Delhi for funding of the proposal 4907-1. NS and IS thank Director, CSIR-NIO 19 for his encouragement. This work was done while ML was a visiting scientist at the CSIR-National 20 Institute of Oceanography (NIO) in Goa, under Institut de Recherche pour le Développement (IRD) 21 funding. JV also acknowledges IRD support for regular visits to NIO. This is NIO contribution number 22 xxxx. 


\section{References:}

Ali MM, Jagadeesh PSV, Jain S (2007)_Effects of eddies on Bay of Bengal cyclone intensity. Eos Trans Amer Geophys. Union 88: 93-95. doi: 10.1029/2007EO080001.

Balaguru K, GR Foltz, LR Leung, ED Asaro, KA Emanuel, H Liu, and SE Zedler (2015) Dynamic Potential Intensity: An improved representation of the ocean's impact on tropical cyclones. Geophys Res Lett, 42 : 67396746, doi :10.1002/2015GL064822

Bender MA, I Ginis and Y Kurihara (1993) Numerical simulations of tropical cyclone- ocean interaction with a highresolution coupled model. J Geophys Res 98:23245-23263. doi:10.1029/93JD02370

Bender MA and I Ginis (2000) Real-case simulations of hurricane-ocean interaction using a high-resolution coupled model: Effects on hurricane intensity. Mon Wea Rev, 128:917-946. doi:10.1175/15200493(2000)128<0917:RCSOHO>2.0.CO;2

Blanke B, and P Delecluse (1993) Variability of the tropical Atlantic ocean simulated by a general circulation model with two different mixed layer physics. J Phys Oceanogr, 23:1363-1388. doi:10.1175/15200485(1993)023<1363:VOTTAO>2.0.CO;2

Brodeau L, B Barnier, A-M Treguier, T Penduff and S Gulev (2010) An ERA40-based atmospheric forcing for global ocean circulation models, Ocean Modelling 31:88-104. doi:10.1016/j.ocemod.2009.10.005. doi: 10.1016/j.ocemod.2009.10.005.

Cione JJ and EW Uhlhorn (2003) Sea surface temperature variability in hurricanes: Implications with respect to intensity change. Mon Wea Rev 131:1783-1796.

Chen F, K Mitchell, J Schaake, Y Xue, H-L Pan, V Koren, QY Duan, M Ek and A Betts (1996) Modeling of land surface evaporation by four schemes and comparison with FIFE observations. J Geophys Res, 101:7251-7268. doi:10.1029/95JD02165.

Chen S, TJ Campbell, H Jin, S Gabersek, RM Hodur, P Martin (2010) Effect of Two-Way Air-Sea Coupling in High and Low Wind Speed Regimes. Mon Wea Rev 138:3579-3602. doi: 10.1175/2009MWR3119.1.

Chou M and M Suarez (1999) A solar radiation parameterization for atmospheric studies, Tech Rep NASA/TM1999-104606, NASA/GSFC.

Dee DP, SM Uppala, AJ Simmons et al. (2011) The ERA-Interim reanalysis: Configuration and performance of the data assimilation system. Q J Roy Meteorol Soc 137:553-597. doi: 10.1002/qj.828

DeMaria M (1996) The effect of vertical shear on tropical cyclone intensity change. J Atmos Sci 53:2076-2087. doi:10.1175/1520-0469(1996)053<2076:TEOVSO>2.0.CO;2

DeMaria M, M Mainelli, LK Shay, JA Knaff and J Kaplan (2005) Further Improvements in the Statistical Hurricane Intensity Prediction Scheme (SHIPS). Wea Forecasting 20:531-543. doi:10.1175/WAF862.1

DeMaria M, CR Sampson, JA Knaff, KD Musgrave (2014) Is tropical cyclone intensity guidance improving? Bull Amer Meteor Soc,95:387-398. doi:10.1175/BAMS-D-12-00240.1

Donelan MA, BK Haus, N Reul, WJ Plant, M Stiassnie, HC Graber, OB Brown and ES Saltzman (2004) On the limiting aerodynamic roughness of the ocean in very strong winds. Geophys Res Lett 31 L18306. doi:10.1029/2004GL019460.

Emanuel KA (1986) An air-sea interaction theory for tropical cyclones. Part 1 : Steady-state maintenance. J Atmos Sci 43:585-604. doi:10.1175/1520-0469(1986)043<0585:AASITF>2.0.CO;2

Emanuel KA (1999) Thermodynamic control of hurricane intensity. Nature, 401:665-669.doi:10.1038/44326.

Emanuel K (2003) Tropical cyclones. Annu Rev Earth Planet Sci 31:75-104. doi: 10.1146/annurev.earth.31.100901.141259

Emanuel KA, DS Nolan (2004) Tropical cyclone activity and global climate. 26th Conf. on Hurricanes and Tropical Meteorology, Miami, FL, Amer. Meteor. Soc. pp 240-241.

Gentry MS and G Lackmann (2010) Sensitivity of simulated tropical cyclone structure and intensity to horizontal resolution. Mon Wea Rev 138:688-704. doi: 10.1175/2009MWR2976.1.

Girishkumar MS, K Suprit, J Chiranjivi, TVS Udaya Bhaskar, M Ravichandran, R Venkat Shesu and E Pattabhi Rama Rao (2014) Observed Oceanic response to tropical cyclone Jal from a moored buoy in the south-western Bay of Bengal. Ocean Dyn 64:325-335. doi:10.1007/s10236-014-0689-6. 
Halliwell GR, LK Shay, J Brewster and WJ Teague (2011) Evaluation and sensitivity analysis to an ocean model response to hurricane Ivan. Mon Wea Rev 139:921-945. doi:10.1175/2010MWR3104.1.

Halliwell GR, S Gopalakrishnan, F Marks, D Willey (2015) Idealized study of ocean impacts on tropical cyclone intensity forecasts. Mon Wea Rev 143:1142-1165. doi: 10.1175/MWR-D-14-00022.1.

Hong X, SW Chang, S Raman, LK Shay and R Hodur (2000) The interaction between Hurricane Opal (1995) and a warm core eddy in the Gulf of Mexico. Mon Wea Rev 128:1347-1365. doi:10.1175/15200493(2000)128<1347:TIBHOA>2.0.CO;2

Hong S-Y and J-OJ Lim (2006) The WRF Single-Moment 6-Class Microphysics Scheme (WSM6), Asia-Pacific, J. Atmos. Sci. 42:129-151.

Ito K, T Kuroda and K Saito (2015) Forecasting a large number of tropical cyclone intensities around Japan using a high-resolution atmosphere-ocean coupled model. Wea Forecasting 30:793-808. doi:10.1175/WAF-D-1400034.1.

Janjic' ZI (1994) The step-mountain Eta coordinate model: Further developments of the convection, viscous sublayer, and turbulence closure schemes. Mon Wea Rev 122:927-945. doi:10.1175/15200493(1994)122<0927:TSMECM>2.0.CO;2.

Jourdain NC, Marchesiello P, Menkes CE, et al (2011) Mesoscale Simulation of Tropical Cyclones in the South Pacific: Climatology and Interannual Variability. J Clim 24:3-25. doi: 10.1175/2010JCLI3559.1

Jullien S, CE Menkes, P Marchesiello, NC Jourdain, M Lengaigne, A Koch-Larrouy, J Lefèvre, EM Vincent and V Faure (2012) Impact of tropical cyclones on the heat budget of the South Pacific Ocean. J Phys Oceanogr 42(11):1882-1906. doi :10.1175/JPO-D-11-0133.1.

Jullien S, P Marchesiello, CE Menkes, J Lefèvre, NC Jourdain, G Samson and M Lengaigne (2014) Ocean feedback to tropical cyclones: Climatology and processes. Clim Dyn 43:,2831-2854. doi:10.1007/s00382-014-2096-6

Kain JS (2004) The Kain-Fritsch convective parameterization: An update. J Appl Meteorol 43:170-181, doi:10.1175/1520-0450(2004)043<0170:TKCPAU>2.0.CO;2.

Knapp KR, MC Kruk, DH Levinson, HJ Diamond and CJ Neumann (2010) The International Best Track Archive for Climate Stewardship (IBTrACS): Unifying Tropical Cyclone Data. Bull Amer Meteor Soc 91(3):363-376. doi:10.1175/2009BAMS2755.1.

Lengaigne M, G Madec, CE Menkes and G Alory (2003) Impact of isopycnal mixing on the tropical ocean circulation. J Geophys Res 108 C11. doi:10.1029/2002JC001704.

Li Z, W Yu, T Li, VSN Murty and F Tangang (2013) Bimodal character of cyclone climatology in Bay of Bengal modulated by monsoon seasonal cycle. J Clim 26:1033-1046. doi:10.1175/JCLI-D-11-00627.1

Lin II, CC Wu, KA Emanuel, IH Lee, CR Wu and IF Pun (2005) The interaction of Supertyphoon Maemi (2003) with a warm ocean eddy. Mon Wea Rev 133:2635-2649. doi: 10.1175/MWR3005.1.

Lin II, CH Chen, IF Pun, WT Liu and CC Wu (2009) Warm ocean anomaly, air sea fluxes, and the rapid intensification of tropical cyclone Nargis (2008). Geophys Res Lett 36 L03817. doi:10.1029/ 2008GL035815.

Liu B, H Liu, L Xie, C Guan and D Zhao (2011) A coupled atmosphere-wave-ocean modeling system: Simulation of the intensity of an idealized tropical cyclone. Mon Wea Rev 139:132-152. doi:10.1175/2010MWR3396.1

Lloyd ID and GA Vecchi (2011) Observational evidence of oceanic controls on hurricane intensity. J Clim. 24:11381153. doi: $10.1175 / 2010$ JCLI3763.1.

Longshore D (2008) Encyclopedia of Hurricanes, Typhoons, and Cyclones. Checkmark books. 468 pp, ISBN 978-08160-7409-9.

Ma Z, J Fei, L Liu, X Huang and X Cheng (2013) Effects of the cold core eddy on tropical cyclone intensity and structure under idealized air-sea interaction conditions, Mon Wea Rev $141: 1285-1303$. doi:10.1175/MWR-D$12-00123.1$

Madec G (2008) NEMO ocean engine. Note du Pôle de modélisation, Institut Pierre-Simon Laplace (IPSL),27, ISSN No 1288-1619.

Mainelli M, M DeMaria, LK Shay and G Goni (2008) Application of oceanic heat content estimation to operational forecasting of recent Atlantic category 5 hurricanes. Wea Forecasting 23:3-16. doi: 10.1175/2007WAF2006111.1.

Masumoto, Y., \& Meyers, G. (1998). Forced Rossby waves in the southern tropical Indian Ocean. J. Geophys. Res.: 103:27589-27602. doi: 10.1029/98JC02546. 
Mavume AF, L Rydberg, M Rouault, JRE Lutjeharms (2009) Climatology and landfall of tropical cyclones in the south-west Indian Ocean. Western Indian Ocean Journal of Marine Science 8:15-36. doi: $\underline{0.4314 / \text { wiojms.v8i1.56672. }}$.

McPhaden MJ, GR Foltz, T Lee, VSN Murty, M Ravichandran, GA Vecchi, J Vialard, JD Wiggert and L Yu (2009) Ocean-atmosphere interactions during cyclone Nargis. Eos Trans Amer Geophys Union 90:53-54, doi:10.1029/2009EO070001.

Mei W, C Pasquero and F Primeau (2012) The effect of translation speed upon the intensity of tropical cyclones over the tropical ocean. Geophys Res Lett 39 L07801. doi:10.1029/2011GL050765.

Menkes CE, M Lengaigne, P Marchesiello, N Jourdain, EM Vincent, J Lefèvre, F Chauvin, J-F Royer (2012) Comparison of tropical cyclogenesis indices on seasonal to interannual timescales. Clim Dyn 38(12):301-321 doi 10.1007/s00382-011-1126-x.

Mlawer EJ, SJ Taubman, PD Brown, MJ Iacono and SA Clough (1997) Radiative transfer for inhomogeneous atmospheres: RRTM, a validated correlated-k model for the longwave. J Geophys Res 102(D14):16663166682, doi:10.1029/97JD00237.

Miyamoto Y, GH Bryan and R Rotunno (2017) An analytical model of maximum potential intensity for tropical cyclones incorporating the effect of ocean mixing, Geophys Res Lett, 44:5826-5835, doi:10.1002/2017GL073670.

Neetu S, Lengaigne M, Vincent EM, et al (2012) Influence of upper-ocean stratification on tropical cyclone-induced surface cooling in the Bay of Bengal. J. Geophys. Res. 117:C12020. doi: 10.1029/2012JC008433

Noh Y, WG Cheon, SY Hong and S Raasch (2003) Improvement of the K-profile model for the planetary boundary layer based on large eddy simulation data. Boundary Layer Meteorol 107(2):401-427. doi:10.1023/A:1022146015946.

Ogata T, R Mizuta, Y Adachi, H Murakami and T Ose (2015) Effect of air-sea coupling on the frequency distribution of intense tropical cyclones over the northwestern Pacific, Geophys Res Lett 42:10415-10421. doi:10.1002/ 2015 GL066774.

Ogata, T., Mizuta, R., Adachi, Y., Murakami, H., \& Ose, T. (2016). Atmosphere-ocean coupling effect on intense tropical cyclone distribution and its future change with $60 \mathrm{~km}$-AOGCM. Scientific reports, 6, 29800.

Périgaud, C., \& Delecluse, P. (1992). Annual sea level variations in the southern tropical Indian Ocean from Geosat and shallow-water simulations. J Geophys Res 97 :20169-20178. doi : 10.1029/92JC01961.

Price JF (1981) Upper ocean response to a Hurricane. J Phys Oceanogr 11:153-175. doi:10.1175/15200485(1981)011<0153:UORTAH > 2.0.CO;2

Riehl H (1950) A model of hurricane formation. J Applied Physics 21, 917-925. doi: 10.1063/1.1699784.

Saji, N. H., B. N. Goswami, P. N. Vinayachandran and T. Yamagata, 1999: A dipole mode in the tropical Indian Ocean. Nature 401:360-363. doi: 10.1038/43854.

Samson G, S Masson, M Lengaigne, MG Keerthi, J Vialard, S Pous, G Madec, N Jourdain, S Jullien, C Menkes, P Marchesiello (2014) The NOW regional coupled model: Application to the tropical Indian Ocean climate and tropical cyclone activity. J. Adv Mod Earth Syst 6(3):700-722. doi:10.1002/2014MS000324.

Schade LR (2000) Tropical cyclone intensity and sea surface temperature. J Atmos Sci 57:3122-3130. doi: 10.1175/1520-0469(2000)057<3122:TCIASS > 2.0.CO;2.

Schade LR and KA Emanuel (1999) The ocean's effect on the inten- sity of tropical cyclones: Results from a simple coupled atmosphere- ocean model. J Atmos Sci 56:642-651. doi:10.1175/1520-0469 (1999)056<0642:TOSEOT>2.0.CO;2.

Sengupta D, RG Bharath, DS Anitha (2008) Cyclone-induced mixing does not cool SST in the post-monsoon north Bay of Bengal. Atmos Sci Lett, 9:1-6. doi: 10.1002/asl.162.

Shay LK, G Goni and PG Black (2000) Effects of a warm oceanic feature on Hurricane Opal. Mon Wea Rev 128:1366-1383. doi: 10.1175/1520-0493(2000)128<1366:EOAWOF>2.0.CO;2.

Skamarock WC and JB Klemp (2008) A time-split nonhydrostatic atmospheric model for weather research and forecasting applications. J Comput Phys 227(7):3465-3485. doi:10.1016/j.jcp.2007.01.037.

Srinivas CV, DV Bhaskar Rao, V Yesubabu, R Baskaran, and B Venkatraman (2013) Tropical cyclone predictions over the Bay of Bengal using the high-resolution Advanced Research Weather Research and Forecasting 
(ARW) model. Q J Roy. Meteorol Soc 139(676):1810- 1825. doi:10.1002/qj.2064.

Valcke S (2013) The OASIS3 coupler: A European climate modelling community software, Geosci Model Dev, 6(2), 373-388, doi:10.5194/gmd-6-373-2013.

Vialard J et al. (2009) Cirene: Air sea interactions in the Seychelles-Chagos thermocline ridge region. Bull Am Meteorol Soc 90,:45-61. doi:10.1175/2008BAMS2499.1.

Vincent EM, M Lengaigne, G Madec, J Vialard, G Samson, N Jourdain, CE Menkes, S Jullien (2012a) Processes setting the characteristics of sea surface cooling induced by tropical cyclones. J Geophys Res 117 C02020. doi:10.1029/2011JC007396.

Vincent EM, M Lengaigne, J Vialard, G Madec, N Jourdain, S Masson (2012b) Assessing the Oceanic Control on the Amplitude of sea Surface Cooling induced by Tropical Cyclones. J Geophys Res 117 C05023. doi:10.1029/2011JC007705.

Vincent EM, KA Emanuel, M Lengaigne, J Vialard, G Madec (2014) Influence of upper ocean stratification interannual variability on tropical cyclones. J Adv Mod Earth Syst 6(3):680-699. doi: 10.1002/2014MS000327

Wang Y and CC Wu (2004) Current understanding of tropical cyclone structure and intensity changes-A review. Meteor Atmos Phys 87:257-278. doi:10.1007/s00703-003-0055-6.

Webster, P. J., A. M. Moore, J. P. Loschnigg, and R. R. Leben, 1999: Coupled oceanic-atmospheric dynamics in the Indian Ocean during 1997-98. Nature 401:356-360. doi:10.1038/43848

Xie S-P, H Annamalai, FA Schott and JP McCreary Jr. (2002) Structure and mechanisms of south Indian Ocean climate variability. J Clim 15(8):864-878. doi: 10.1175/1520-0442(2002)015<0864:SAMOSI>2.0.CO;2.

Xie, S. P., Hu, K., Hafner, J., Tokinaga, H., Du, Y., Huang, G., \& Sampe, T. (2009). Indian Ocean capacitor effect on Indo-western Pacific climate during the summer following El Niño. J Clim 22:730-747. doi: 10.1175/2008JCLI2544.1.

Yablonsky RM, and I Ginis (2009) Limitation of one-dimensional ocean models for coupled hurricane-ocean model forecasts. Mon Wea Rev 137:4410-4419. doi:10.1175/2009MWR2863.1.

Yu L and MJ McPhaden (2011) Ocean Preconditioning of Cyclone Nargis in the Bay of Bengal: Interaction between Rossby Waves, Surface Fresh Waters, and Sea Surface Temperatures. J Phys Oceanogr 41:1741-1755. doi: 10.1175/2011JPO4437.1

Zarzycki CM (2016) Tropical Cyclone Intensity Errors Associated with Lack of Two-Way Ocean Coupling in HighResolution Global Simulations. J Clim 29:8589-8610. doi: 10.1175/JCLI-D-16-0273.1.

Zedler SE (2009) Simulations of the ocean response to a hurricane: Nonlinear processes. J Phys Oceanogr 39:26182634. doi: $10.1175 / 2009 \mathrm{JPO} 4062.1$.

Zhu H, U Wolfgang and SK Roger (2004) Ocean effects on tropical cyclone intensification and inner-core asymmetries. J Atmos Sci 61:1245-1258. doi: 10.1175/1520-0469(2004)061<1245:OEOTCI>2.0.CO;2. 
(a) TCs distribution: OBS

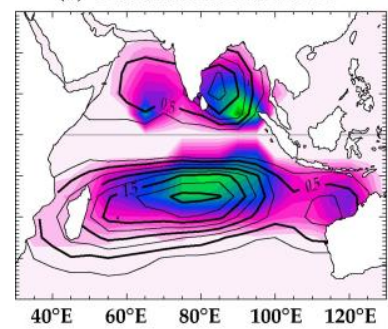

$\begin{array}{lllll}40^{\circ} \mathrm{E} & 60^{\circ} \mathrm{E} & 80^{\circ} \mathrm{E} & 100^{\circ} \mathrm{E} & 120^{\circ} \mathrm{E}\end{array}$ (b) TCs distribution: KF-CPL

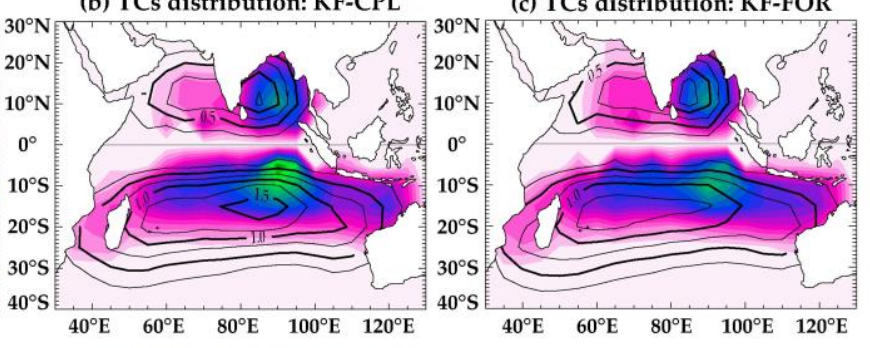

$\begin{array}{llllll}0.0 & 0.6 & 1.2 & 1.8 & 2.4 & 3.0\end{array}$ (c) TCs distribution: KF-FOR

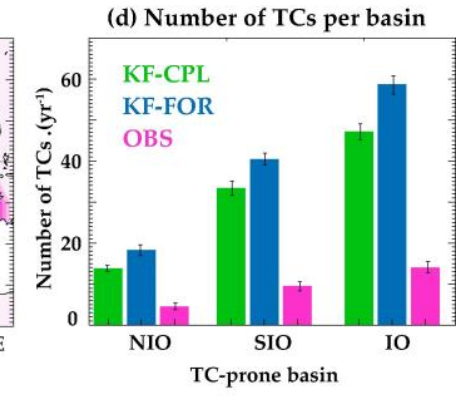

Figure 1: Climatological distribution of normalised (i.e. \% of the total occurrence rate at each location) cyclogenesis (colour) and TC density (contour) for (a) observations, (b) KF-CPL and (c) KF-FOR simulations. (d) Histogram of the number of TCs in the NIO, SIO and IO basins for each dataset (whiskers indicate the $90 \%$ confidence interval based on a student $\mathrm{t}$-test). 
(a) SST: KF-CPL

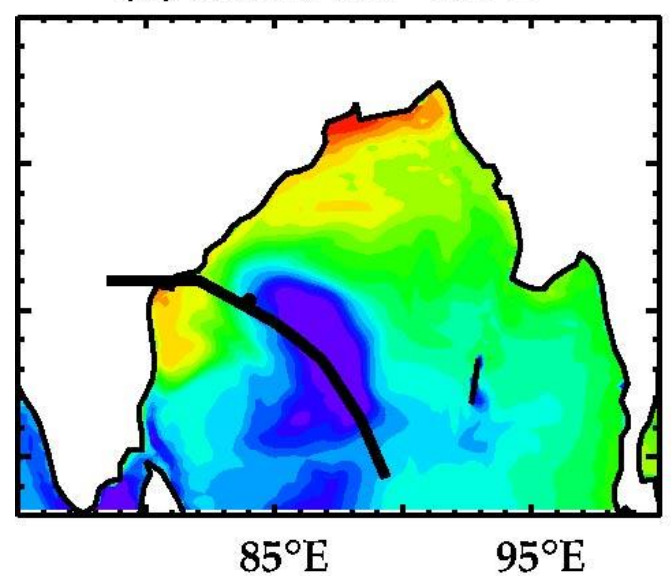

(b) SST: KF-FOR

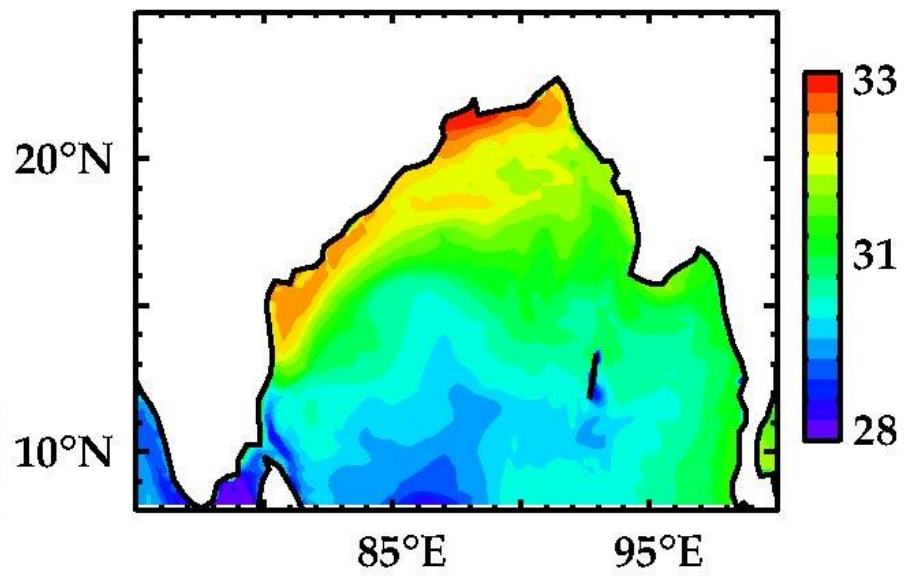

Figure 2: Sea surface temperature $\left({ }^{\circ} \mathrm{C}\right)$ snapshot for the (a) KF-CPL and (b) KF-FOR simulations. The SST boundary condition of the KF-FOR simulation is obtained after filtering out (see text for details) the TC cold wake from the SST field shown in (a). The TC track from the KF-CPL simulation is shown by a black line on panel (a). 
(a) SIO Cyclogenesis seasonal cycle: OBS

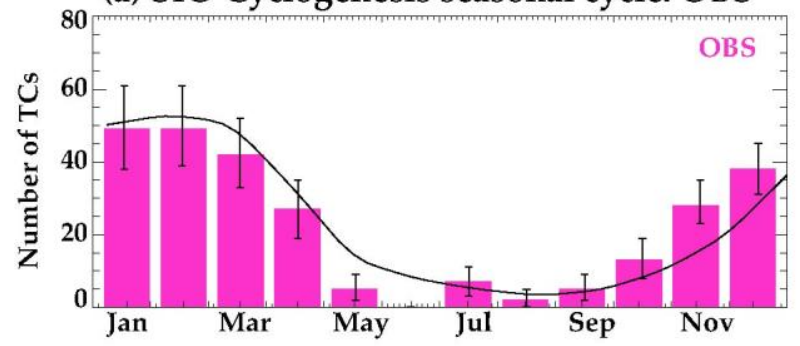

(b) SIO Cyclogenesis seasonal cycle: KF-CPL

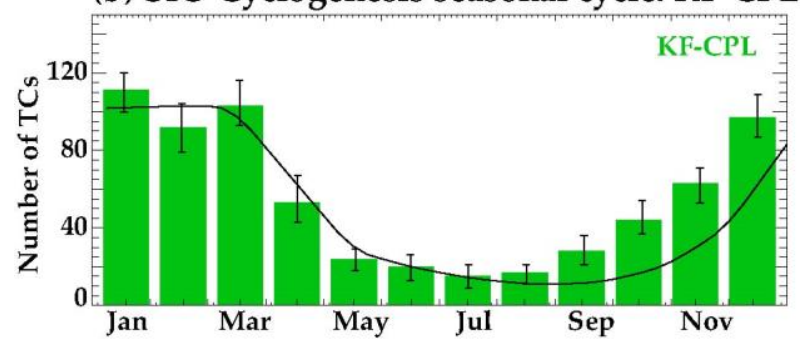

(c) SIO Cyclogenesis seasonal cycle: KF-FOR

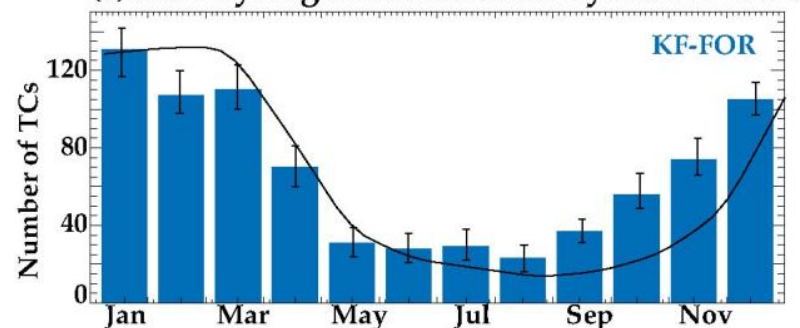

(d) SIO Cyclogenesis: KF-CPL minus KF-FOR

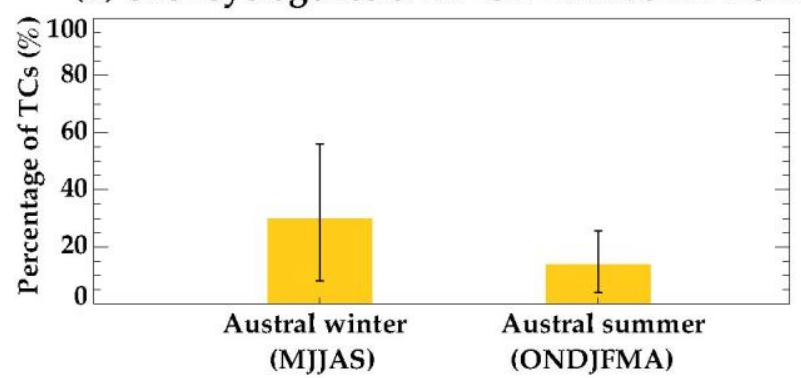

(e) NIO Cyclogenesis seasonal cycle: OBS

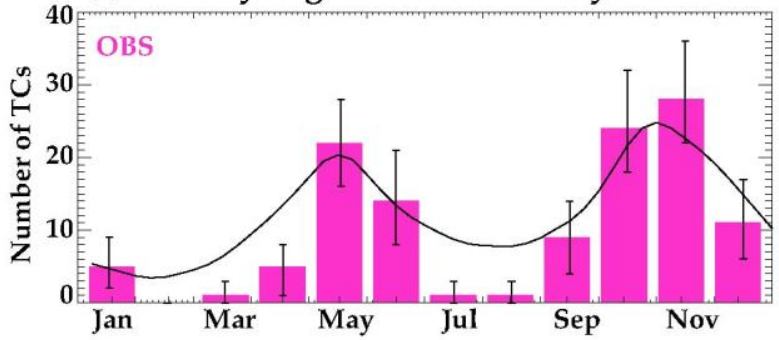

(f) NIO Cyclogenesis seasonal cycle: KF-CPL

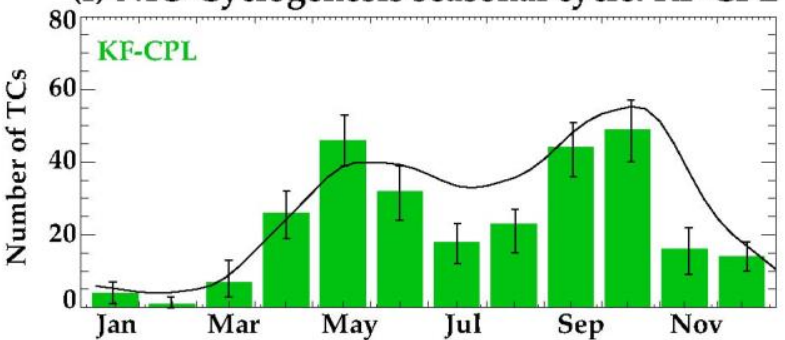

(g) NIO Cyclogenesis seasonal cycle: KF-FOR

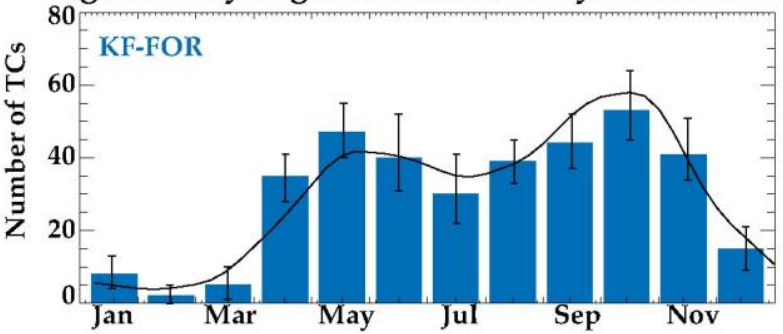

(h) NIO Cyclogenesis: KF-CPL minus KF-FOR

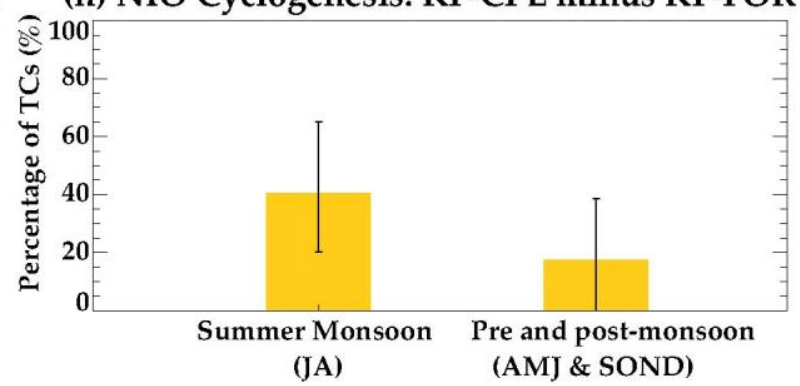

Figure 3: Histogram of the percentage of TCs occurring each calendar month in the (left column) northern and (right column) southern IO for (a,e) observations, (b,f) KF-CPL and (c,g) KF-FOR simulations. The monthly climatological evolution of the corresponding GPI index (northern IO: $40^{\circ} \mathrm{E}-100^{\circ} \mathrm{E} ; 0^{\circ}-25^{\circ} \mathrm{N}$ and southern IO: $\left.30^{\circ} \mathrm{E}-130^{\circ} \mathrm{E} ; 0^{\circ}-25^{\circ} \mathrm{S}\right)$ is overlaid as a black curve. Reduction of the number of TCs $(\%)$ in KF-CPL relative to KF-FOR for the cyclonic and non-cyclonic seasons for (d) northern and (h) southern IO. On all panels, the whiskers display the $90 \%$ confidence interval based on a student t-test. 


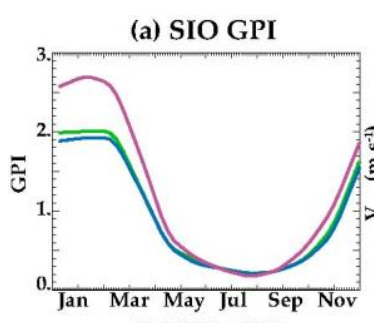

(f) NIO GPI

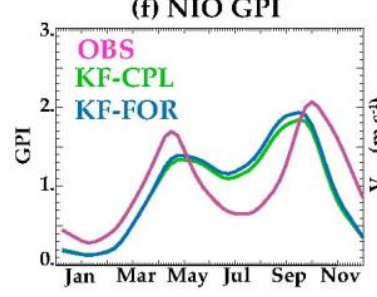

(b) SIO V

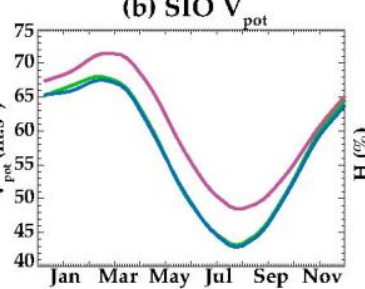

(g) NIO V

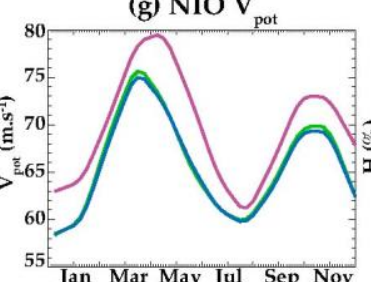

(c) $\mathrm{SIOH}$

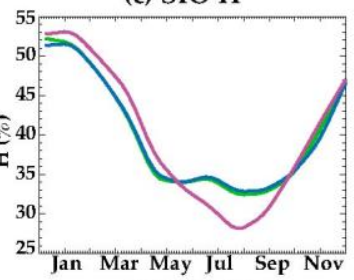

(h) $\mathrm{NIO} \mathrm{H}$

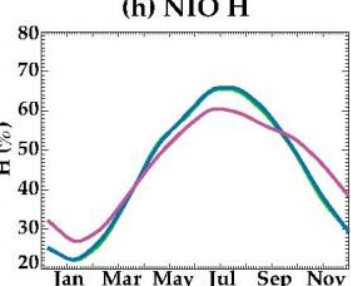

(d) SIO $n$

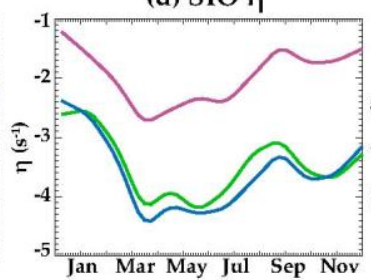

(i) $\mathrm{NIO} \eta$

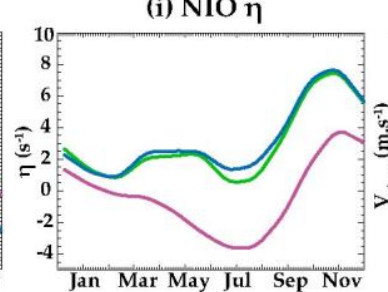

(e) SIO V

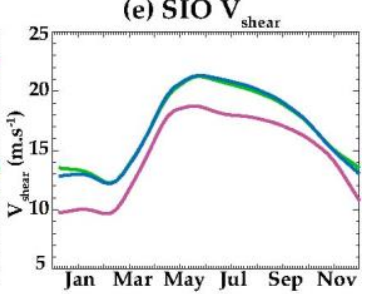

(j) NIO $\mathrm{V}_{\text {shear }}$

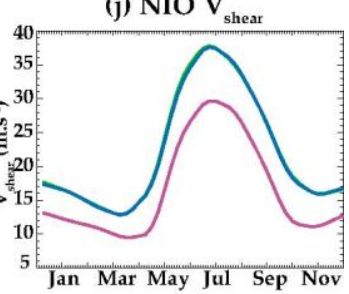

Figure 4: Seasonal evolution of (a,f) Genesis Potential Index (GPI), (b,g) Maximum potential Intensity $\left(\mathrm{V}_{\mathrm{pot}}\right),(\mathbf{c}, \mathbf{h})$ relative humidity at $600 \mathrm{hPa}(\mathrm{H}),(\mathbf{d}, \mathbf{i})$ vorticity at $850 \mathrm{hPa}(\square)$ and $(\mathbf{e}, \mathbf{j})$ vertical wind shear $\left(\mathrm{V}_{\text {shear }}\right.$ ) for observations (purple), KF-CPL (green) and KF-FOR (blue) in (top) the southern IO and (bottom) the northern IO. 


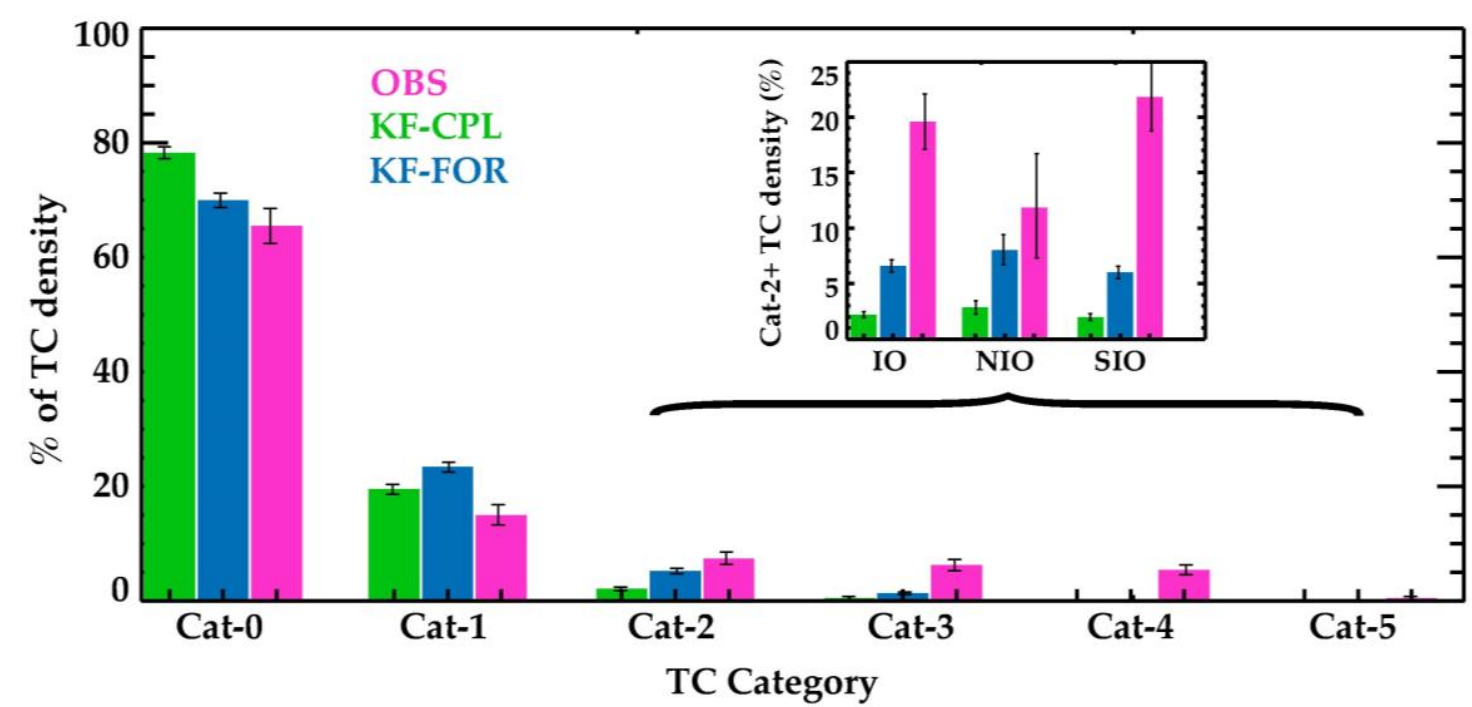

Figure 5: Histogram of the percentage of Indian Ocean TCs as a function of TC intensity, based on 4 maximum TC wind for observations (purple), KF-CPL (green) and KF-FOR (blue) simulations. The inset 5 indicates the percentage of intense TCs (defined as category 2 or above). The whiskers display the $90 \%$ 6 confidence interval, computed using a Student's t-test. 
(a) IO TC-induced cooling: KF-CPL vs. OBS

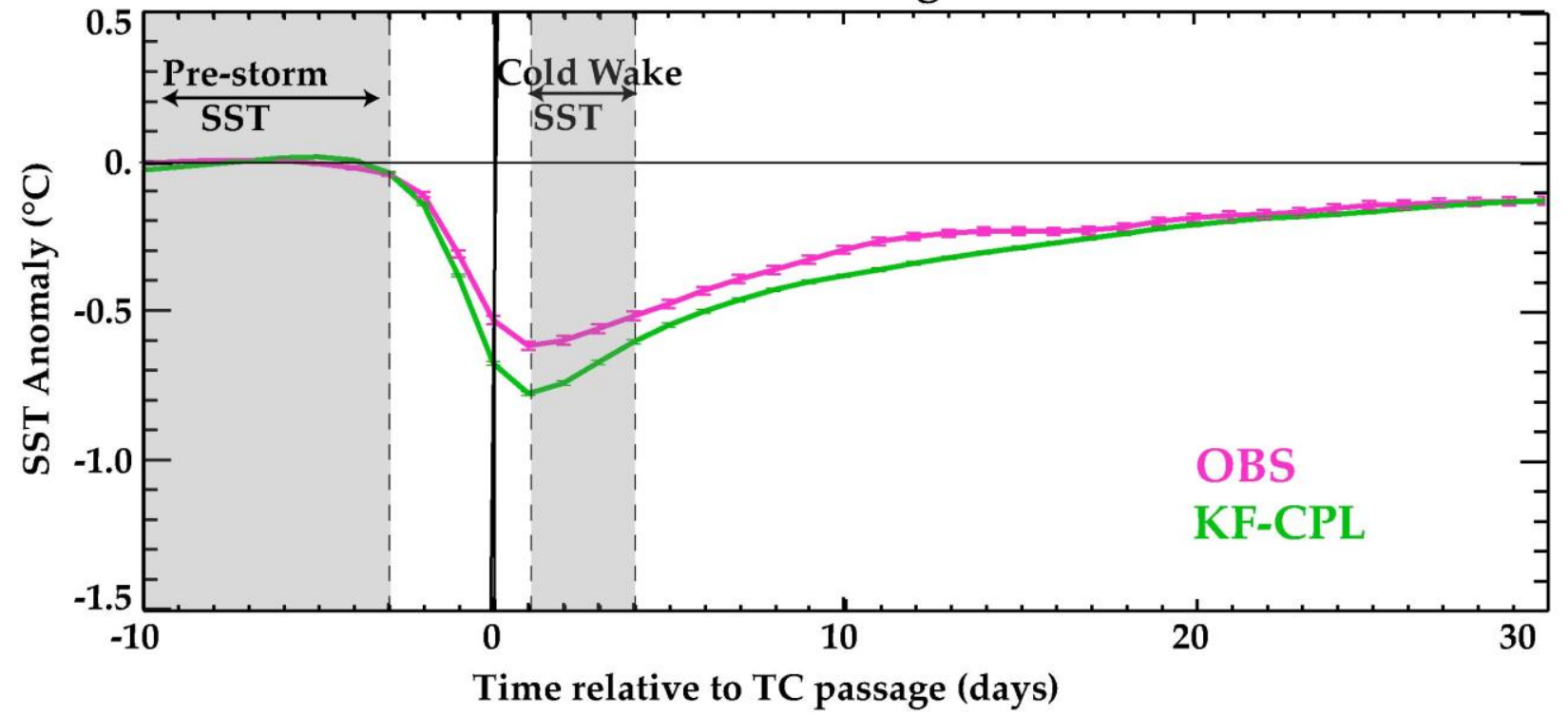

(b) TC cooling vs wind: OBS
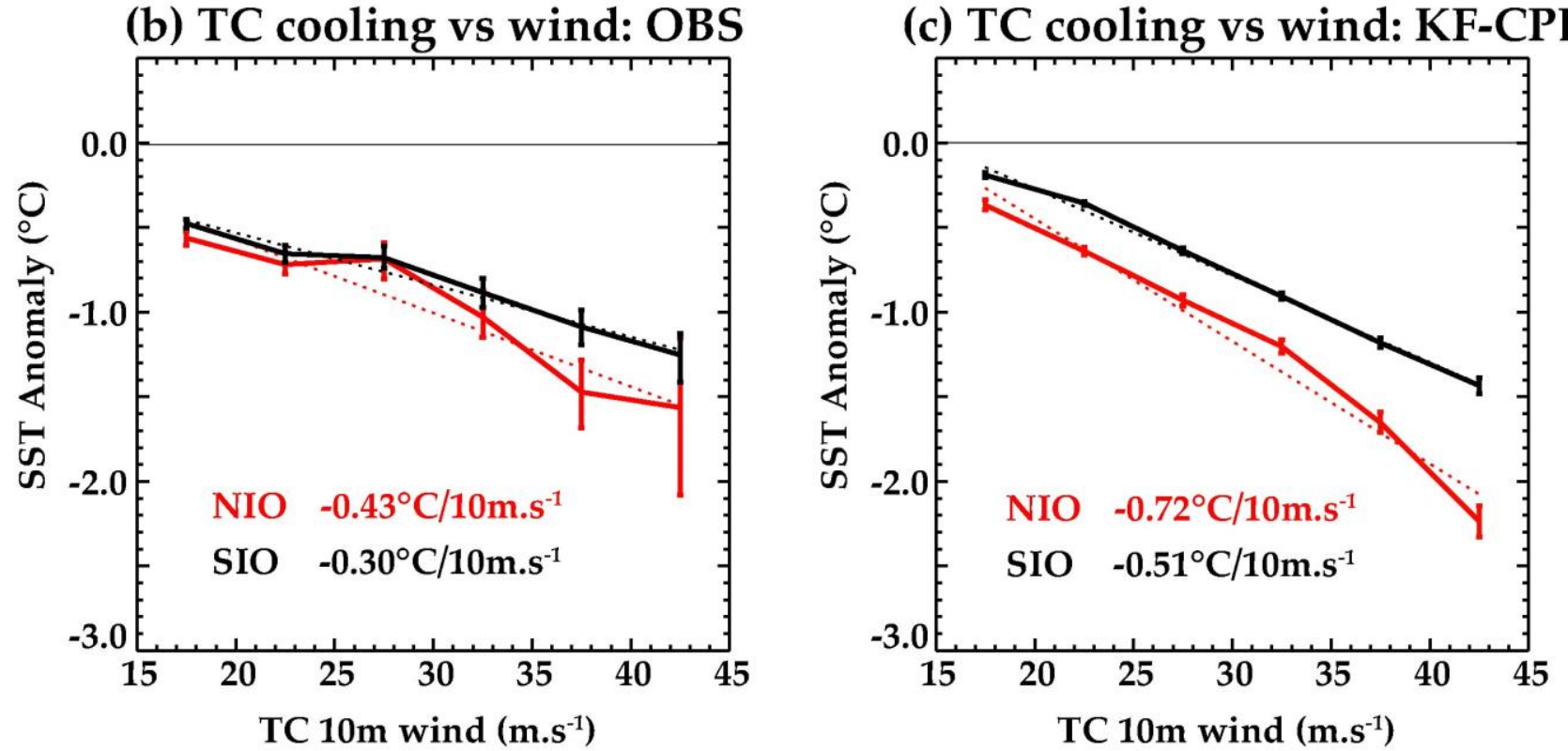

Figure 6: (a) Composite evolution of the TC-induced SST cooling within $200 \mathrm{~km}$ of all TC-tracks in the IO (in ${ }^{\circ} \mathrm{C}$ ) for observations (purple) and the KF-CPL experiment (green). Northern (red) and southern (black) IO mean TC-induced cooling as a function of maximum wind speed for (b) observations and (c) KF-CPL. Whiskers indicate the $90 \%$ confidence level from a bootstrap method. The slope of the linear fit is also indicated as a dotted line. 
(a) Translation speed

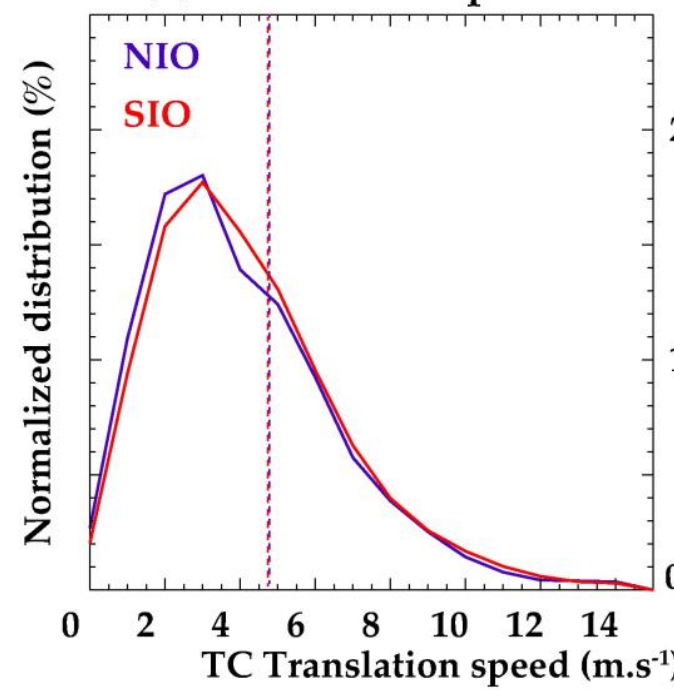

(b) $\mathrm{CI}$

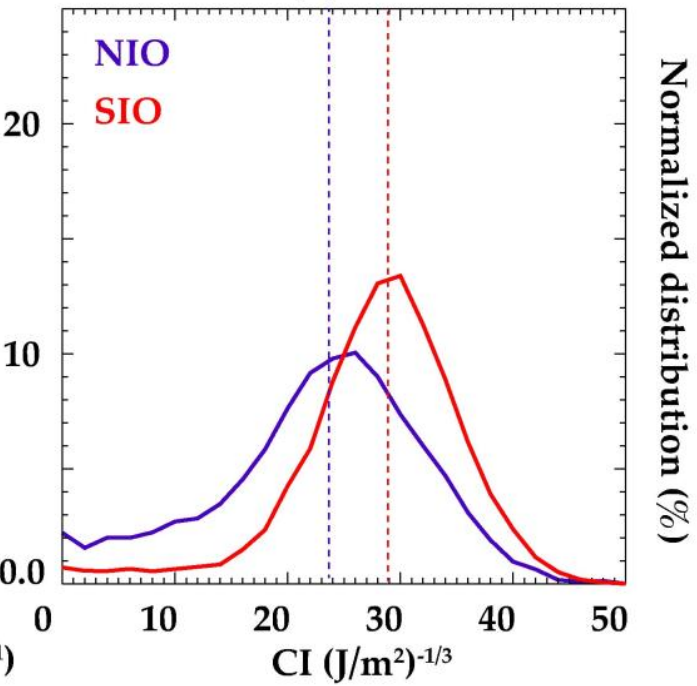

(c) CI map for TC-prone seasons

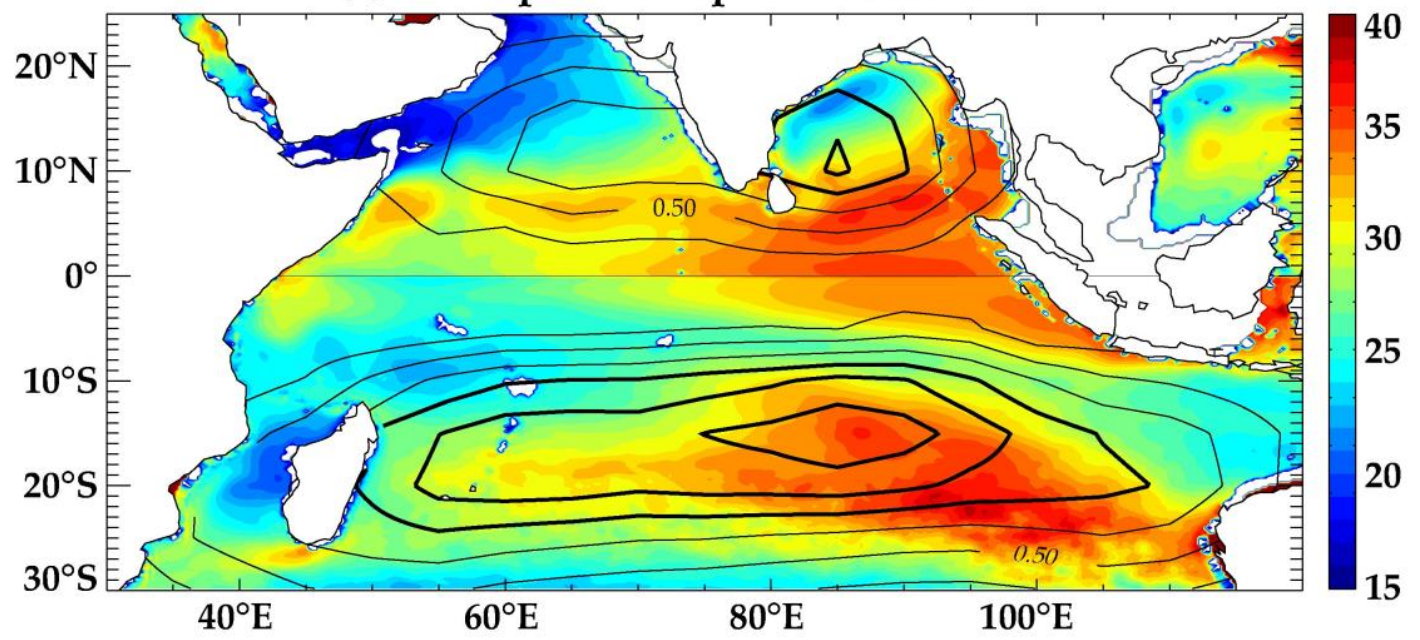

(d) Depth(SST-2 $\left.{ }^{\circ} \mathrm{C}\right)$ map for TC-prone seasons

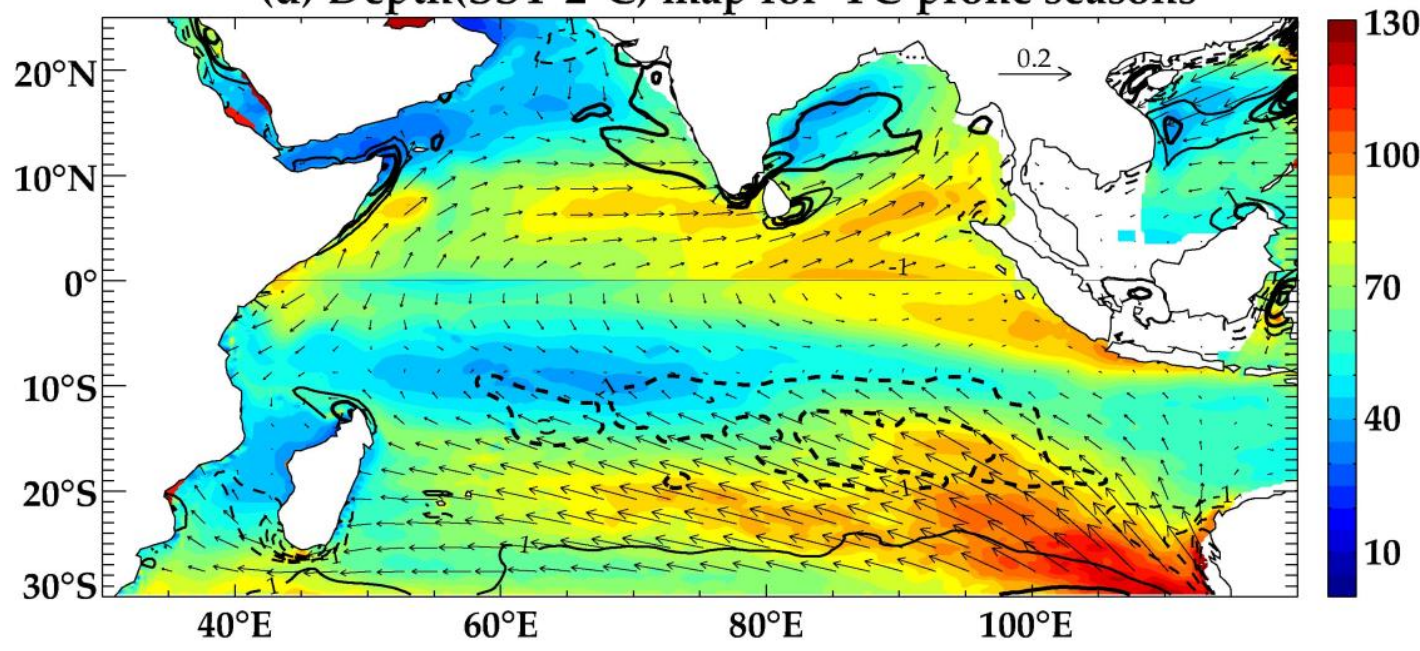

3 Figure 7: KF-CPL model normalized distribution of (a) TC translation speed and (b) cooling inhibition 4 index (CI) under TCs for the NIO (blue) and SIO (red) basins. Climatological maps of (c) CI (color) and 5 normalized TCs density (contour) and (d) depth of SST- ${ }^{\circ} \mathrm{C}$ isotherm (color), wind stress (vectors) and 6 wind stress curl (contour, dashed for negative values) climatological maps for extended cyclonic seasons 7 (November to April for the Southern Hemisphere and April to December for the Northern Hemisphere). 

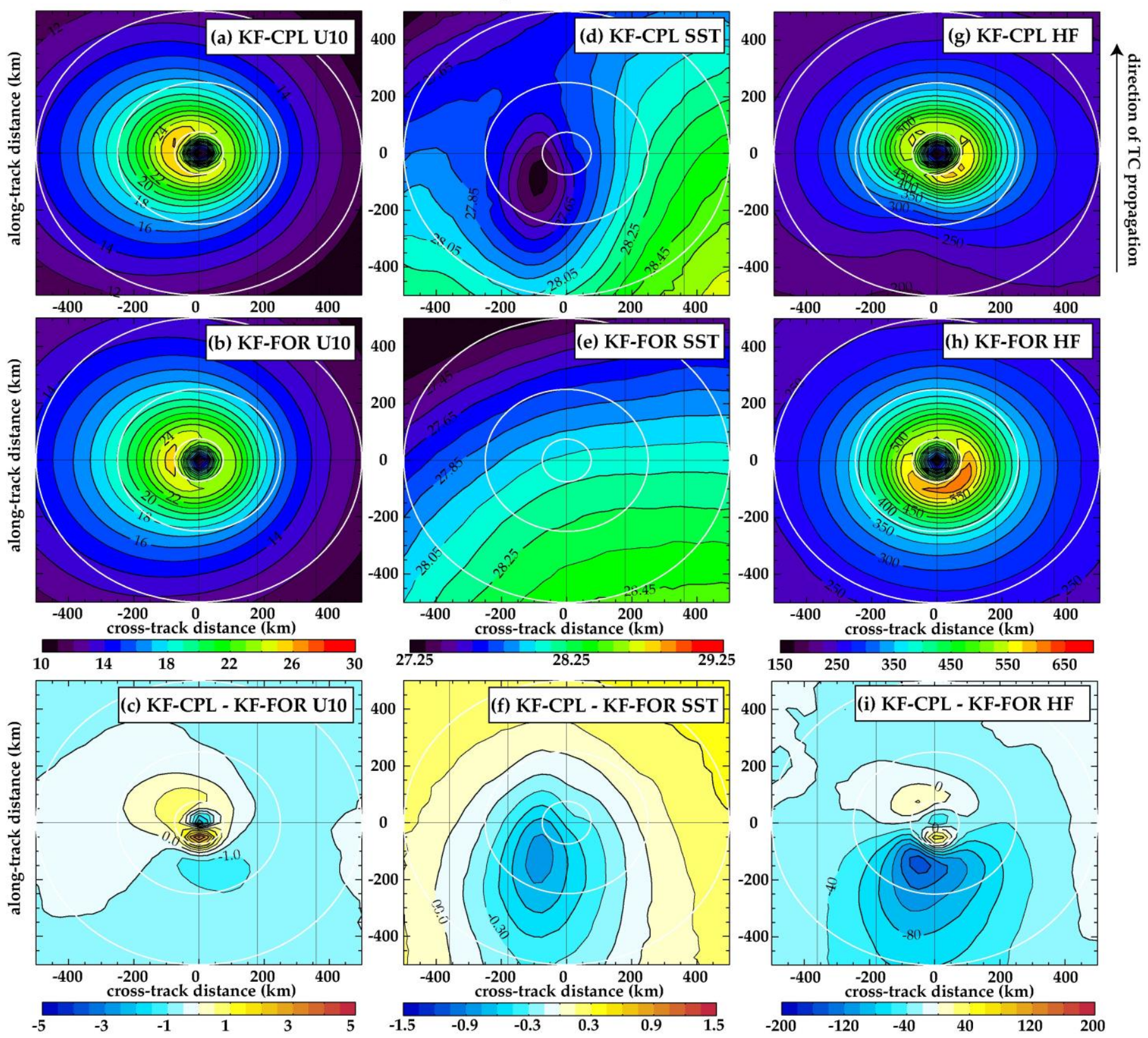

Figure 8: Southern IO composite of surface conditions under TCs: (left) wind speed, (middle) SST and (right) upward surface enthalpy flux (latent plus sensible) for (top) KF-CPL experiment, (middle) KFFOR experiment and (bottom) KF-CPL minus KF-FOR. The smallest white circle represents the radius of maximum winds, the intermediate white circle represents the $250 \mathrm{~km}$ radius and the biggest white circle represent the $500 \mathrm{~km}$ radius. 
TCs composite in the northern IO
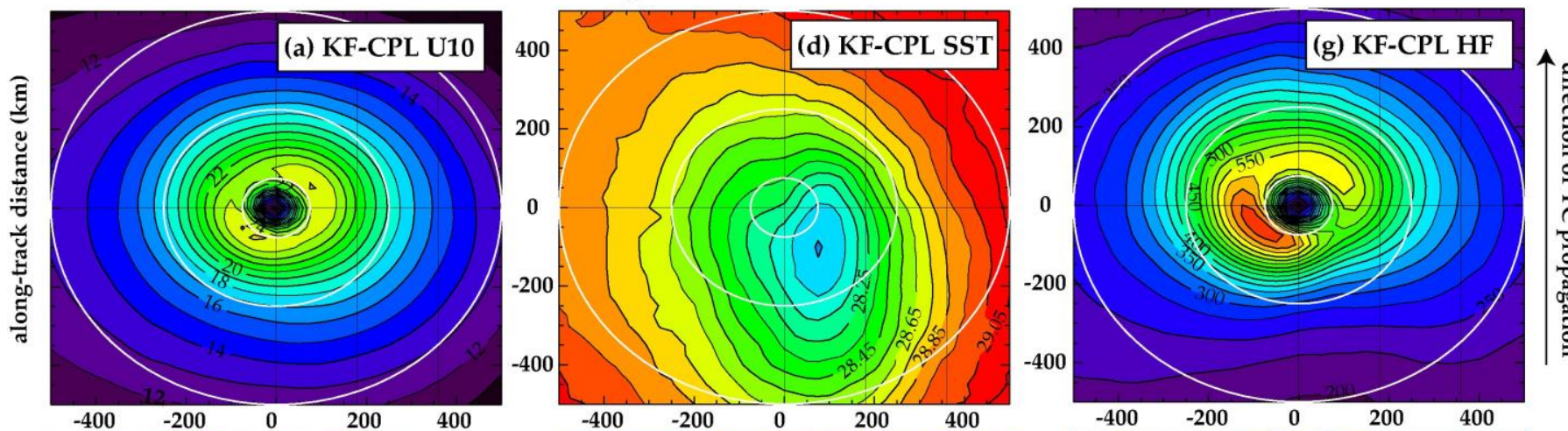

个?.
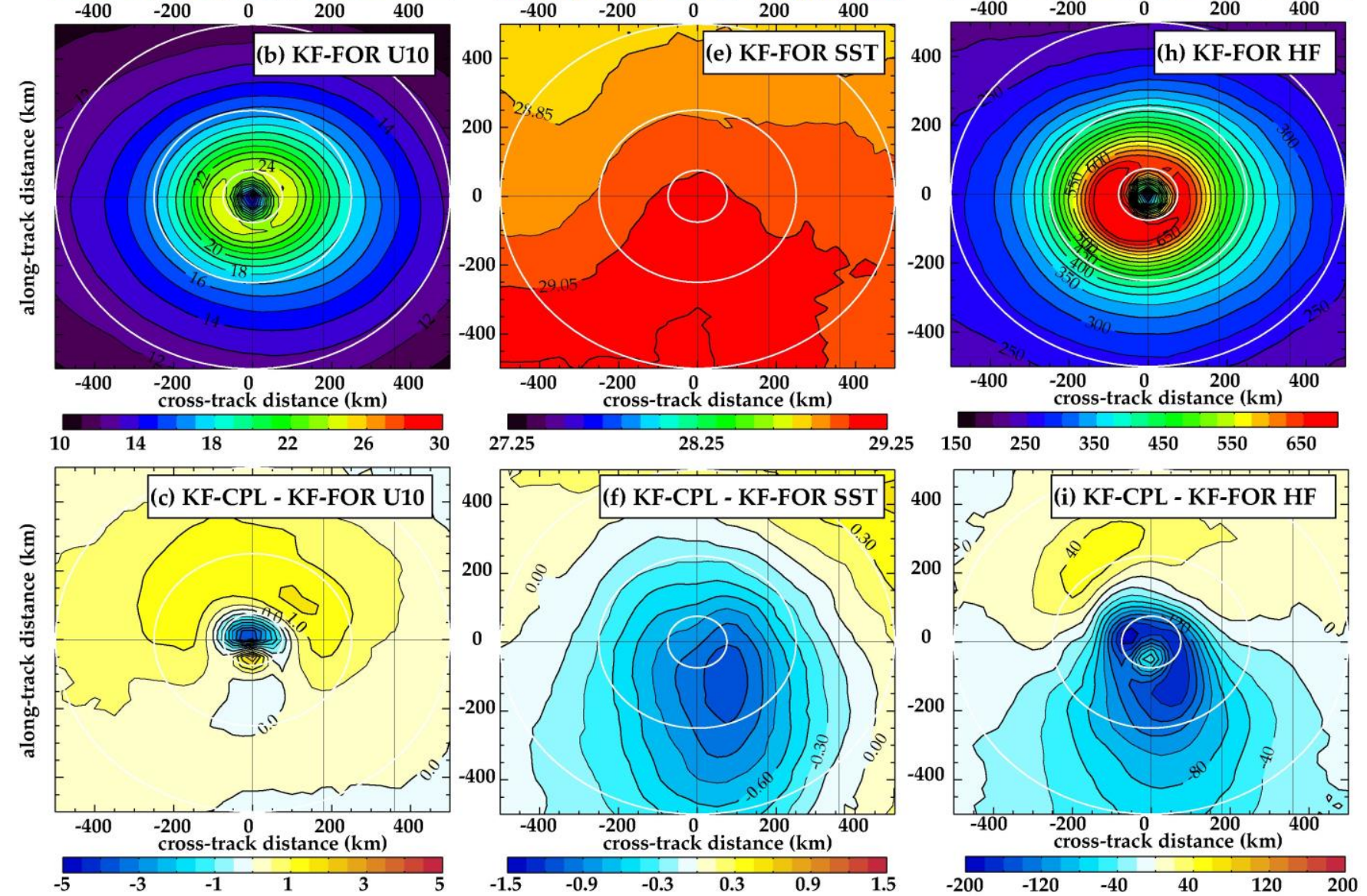

Figure 9: Same as Figure 8 for the northern IO. 
(a) KF-FOR HF

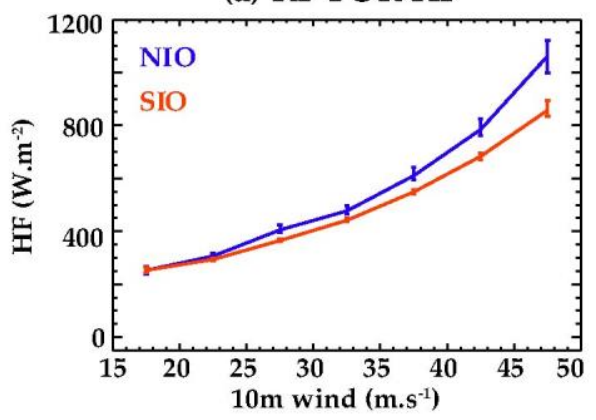

(b) KF-FOR dU10/dt

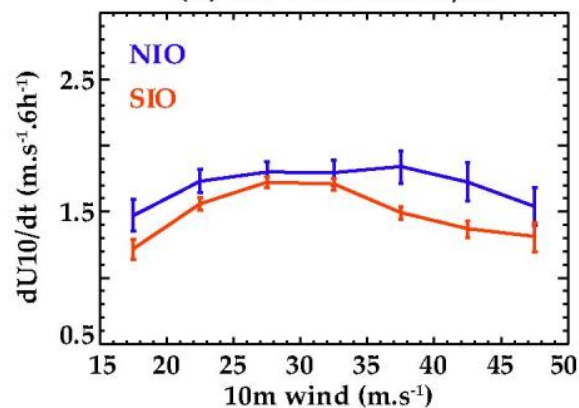

(c) KF-FOR SST

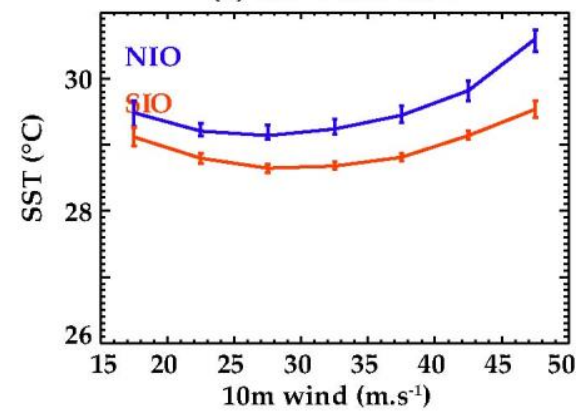

Figure 10: Mean (a) inner-core (i.e. within $200 \mathrm{~km}$ of the TC centre) upward surface enthalpy flux, (b) time-derivative of maximum wind speed and (c) inner-core (i.e. within $200 \mathrm{~km}$ of the TC centre) SST as a function of the wind speed for intensifying TCs in the KF-FOR experiment, over the northern(blue) and southern(red) IO. This figure was performed by averaging within $5 \mathrm{~m} . \mathrm{s}^{-1}$ bins. 
(a) KFCPL-KFFOR HF

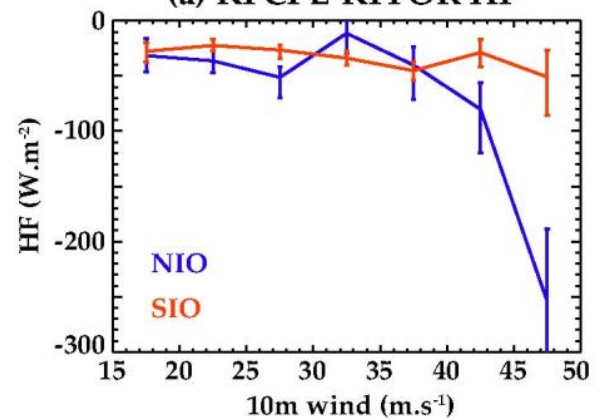

(d) NIO HF: Fast vs slow

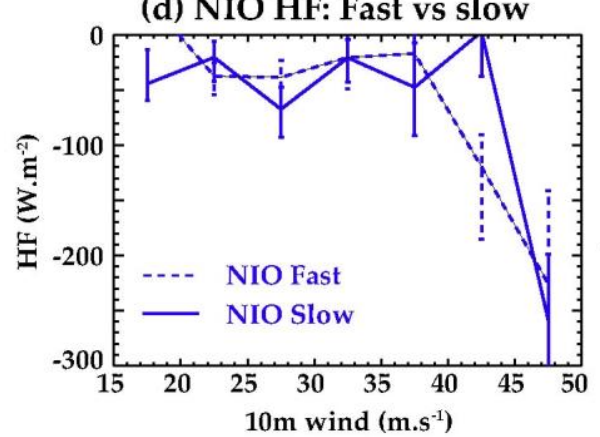

(b) KFCPL-KFFOR dU10/dt

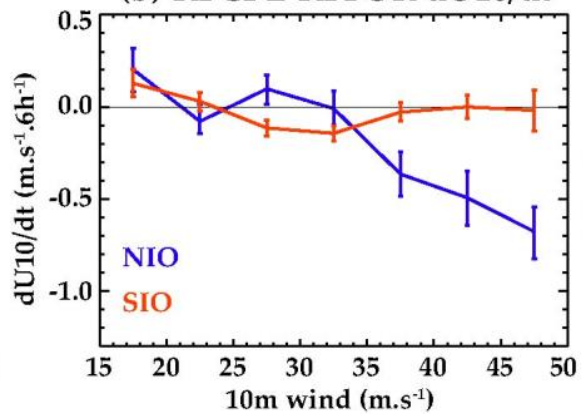

(e) NIO dU10/dt: Fast vs slow

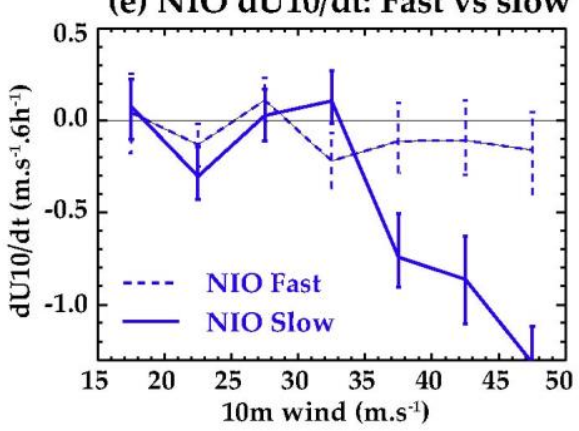

(c) KFCPL-KFFOR SST

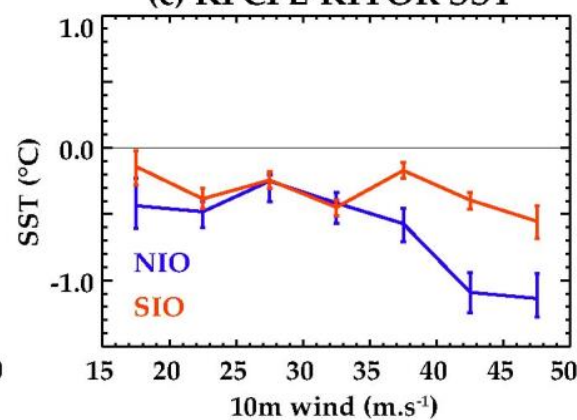

(f) NIO SST: Fast vs slow

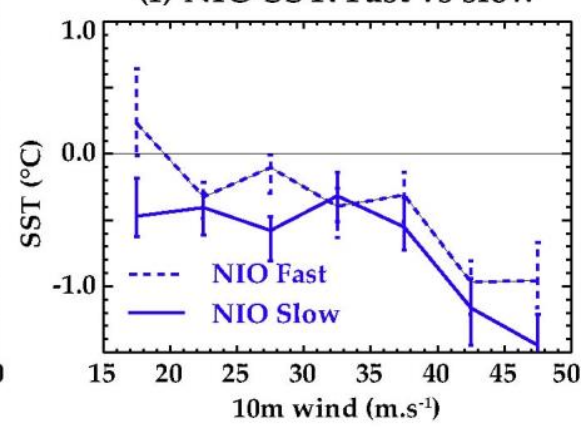

Figure 11: Mean KF-CPL minus KF-FOR (a) inner-core (i.e. within $200 \mathrm{~km}$ of the TC centre) upward enthalpy flux, (b) time-derivative of maximum wind speed and (c) inner-core (i.e. within $200 \mathrm{~km}$ of the TC centre) SST as a function of the wind speed in the KF-FOR experiment for intensifying TCs in the northern (blue) and southern (red) IO. (d-f) Same as (a-c) but for slow- and fast-moving (with a translation speed smaller than or larger than $4 \mathrm{~m} . \mathrm{s}^{-1}$ ) intensifying TCs in the northern IO. This figure was performed by 7 averaging with $5 \mathrm{~m} \cdot \mathrm{s}^{-1}$ bins. 
(a) TCs distribution: OBS

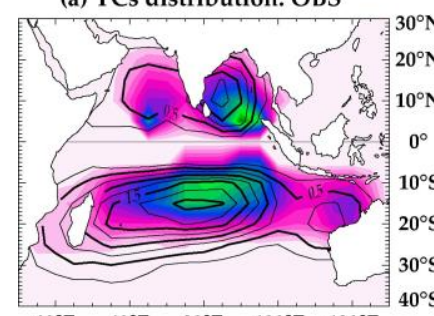

$\begin{array}{lllll}40^{\circ} \mathrm{E} & 60^{\circ} \mathrm{E} & 80^{\circ} \mathrm{E} & 100^{\circ} \mathrm{E} & 120^{\circ} \mathrm{E}\end{array}$ (b) TCs distribution: BMJ-CPL

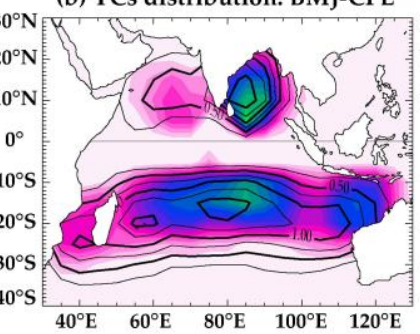

$\begin{array}{llllll}0.0 & 0.6 & 1.2 & 1.8 & 2.4 & 3 .\end{array}$ (c) TCs distribution: BMJ-FOR

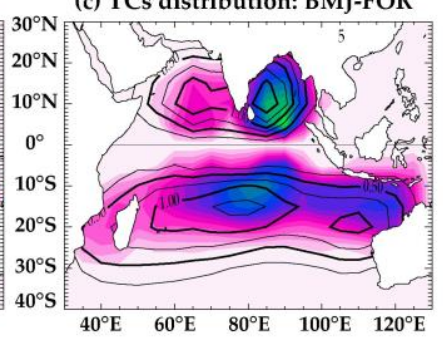

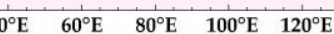

(d) Number of TCs per basin

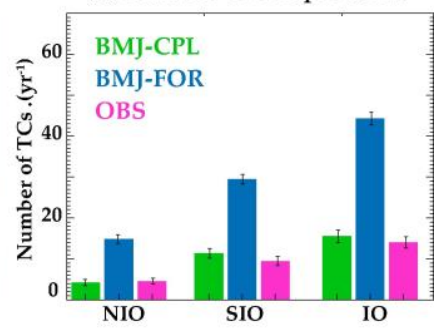

TC-prone basin
4

5 6

Figure 12: Same as Figure 1 but for BMJ-CPL and BMJ-FOR. 
(a) NIO Cyclogenesis seasonal cycle: OBS

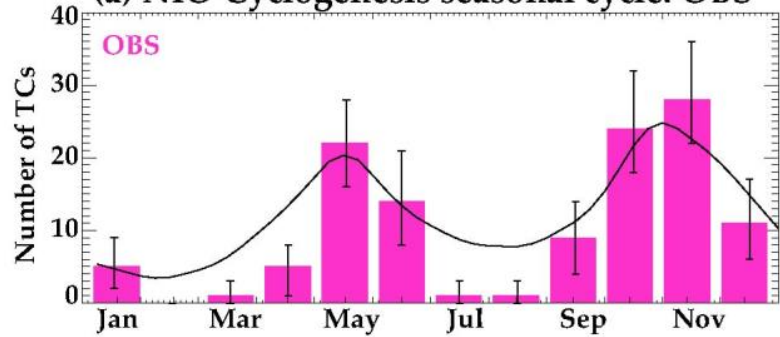

(b) NIO Cyclogenesis seasonal cycle: BMJ-CPL

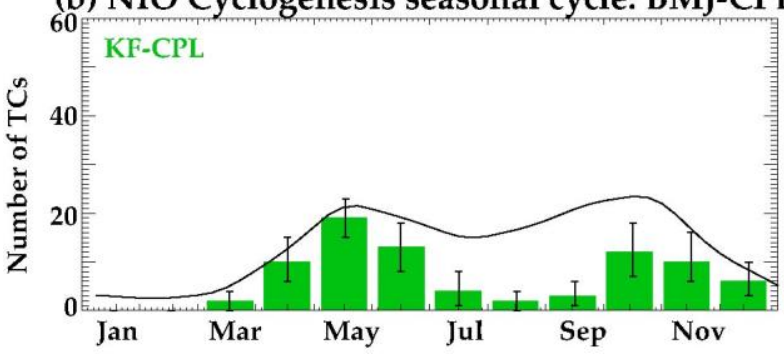

(c) NIO Cyclogenesis seasonal cycle: BMJ-FOR

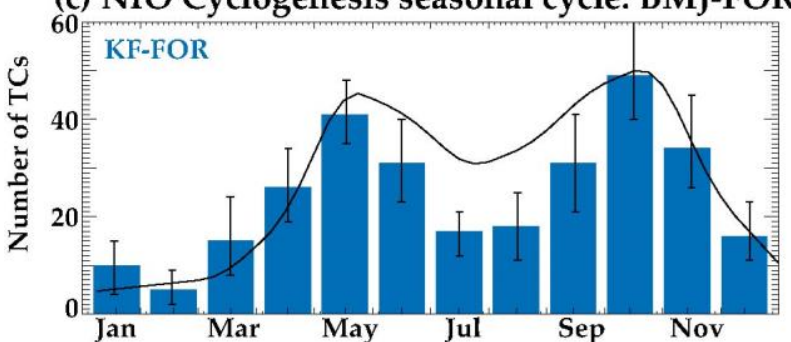

(d) NIO Cyclogenesis: BMJ-CPL minus BMJ-FOR

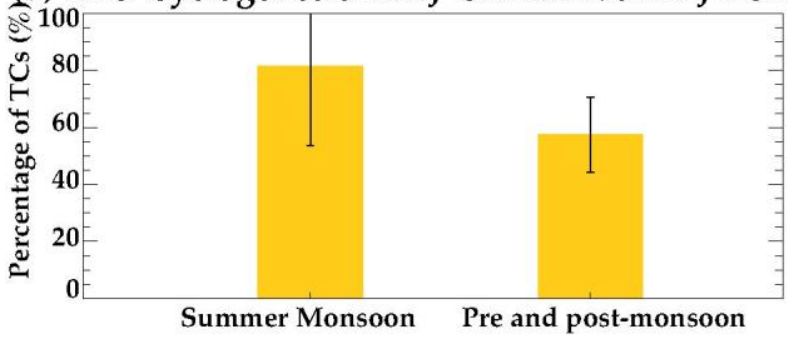

(e) SIO Cyclogenesis seasonal cycle: OBS

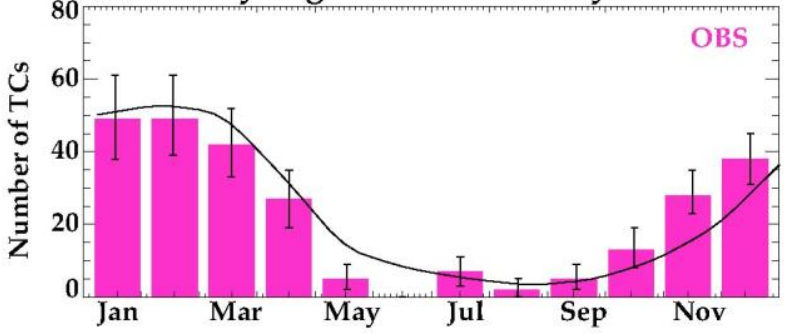

(f) SIO Cyclogenesis seasonal cycle: BMJ-CPL

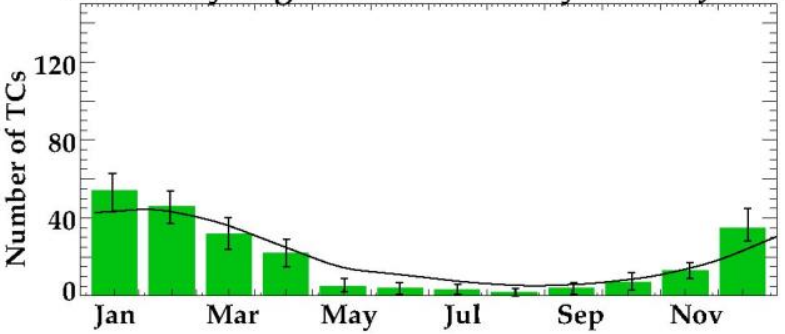

(g) SIO Cyclogenesis seasonal cycle: BMJ-FOR

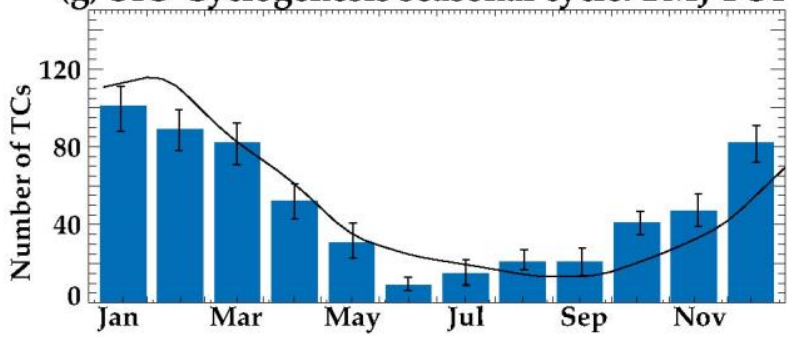

(h) SIO Cyclogenesis: BMJ-CPL minus BMJ-FOR

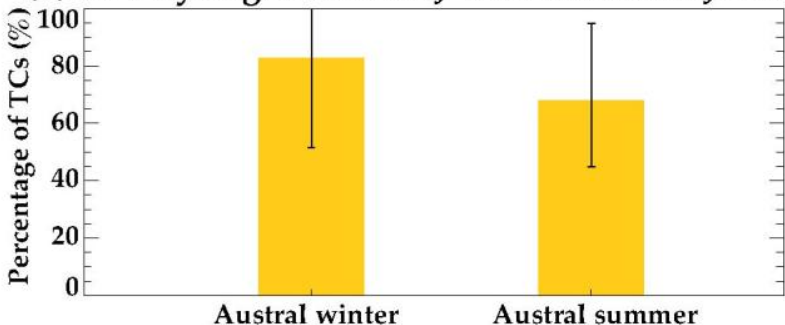

Figure 13: Same as Figure 3 but for BMJ-CPL and BMJ-FOR. 


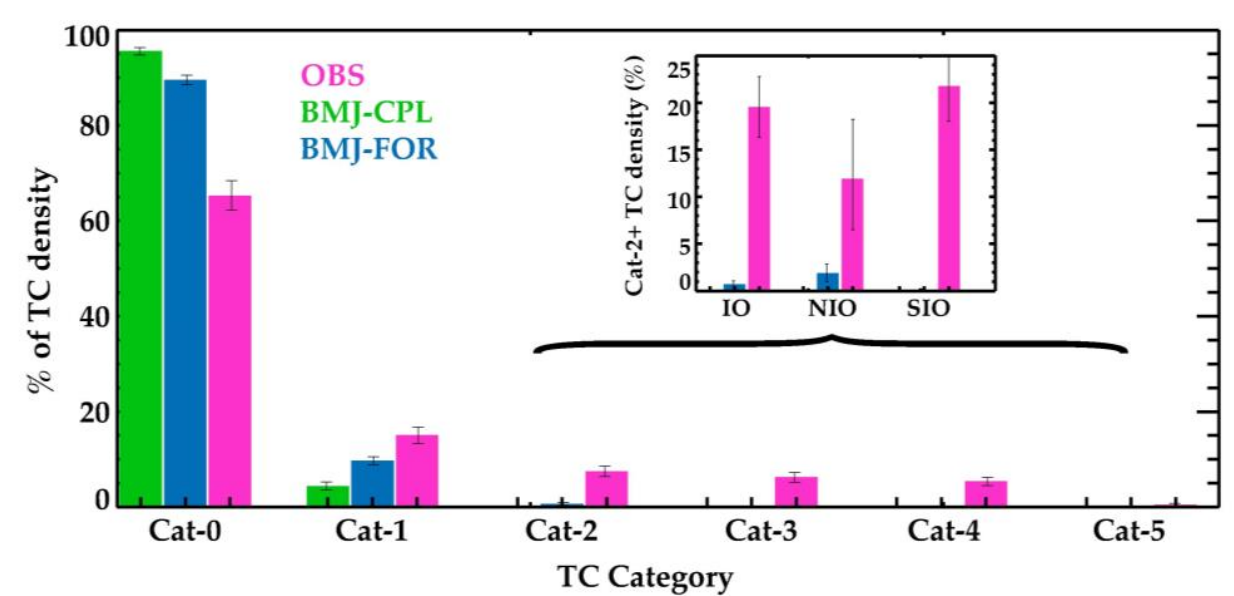

2 Figure 14. Same as Figure 5 but for BMJ-CPL and BMJ-FOR. 
(a) IO TC-induced cooling: BMJ-CPL vs. OBS

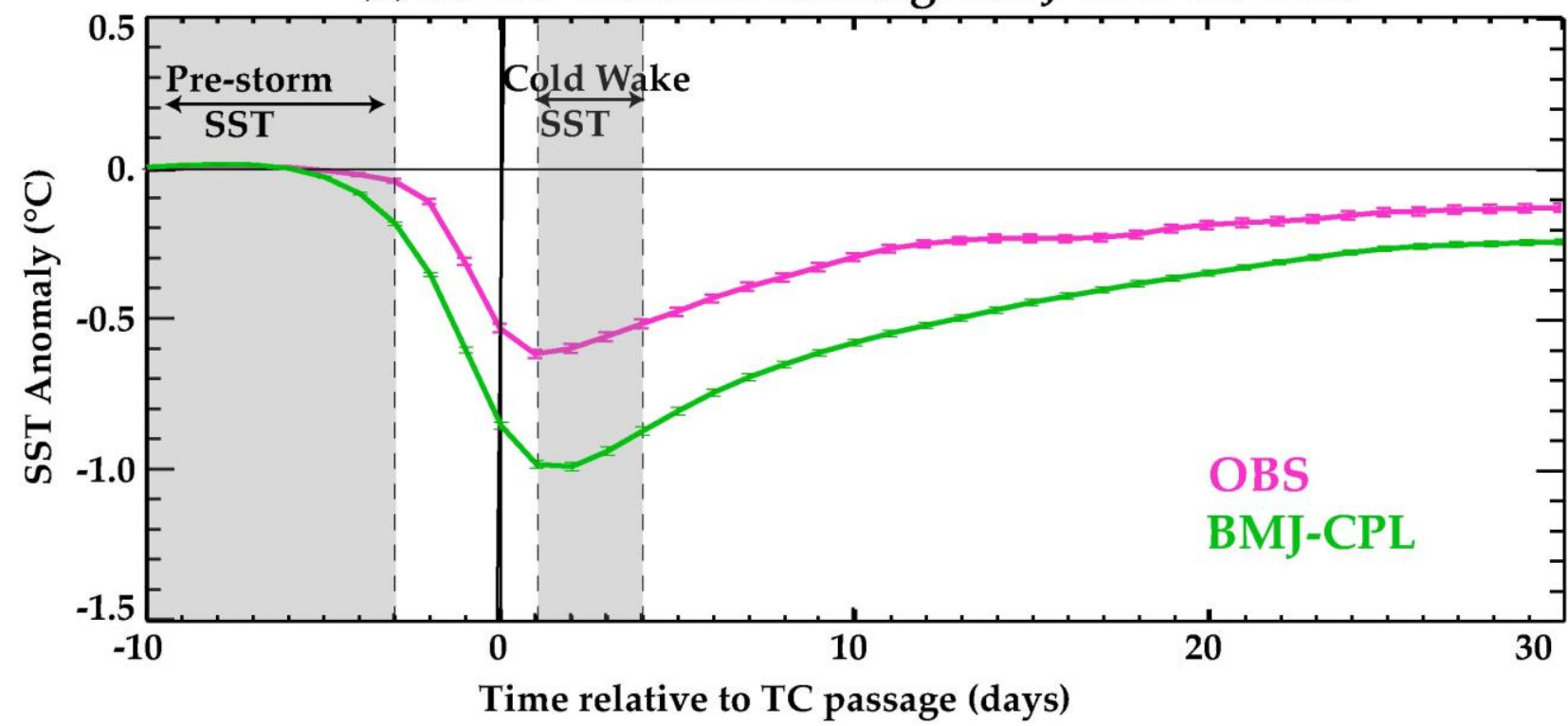

(b) TC cooling vs wind: OBS

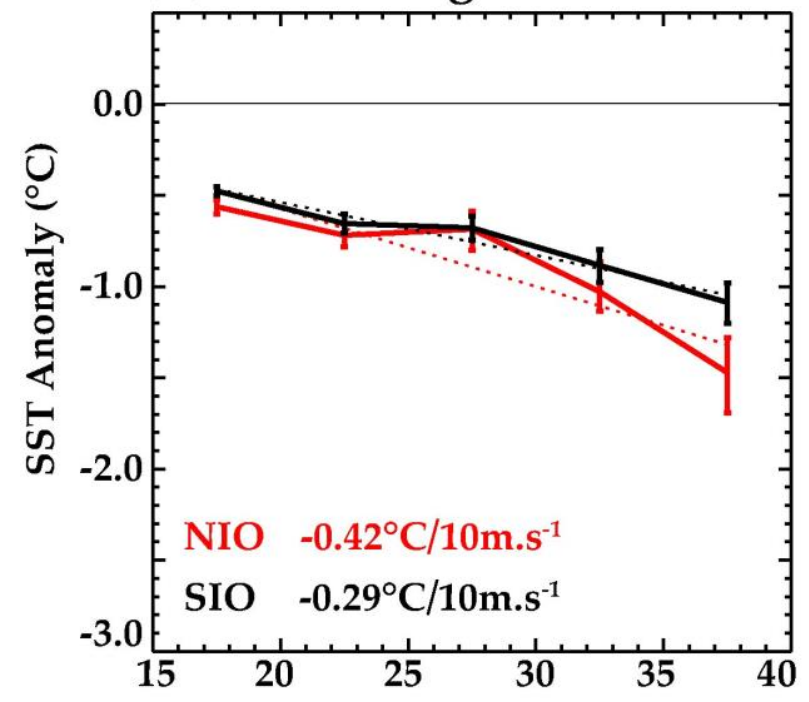

TC $10 \mathrm{~m}$ wind $\left(\mathrm{m} . \mathrm{s}^{-1}\right)$ (c) TC cooling vs wind: BMJ-CPL

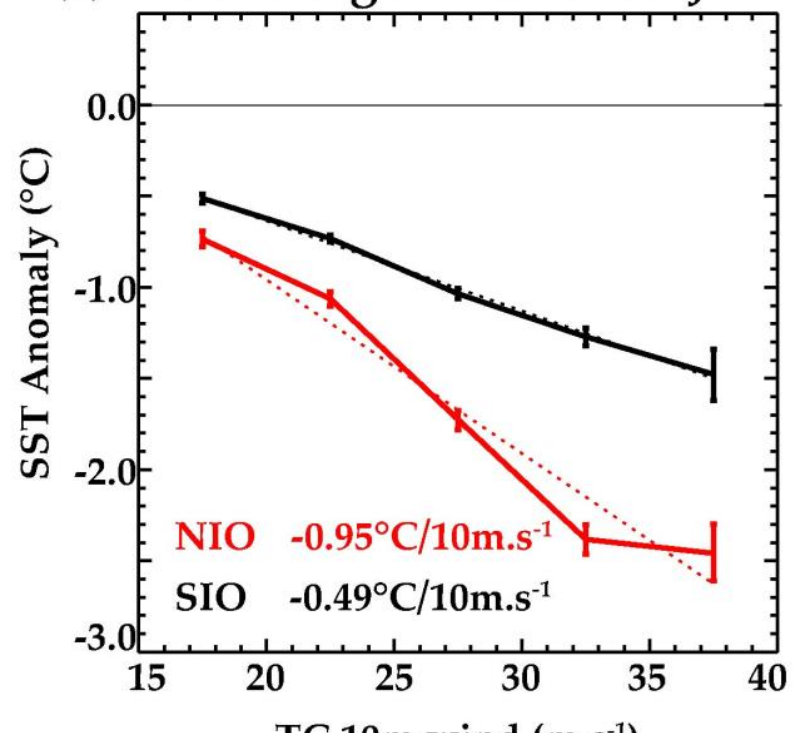

TC $10 \mathrm{~m}$ wind $\left(\mathrm{m} . \mathrm{s}^{-1}\right)$

Figure 15. Same as Figure 6 but for BMJ-CPL and BMJ-FOR. 

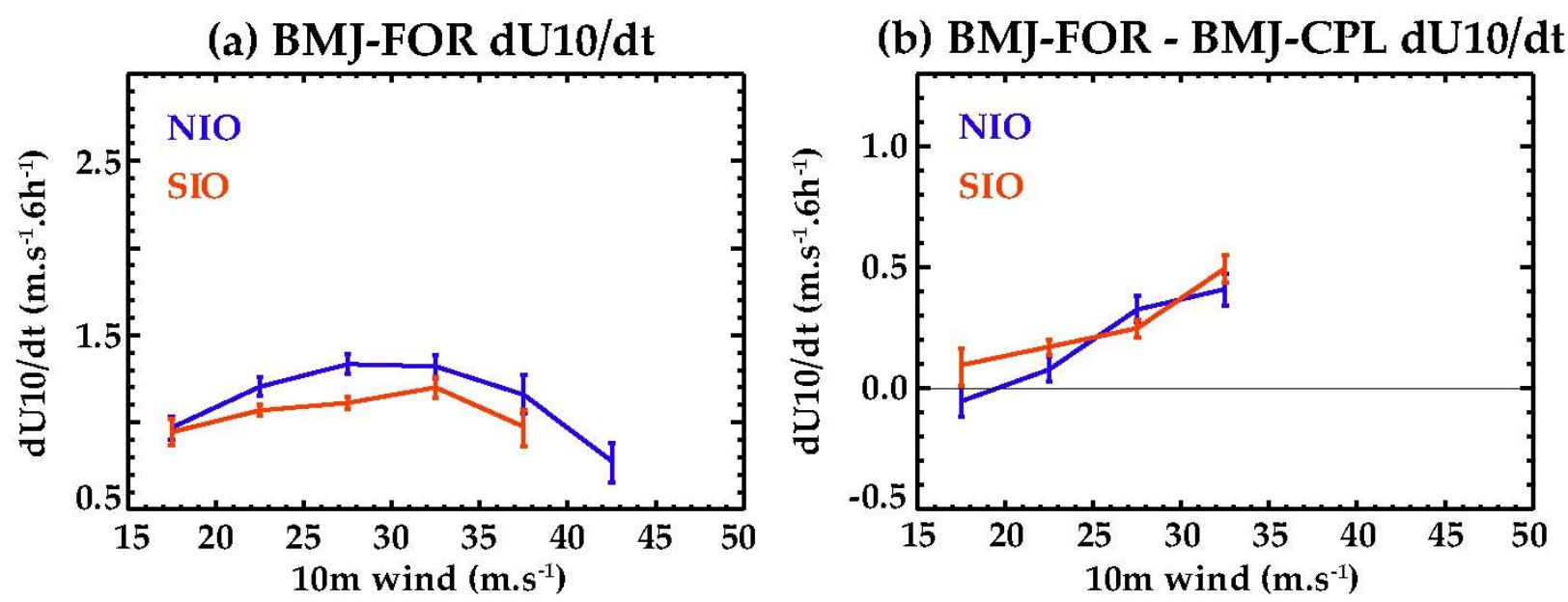

Figure 16. Same as Figure $10 \mathrm{~b}$ and $11 \mathrm{c}$ but for BMJ-CPL and BMJ-FOR. 
(a) SIO Cyclogenesis seasonal cycle: OBS

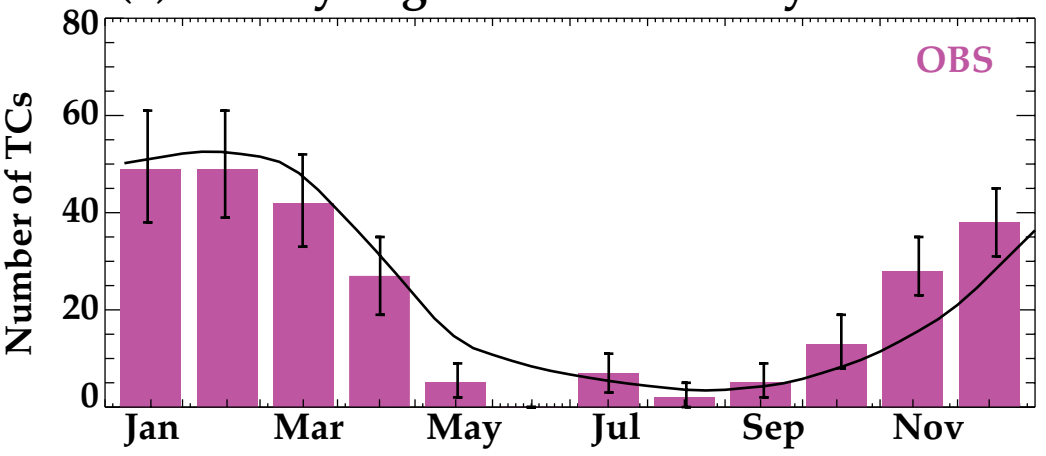

(b) SIO Cyclogenesis seasonal cycle: KF-CPL

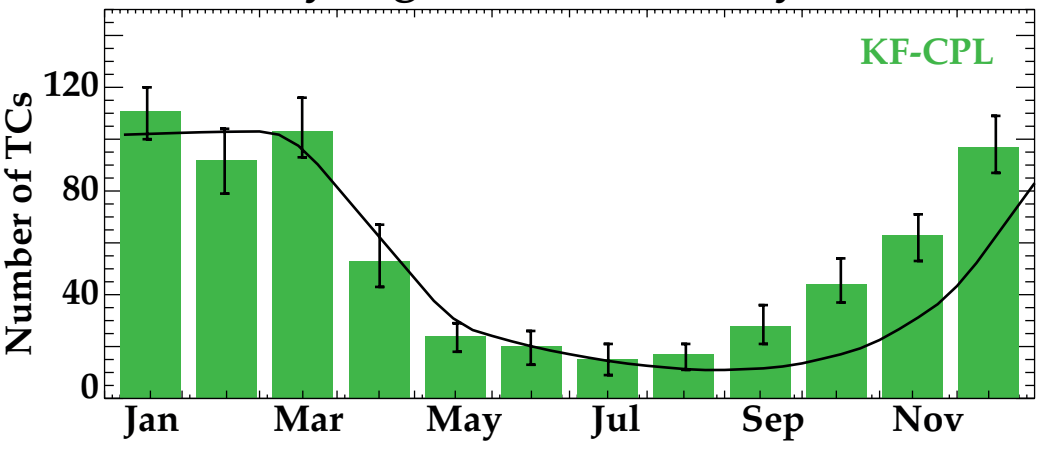

(c) SIO Cyclogenesis seasonal cycle: KF-FOR

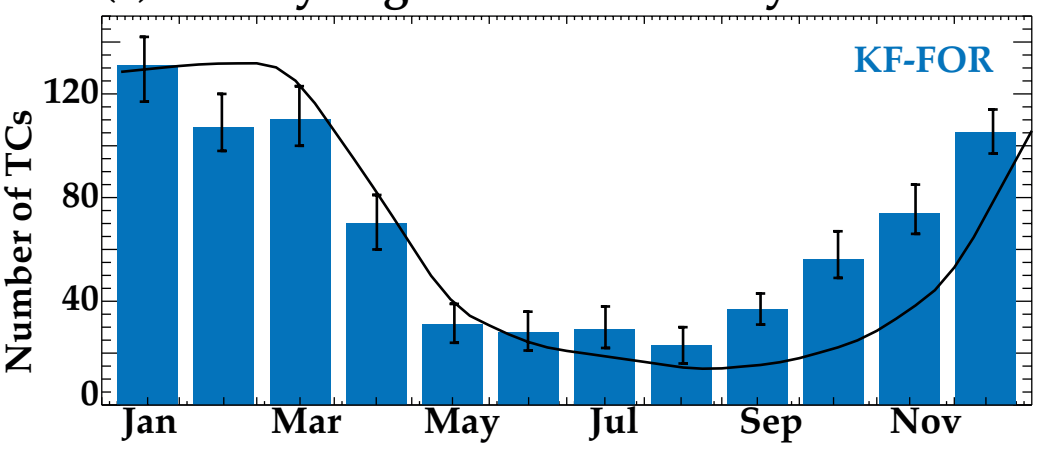

(d) SIO Cyclogenesis: KF-CPL minus KF-FOR

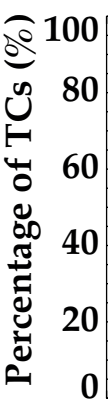

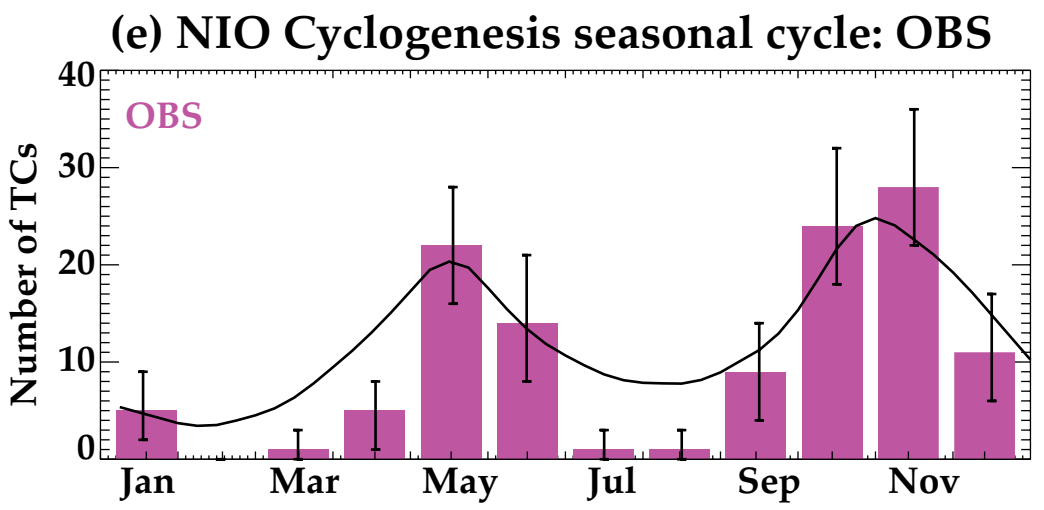

(f) NIO Cyclogenesis seasonal cycle: KF-CPL

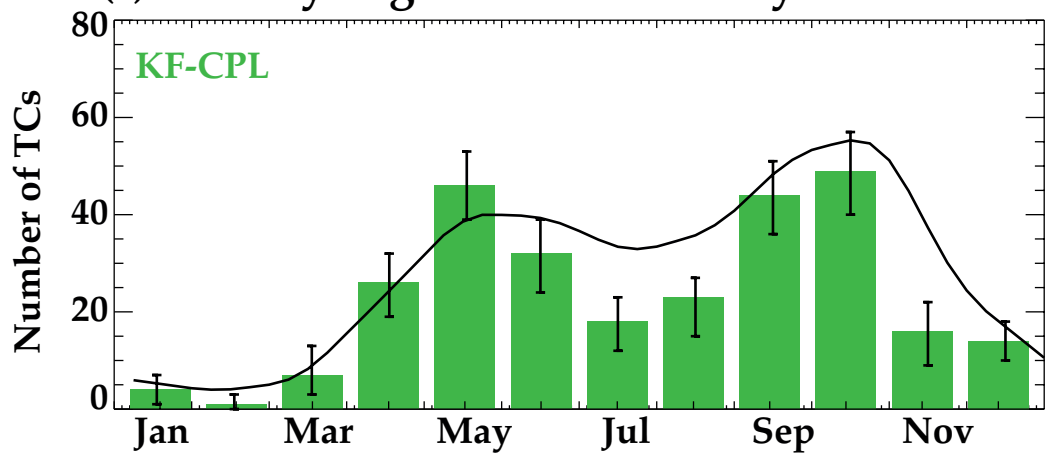

(g) NIO Cyclogenesis seasonal cycle: KF-FOR

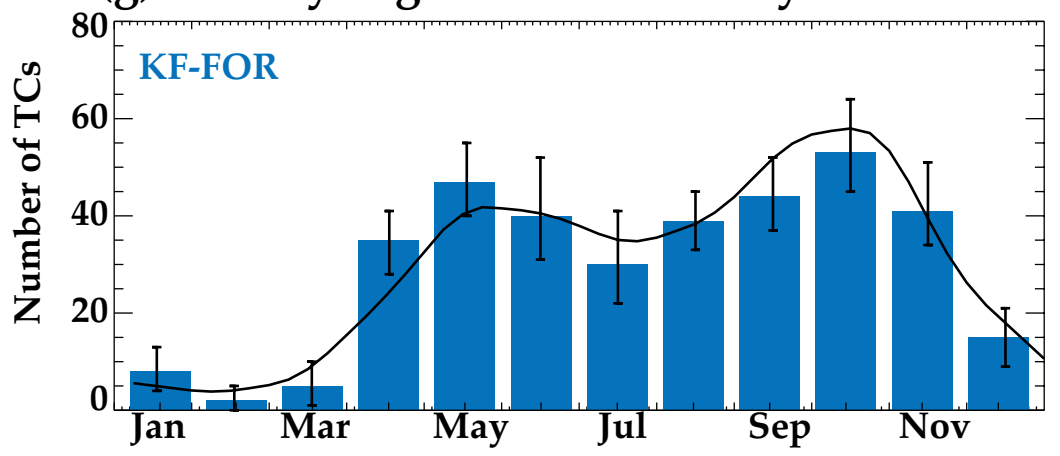

(h) NIO Cyclogenesis: KF-CPL minus KF-FOR

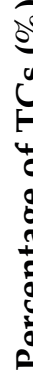

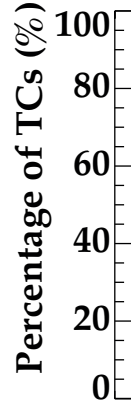

Austral summer (ONDJFMA)
Summer Monsoon Pre and post-monsoon (JA) (AMJ \& SOND) 


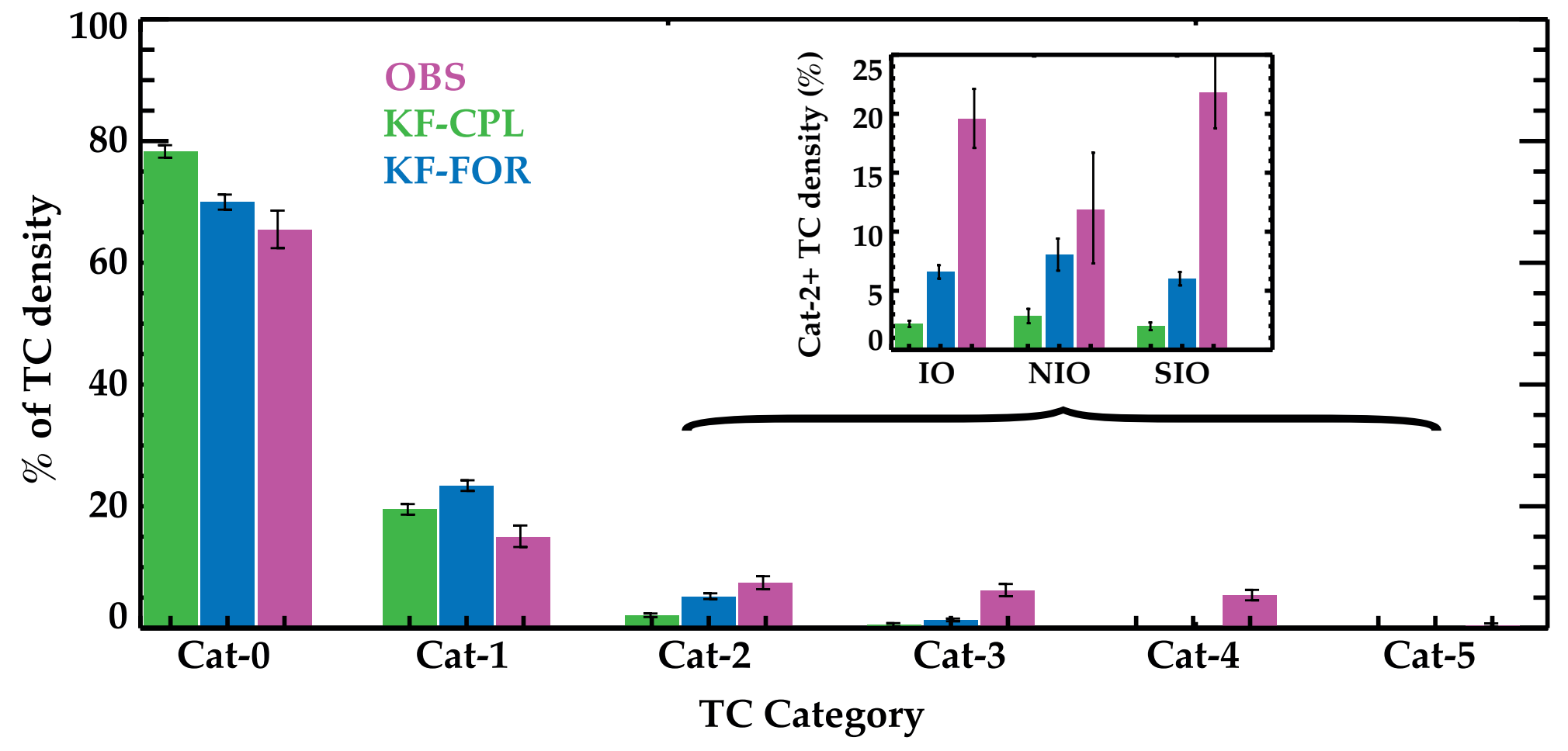


(a) IO TC-induced cooling: KF-CPL vs. OBS

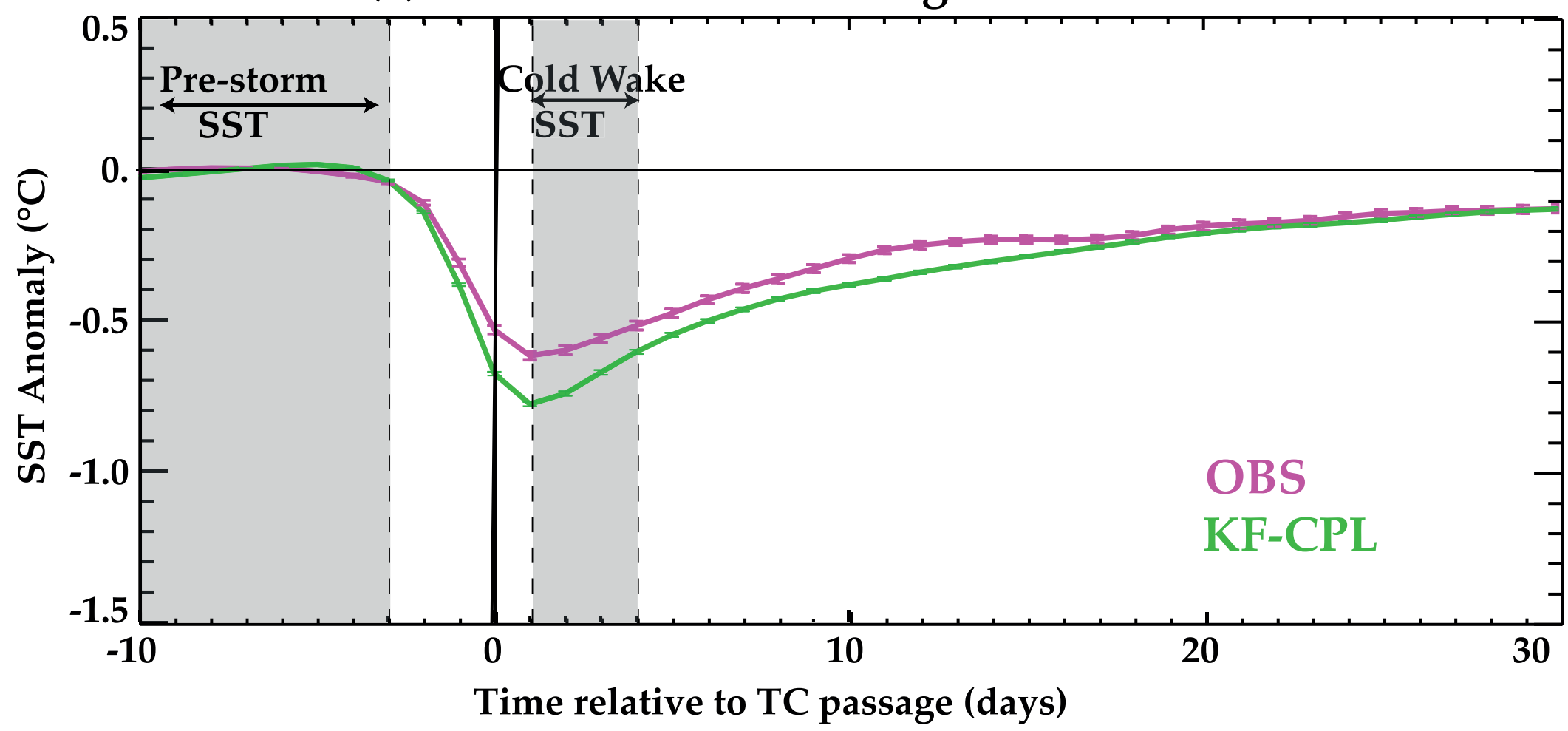

(b) TC cooling vs wind: OBS

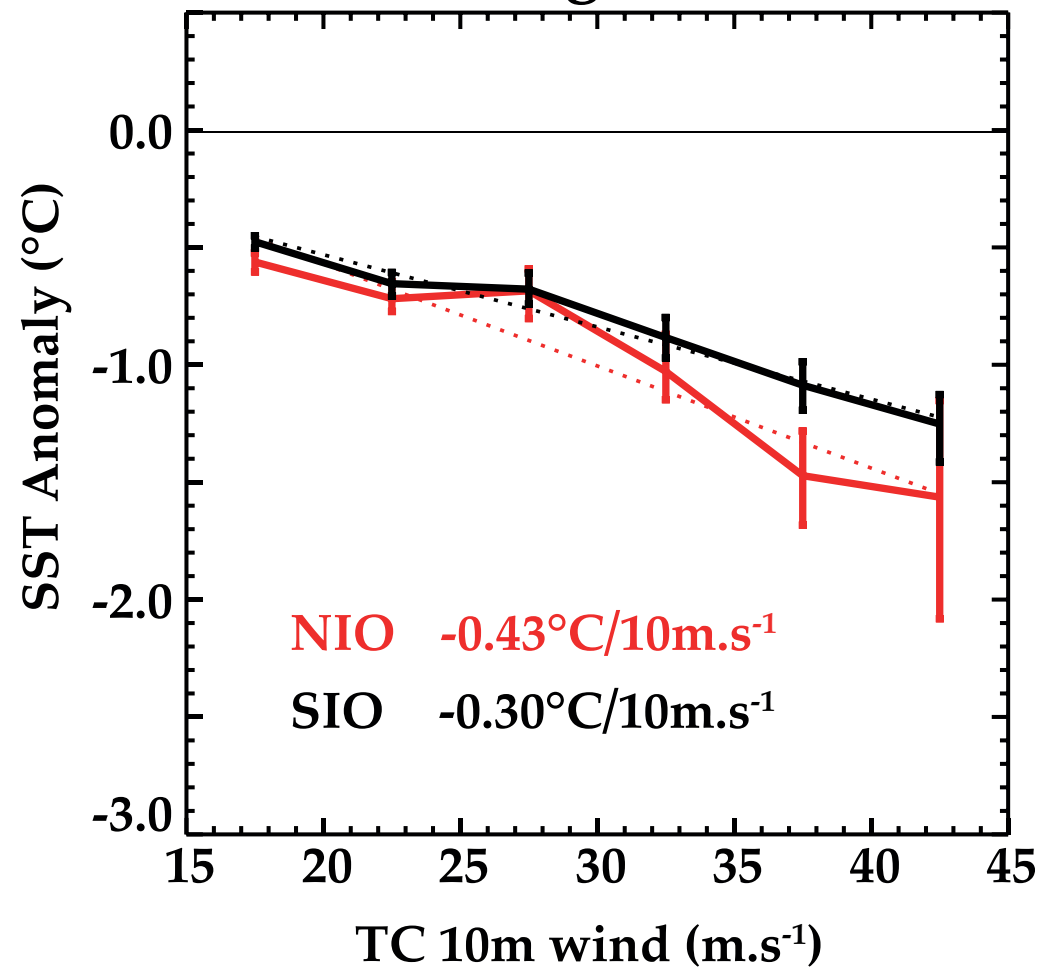

(c) TC cooling vs wind: KF-CPL

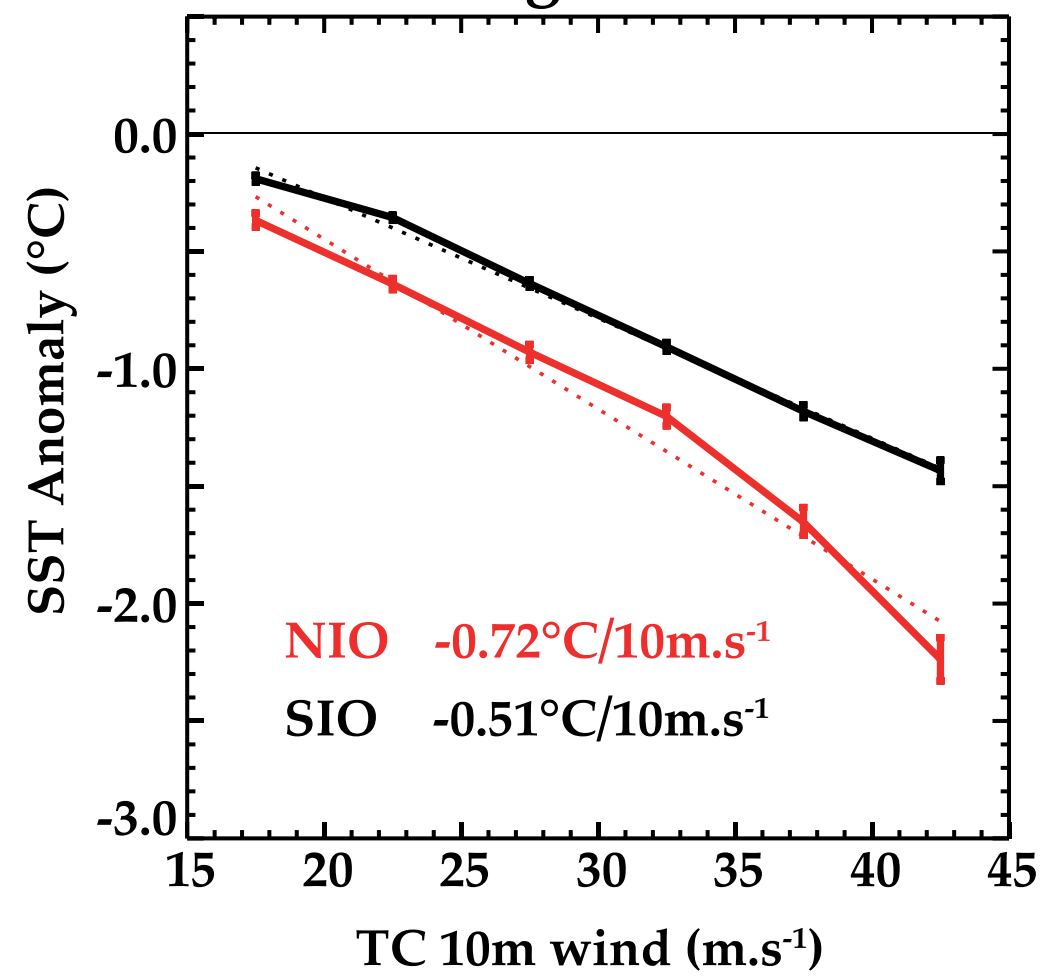




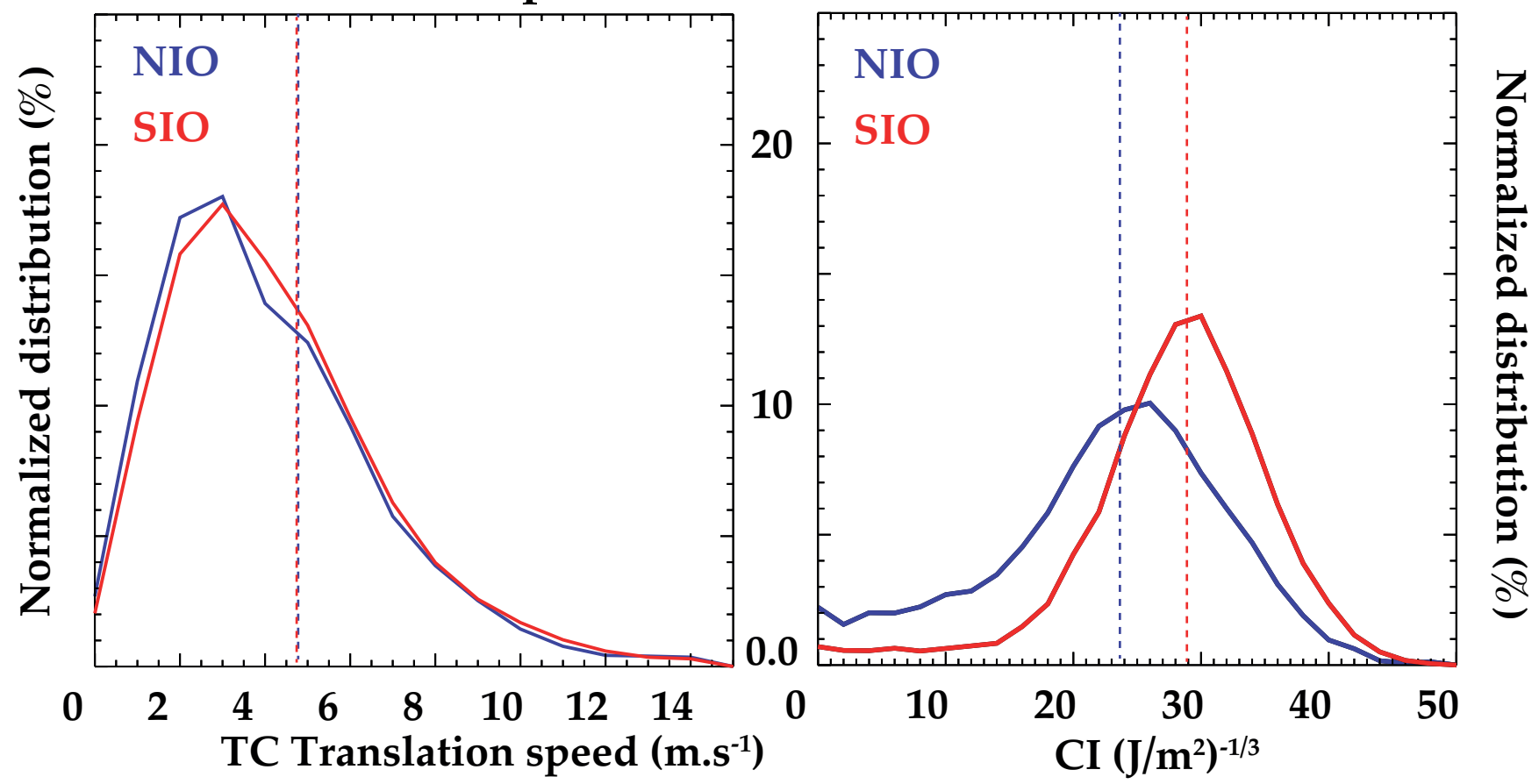

(c) CI map for TC-prone seasons

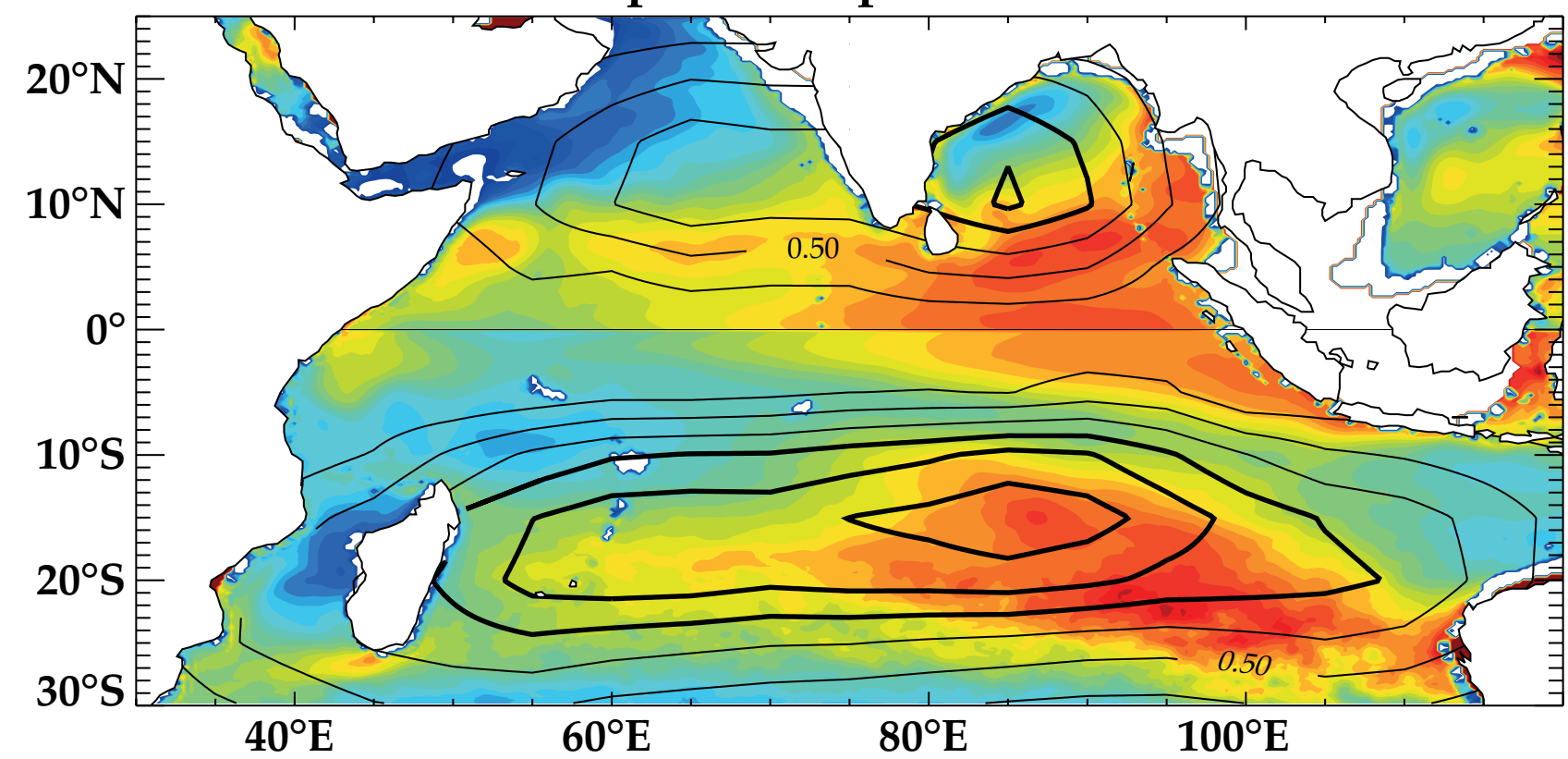

(d) Depth(SST-2 $\left.{ }^{\circ} \mathrm{C}\right)$ map for TC-prone seasons

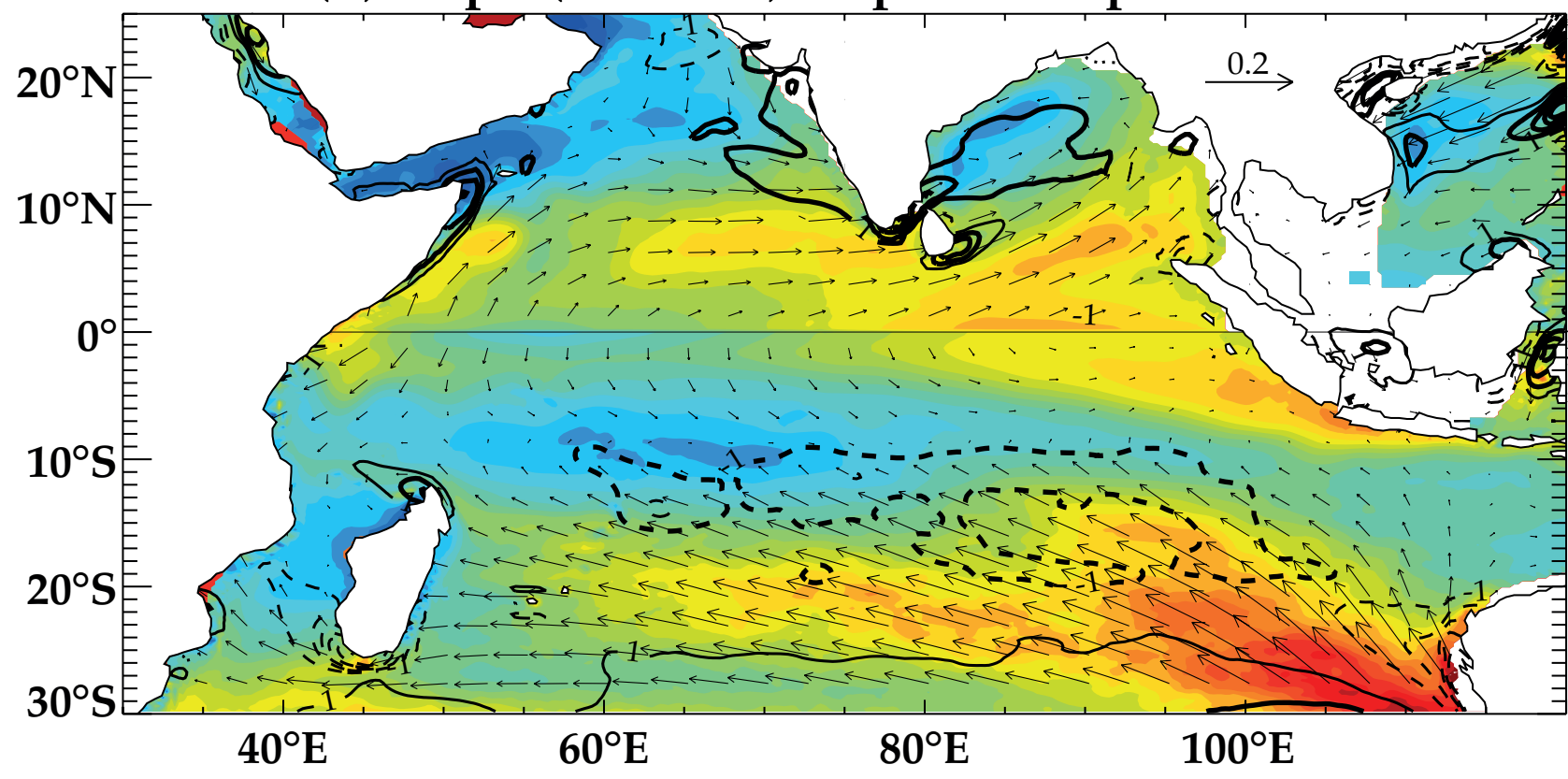




\section{TCs composite in the southern IO}
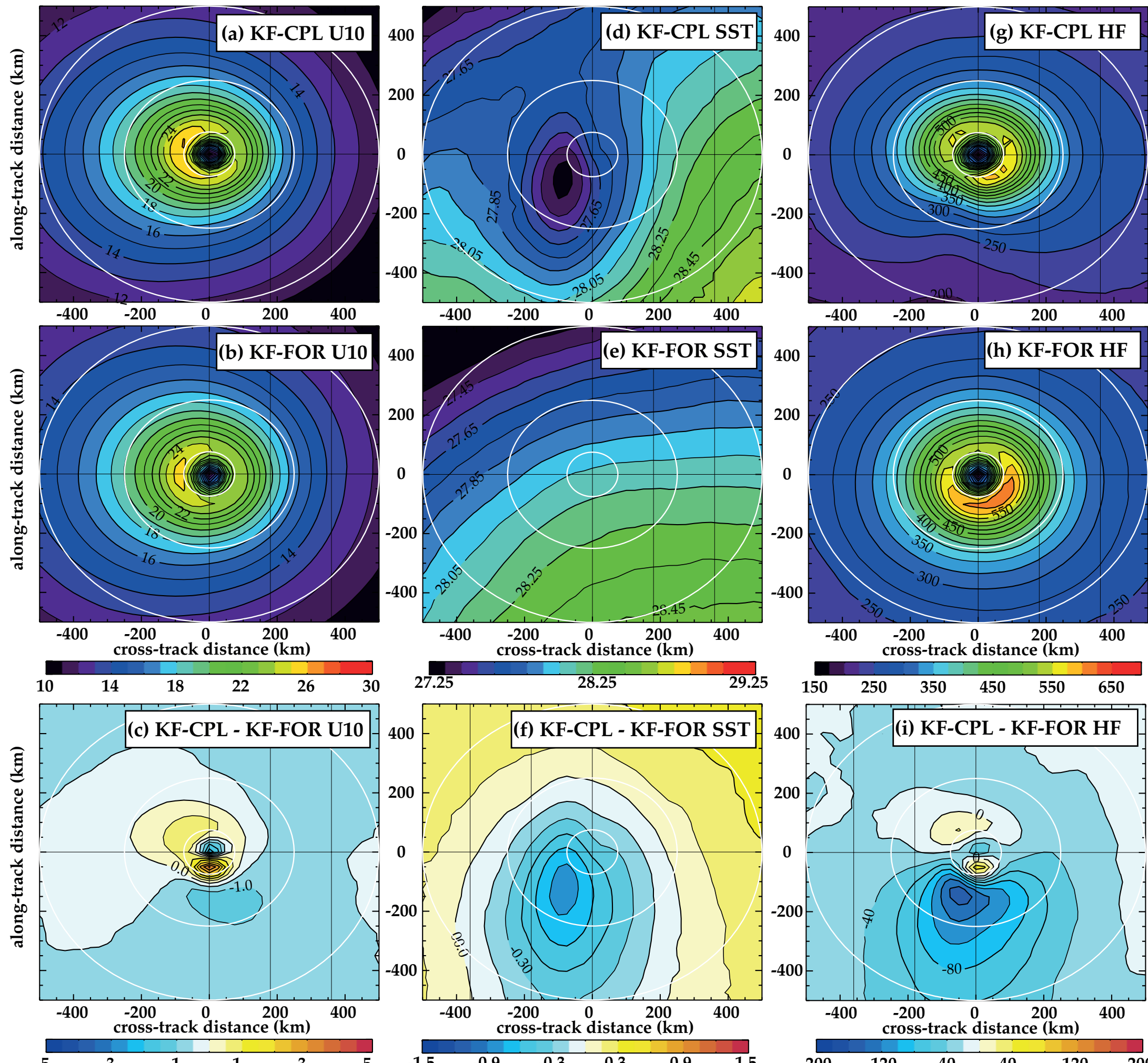
TCs composite in the northern IO
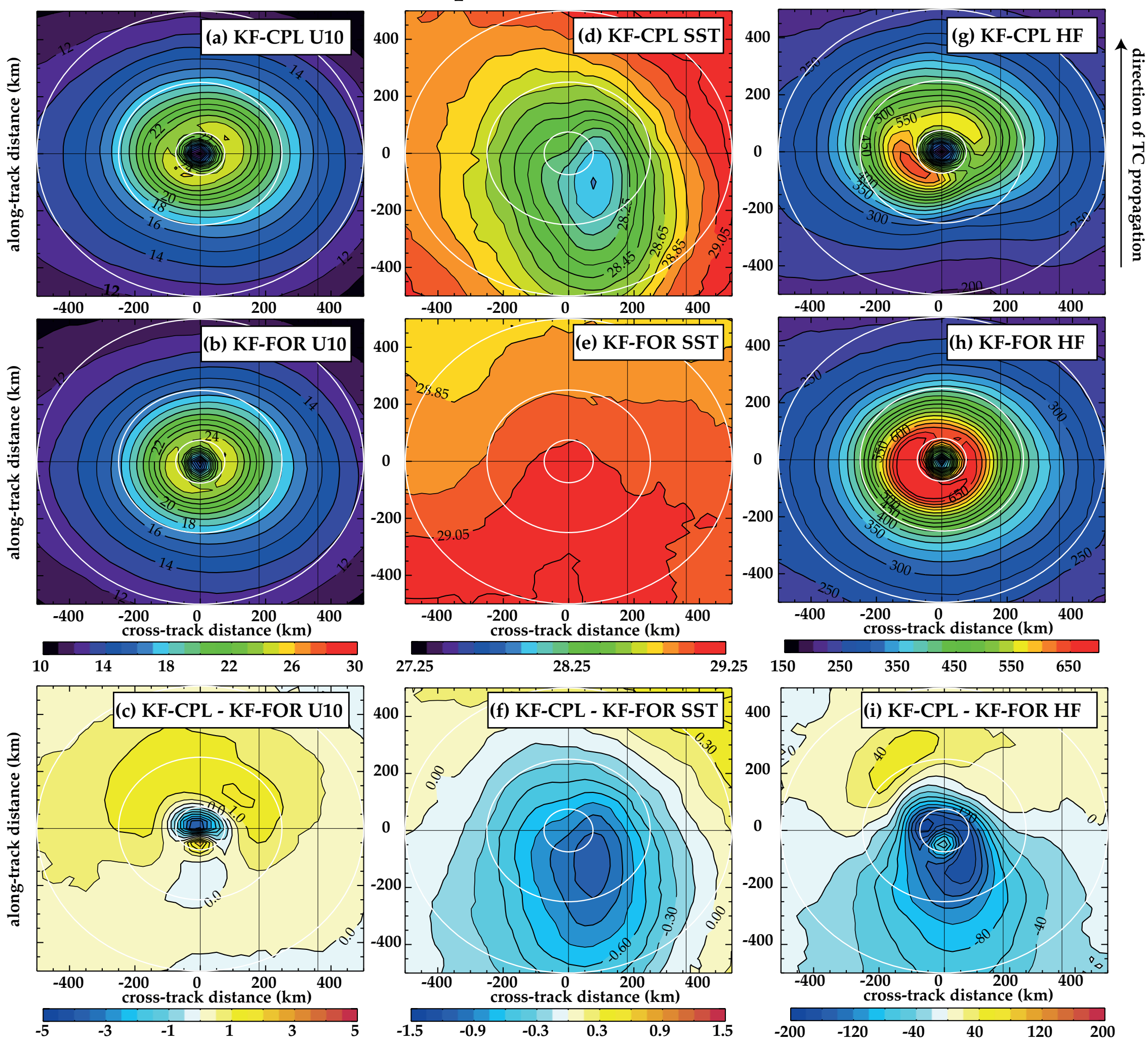
(a) KF-FOR HF

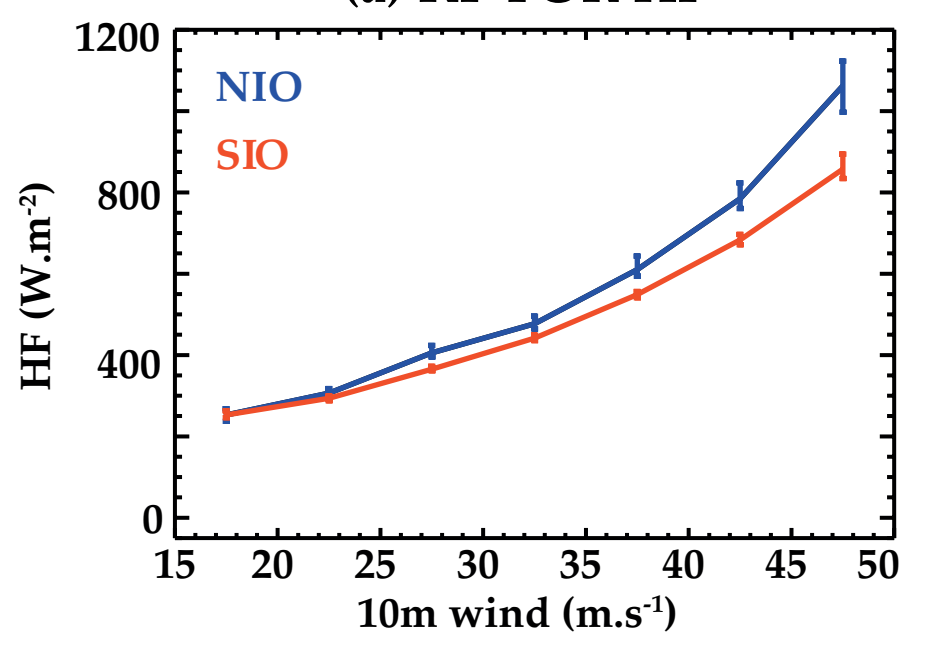

(b) KF-FOR dU10/dt

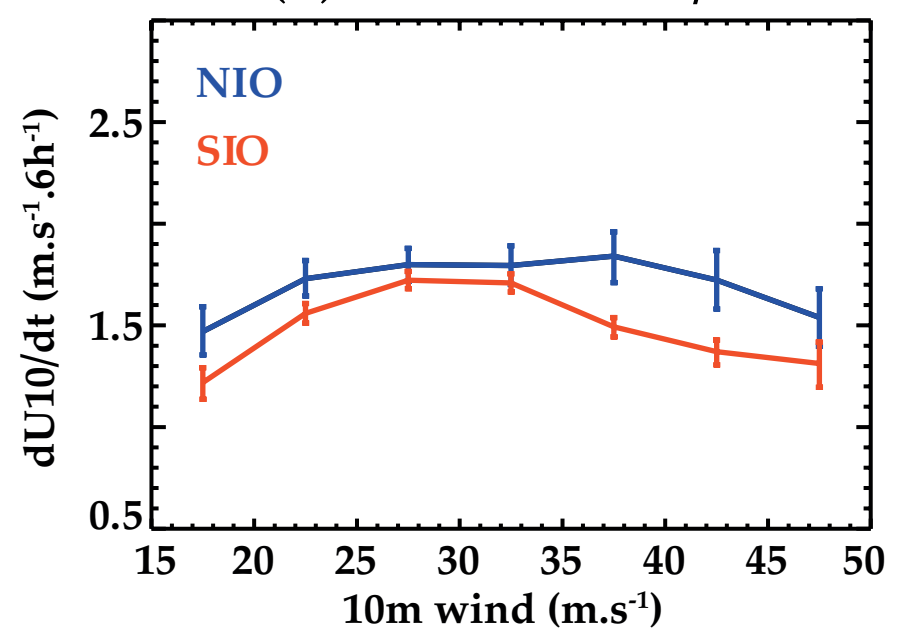

(c) KF-FOR SST

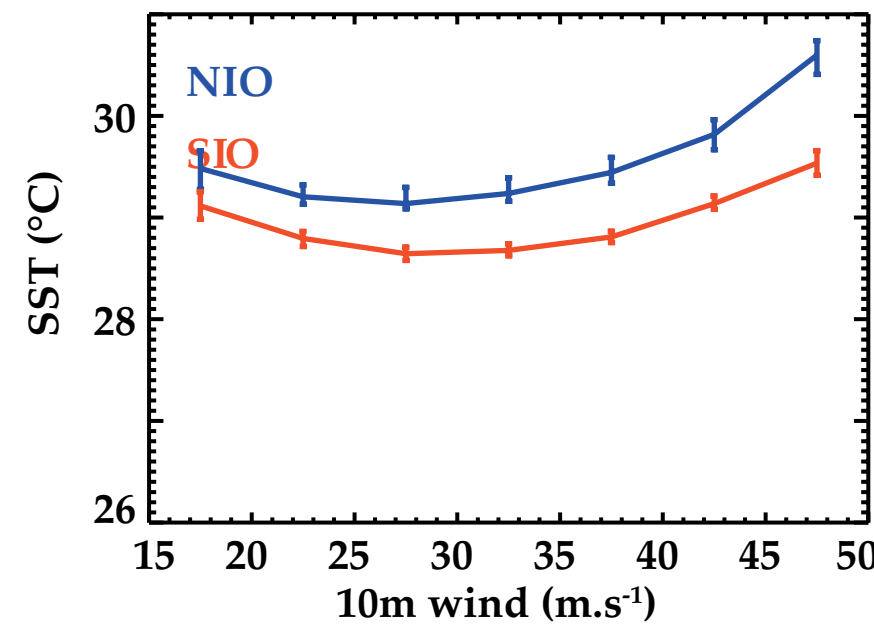


(a) KFCPL-KFFOR HF

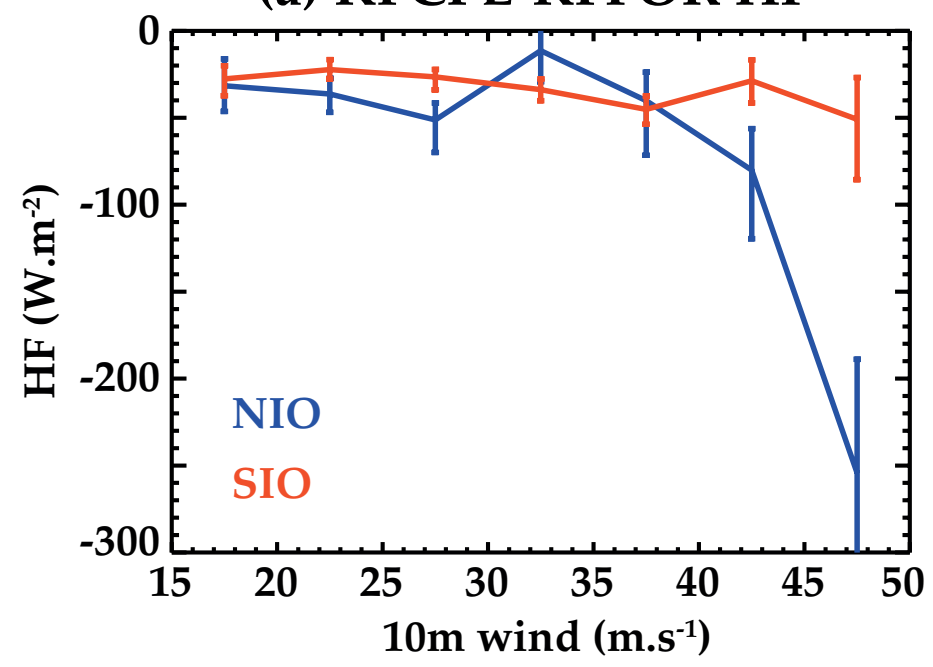

(d) NIO HF: Fast vs slow

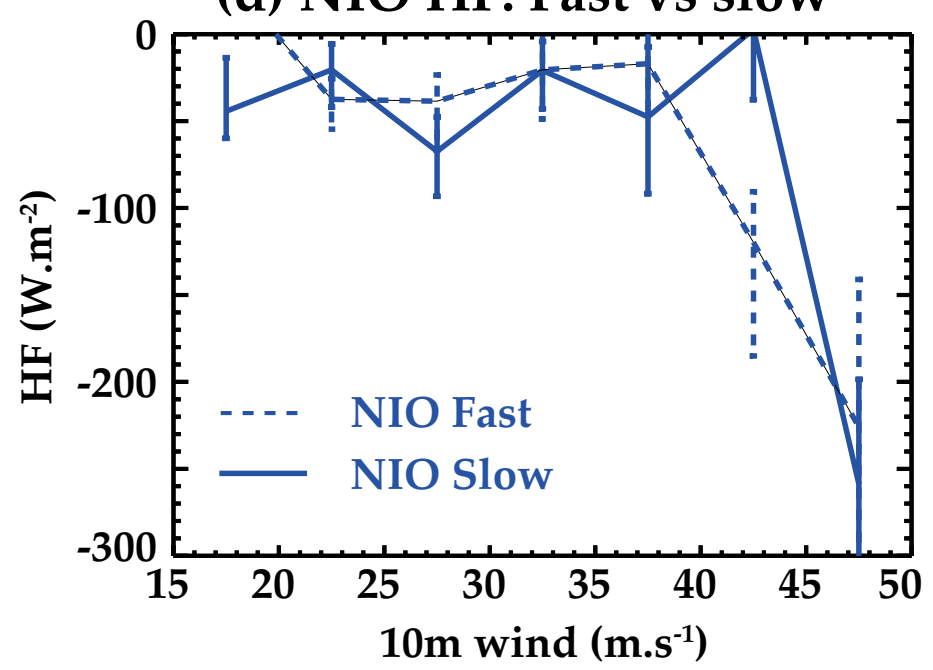

(b) KFCPL-KFFOR dU10/dt

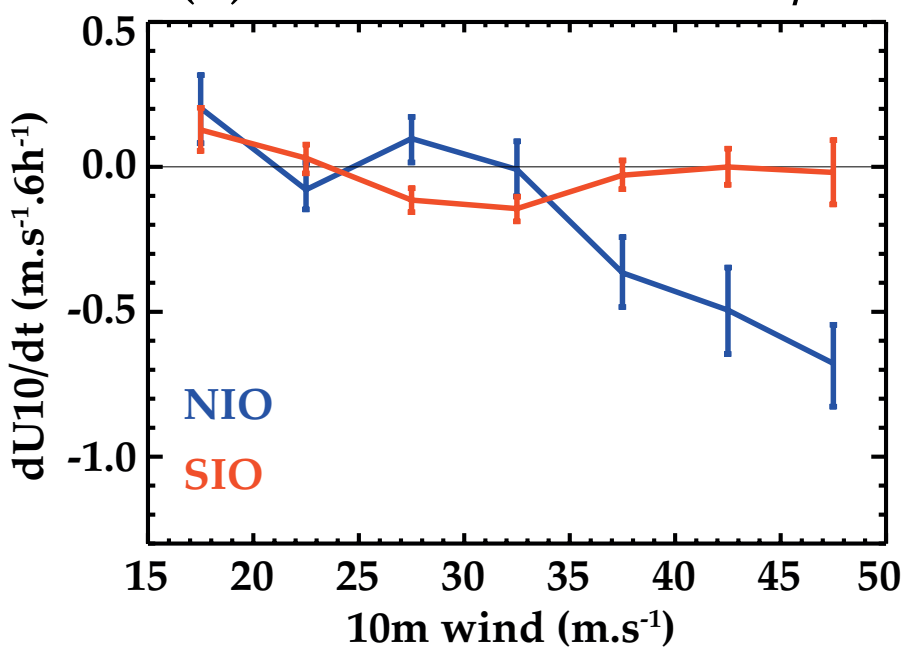

(e) NIO dU10/dt: Fast vs slow

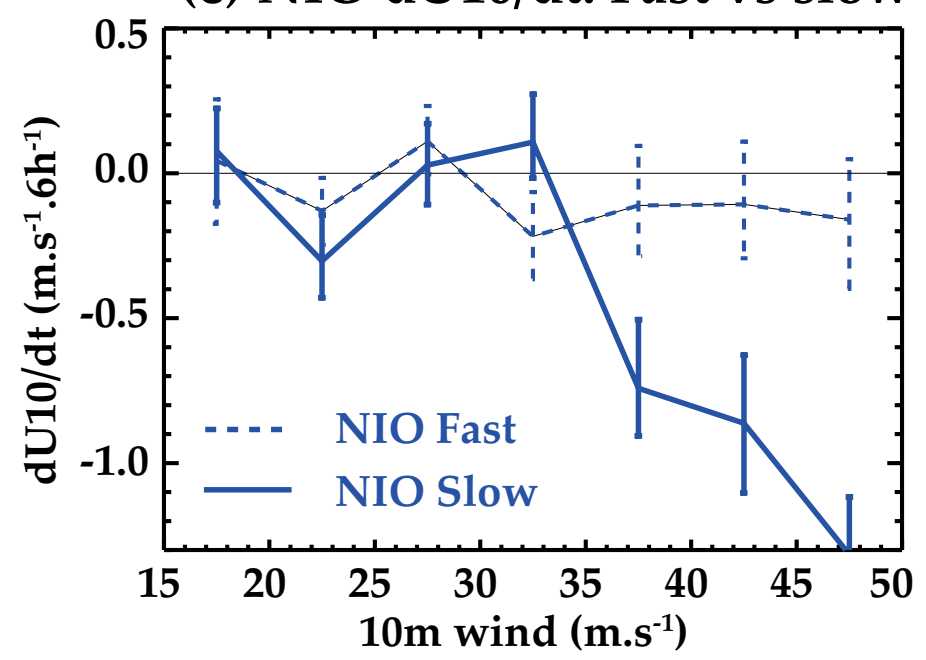

(c) KFCPL-KFFOR SST

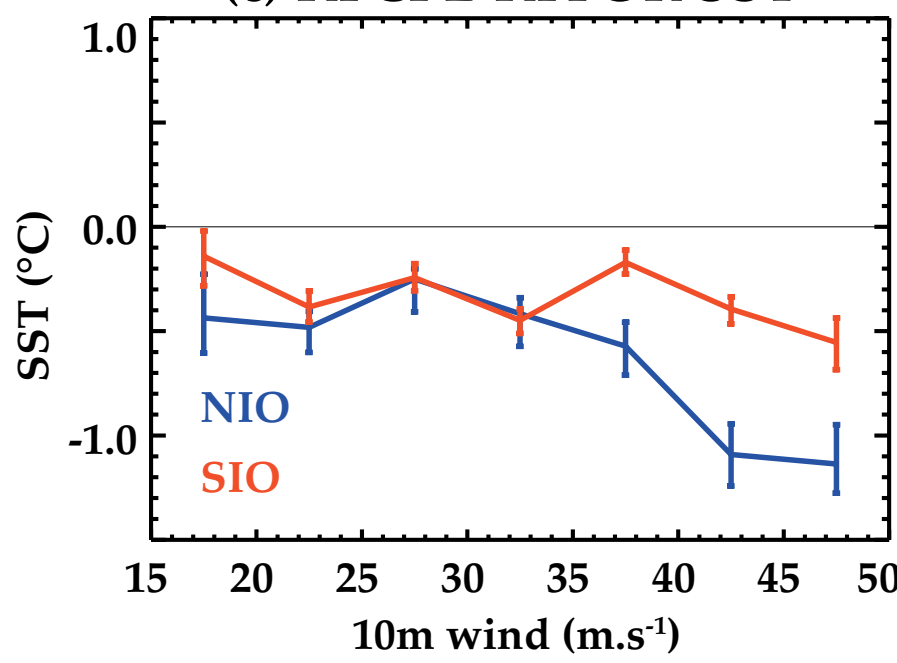

(f) NIO SST: Fast vs slow

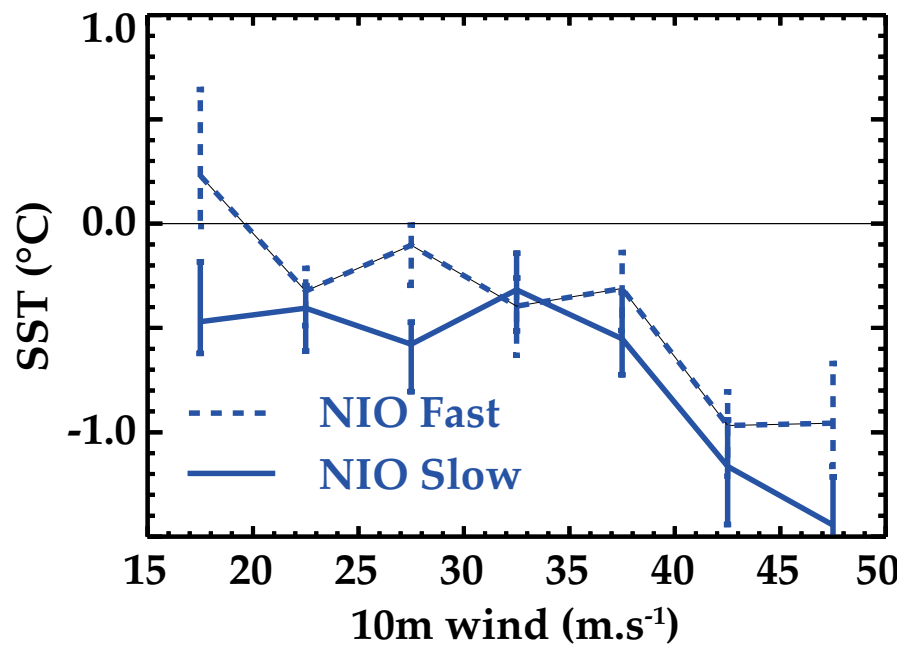


(a) NIO Cyclogenesis seasonal cycle: OBS
40 ens

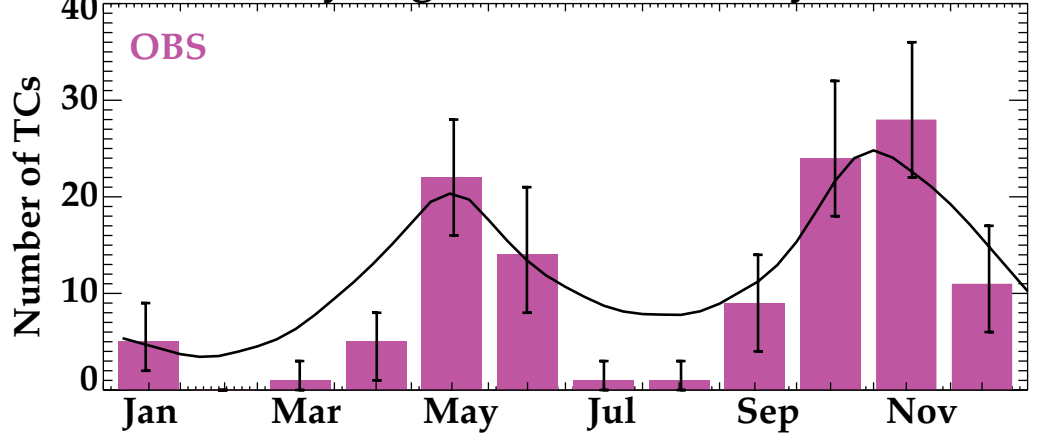

(b) NIO Cyclogenesis seasonal cycle: BMJ-CPL

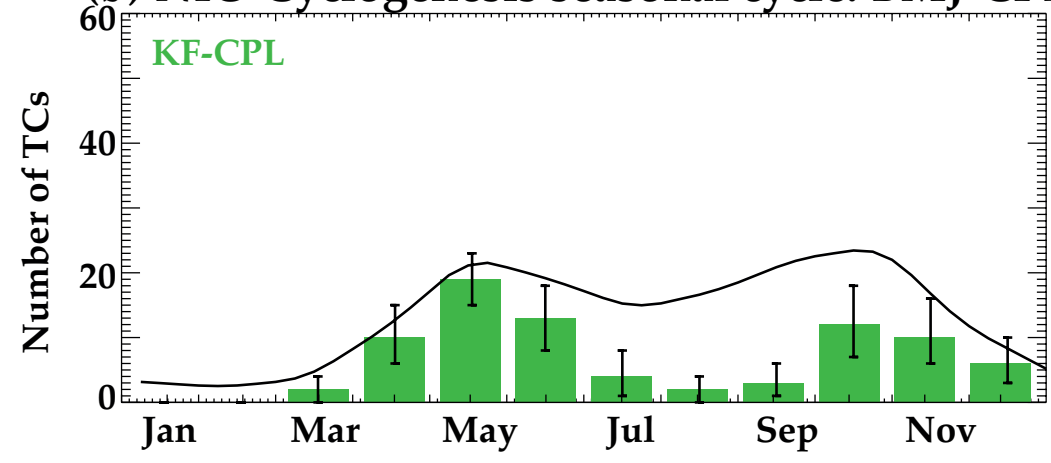

(c) NIO Cyclogenesis seasonal cycle: BMJ-FOR

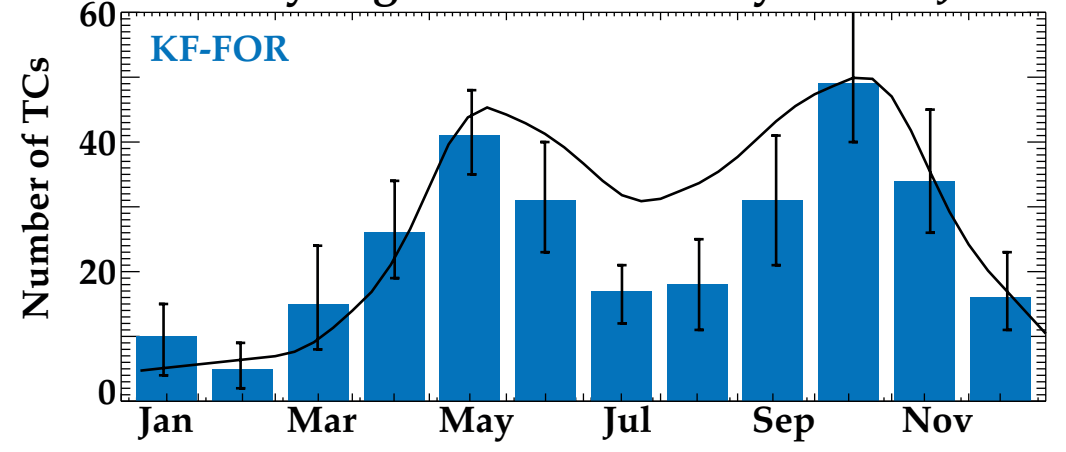

(d) NIO Cyclogenesis: BMJ-CPL minus BMJ-FOR

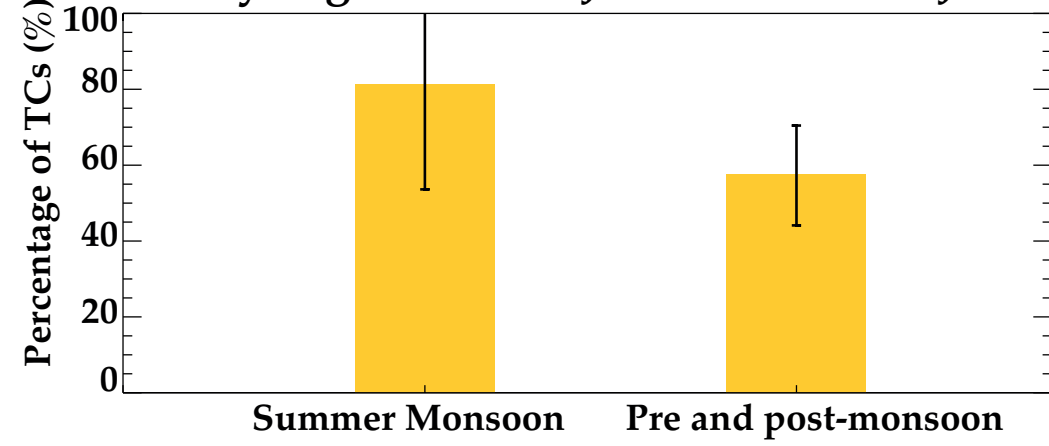

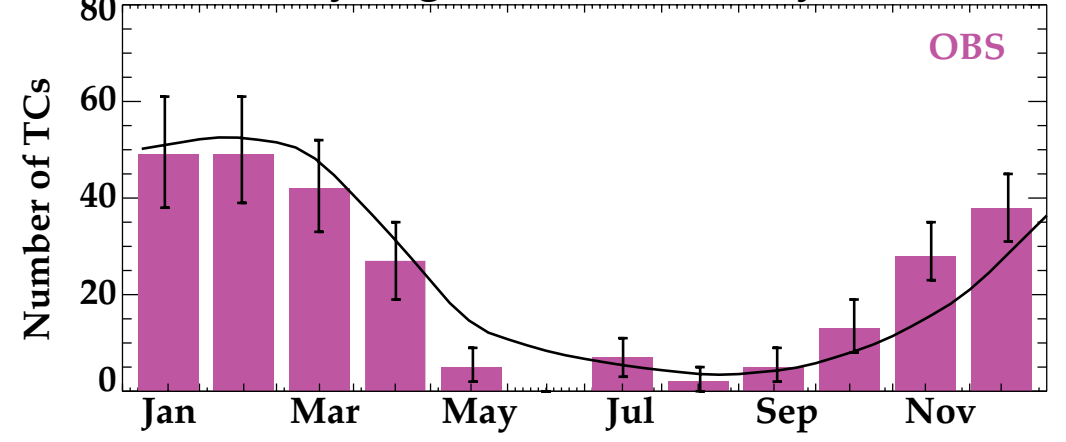

(f) SIO Cyclogenesis seasonal cycle: BMJ-CPL

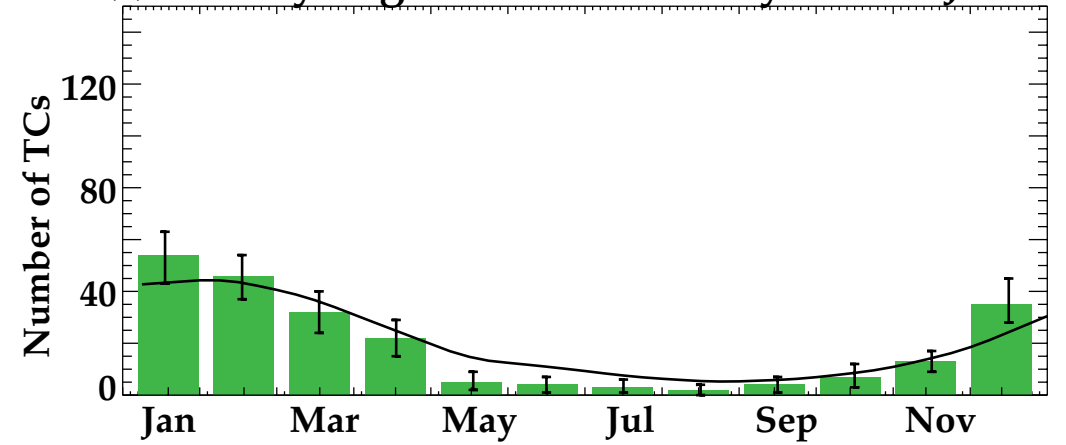

(g) SIO Cyclogenesis seasonal cycle: BMJ-FOR

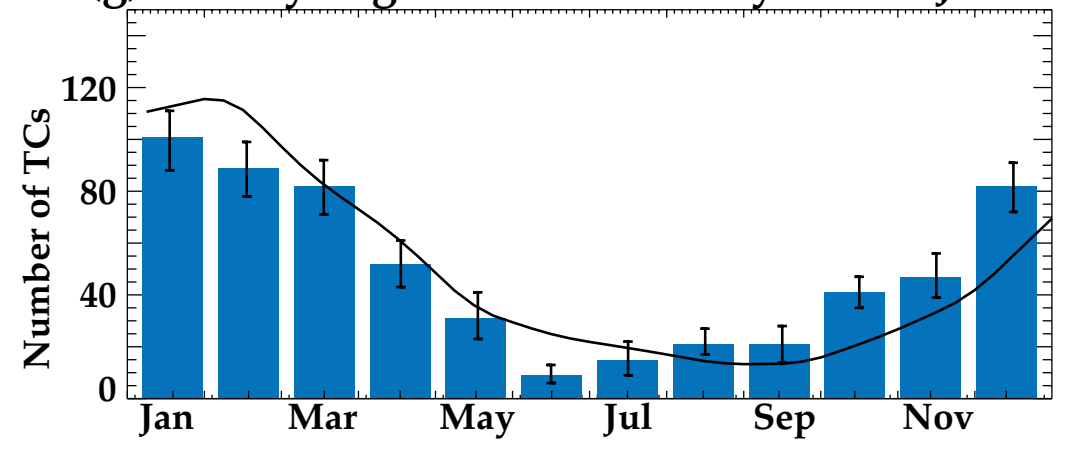

(h) SIO Cyclogenesis: BMJ-CPL minus BMJ-FOR

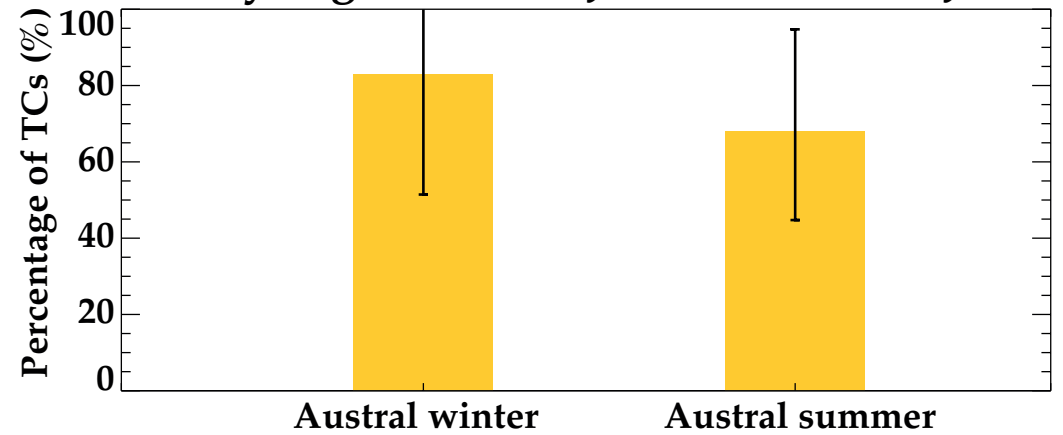




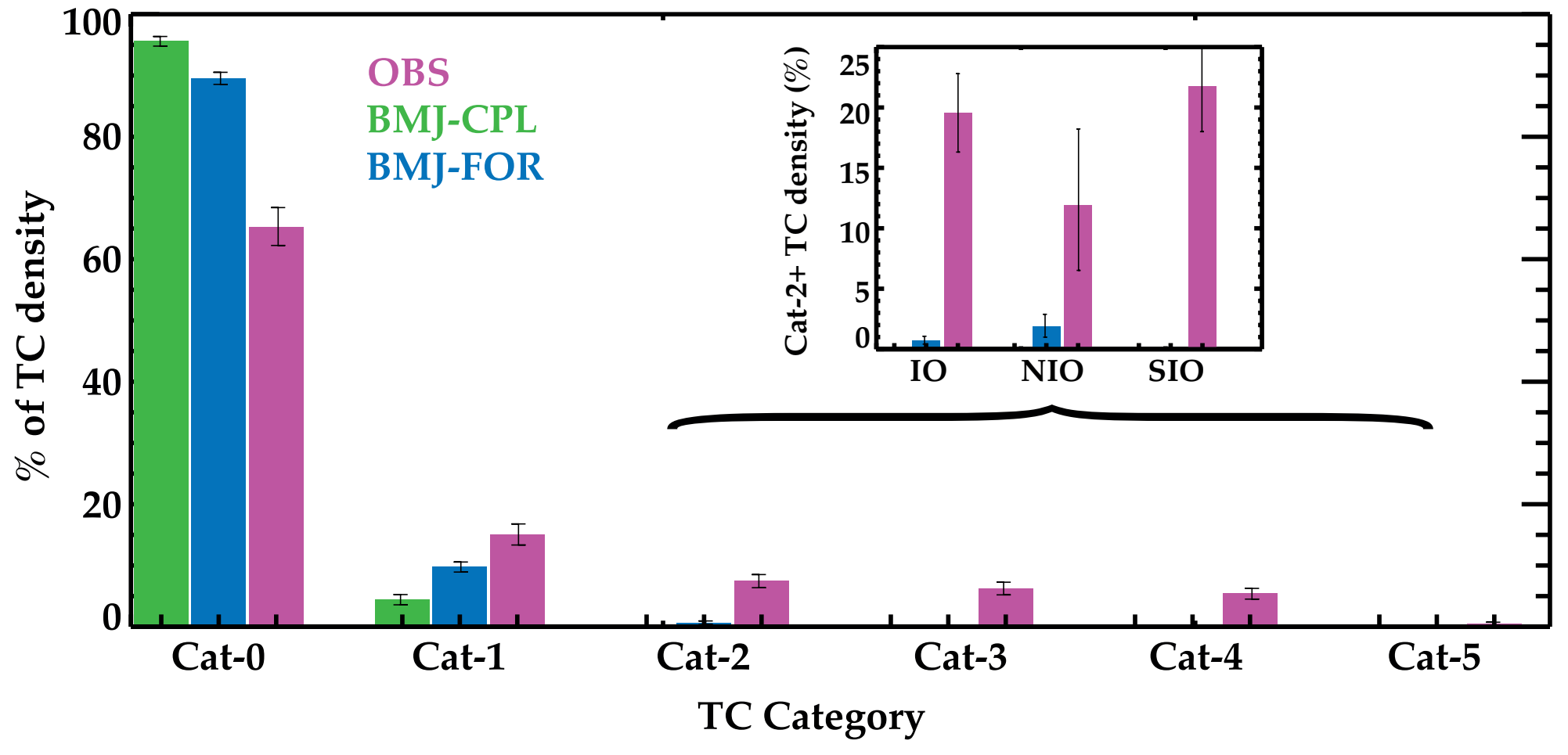


(a) IO TC-induced cooling: BMJ-CPL vs. OBS

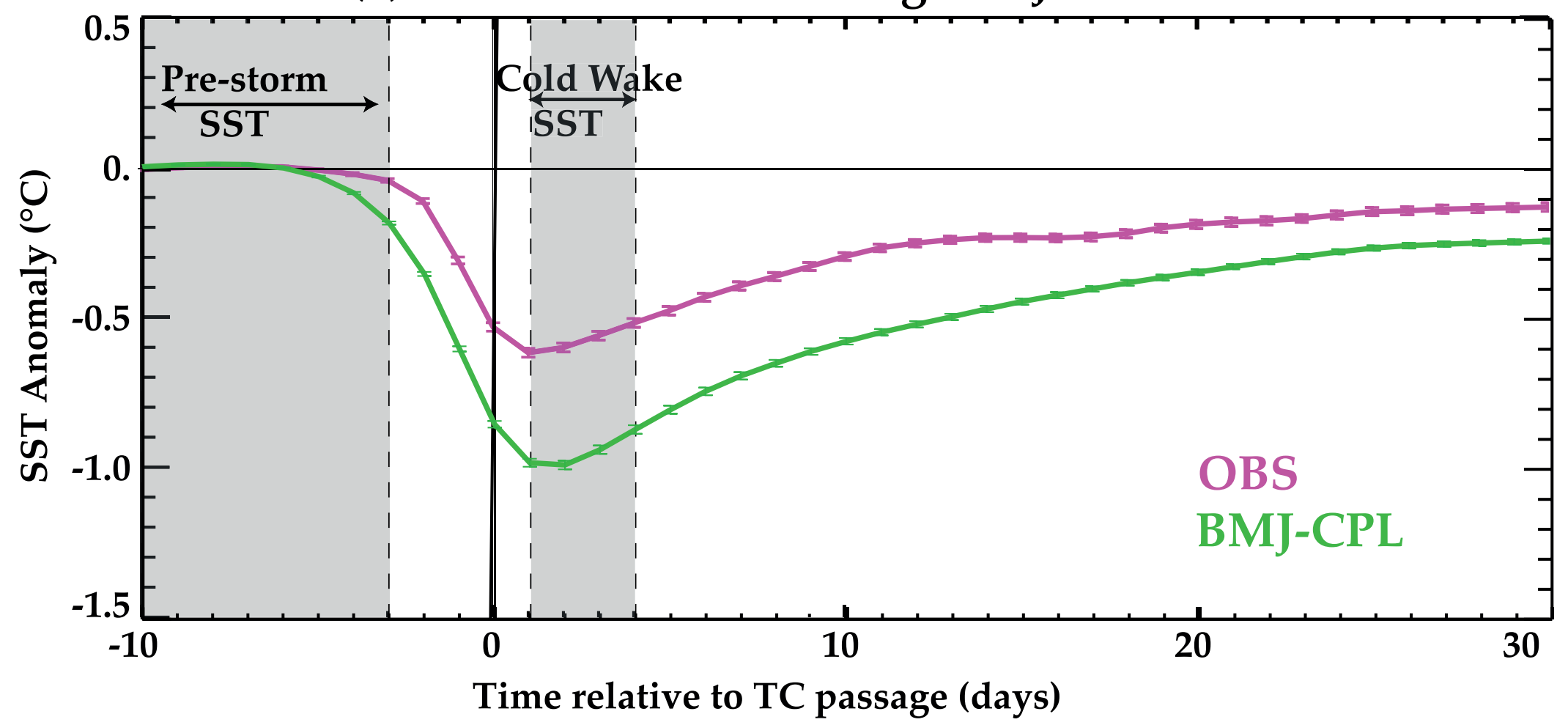

(b) TC cooling vs wind: OBS

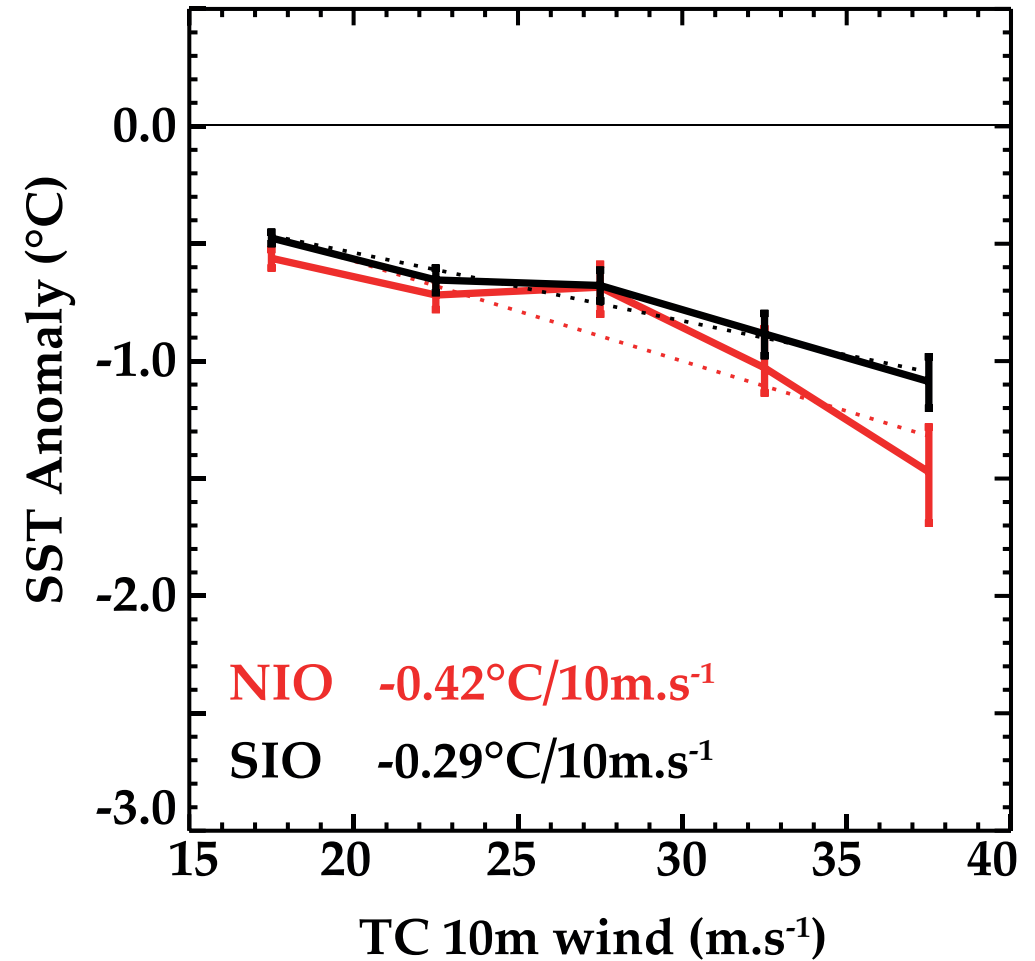

(c) TC cooling vs wind: BMJ-CPL

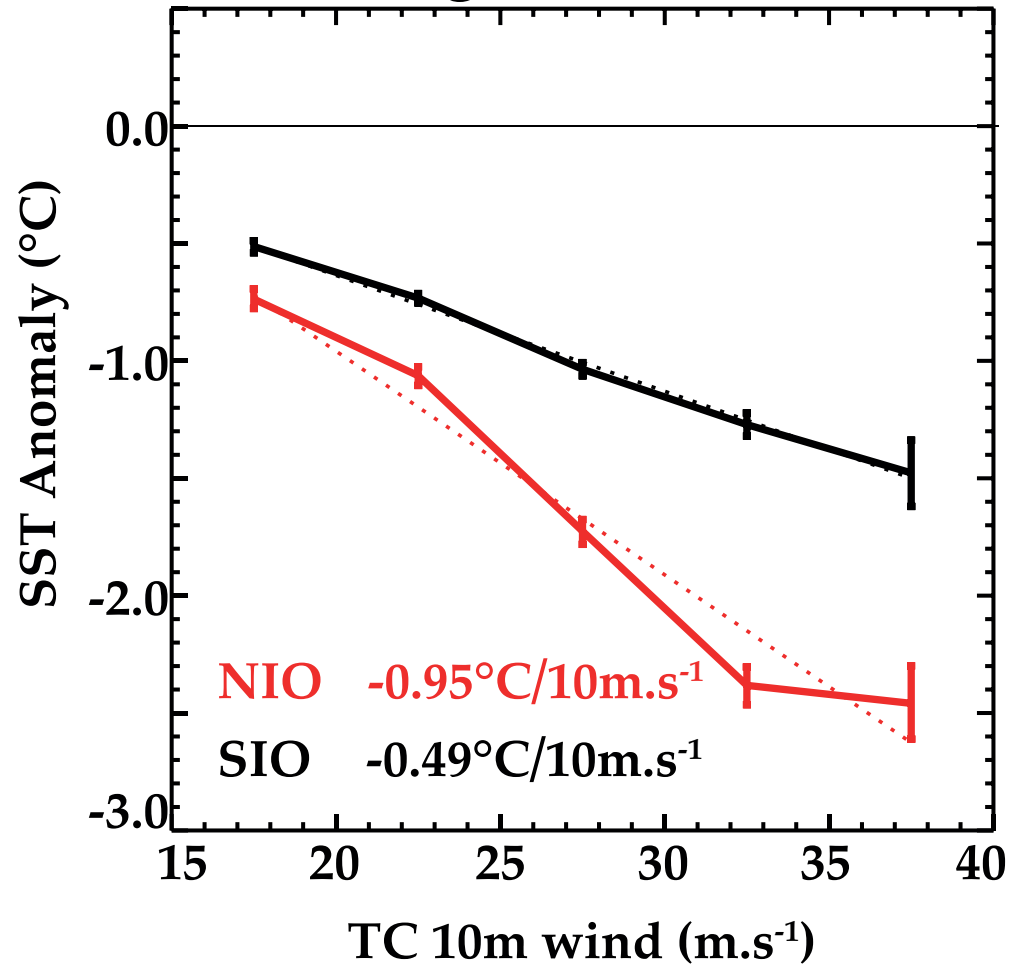


(a) BMJ-FOR dU10/dt

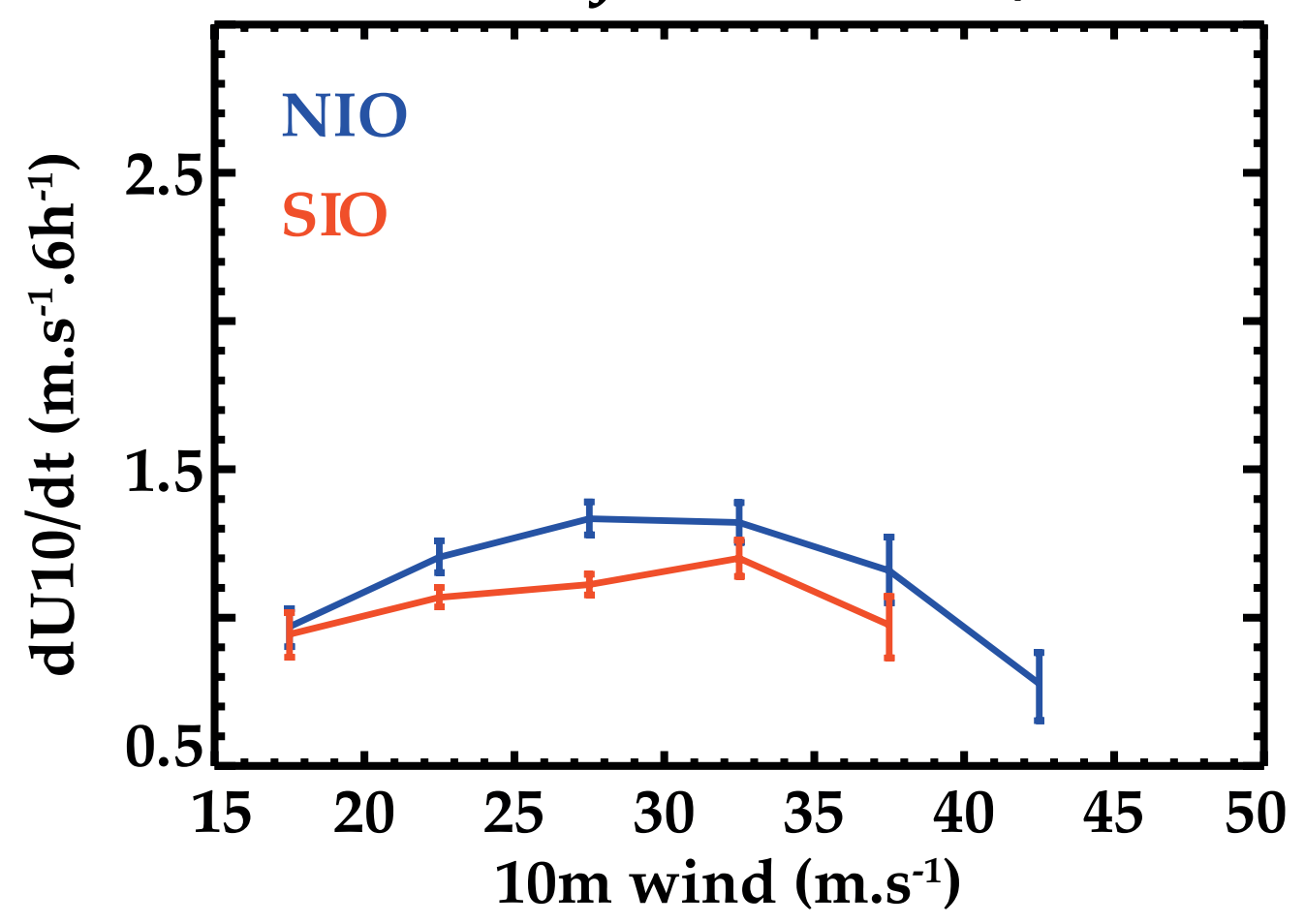

(b) BMJ-FOR - BMJ-CPL dU10/dt

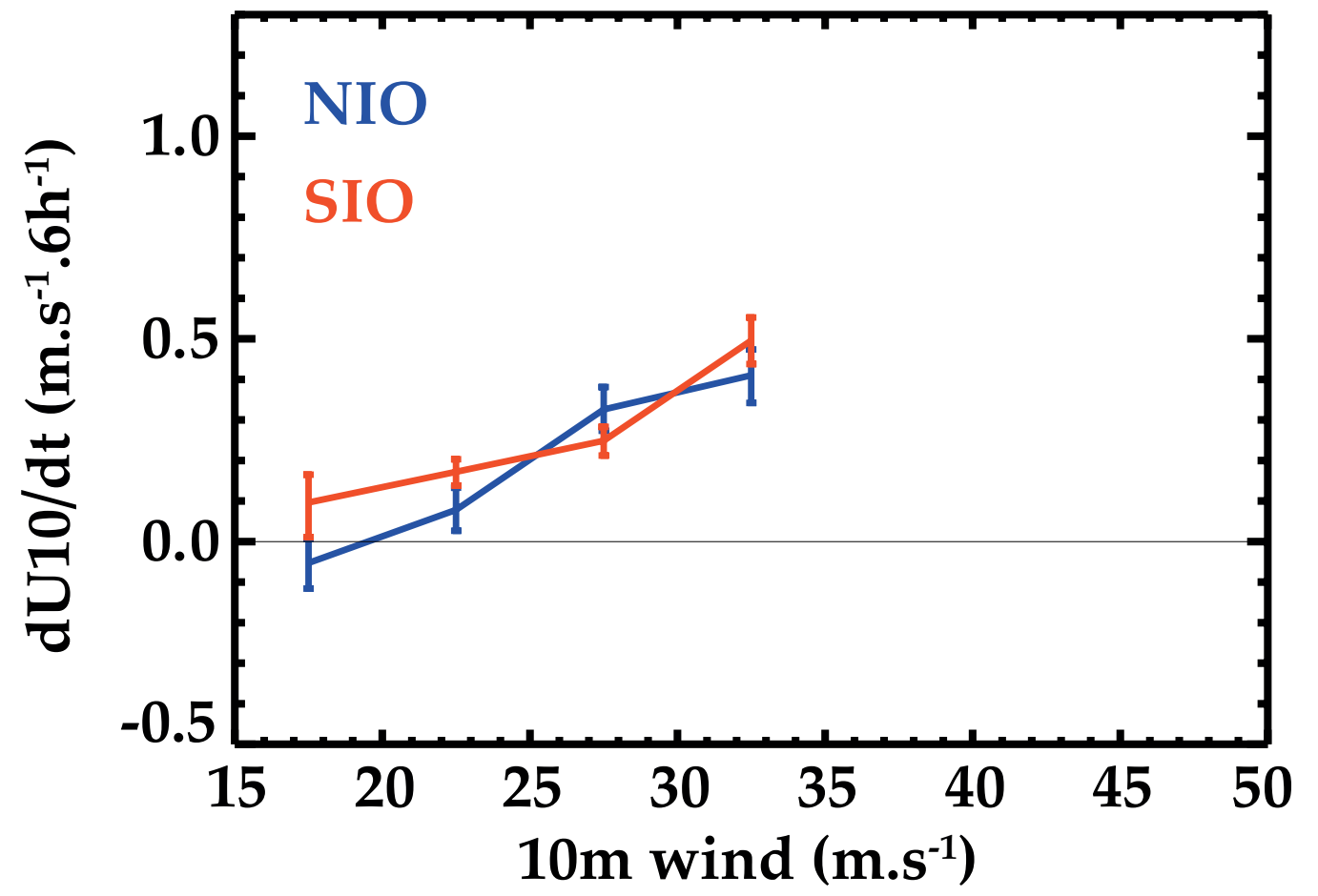

